\title{
V. Jahre der Entscheidung: Ende 1935 bis 1939
}

\section{Radikalisierung und Neopazifismus}

Mehrere Ereignisse haben dazu beigetragen, den republikanischen Konsens seit Ende $1935 \mathrm{zu}$ untergraben und die Fronten weiter zu polarisieren. Hatte nach dem Aufstand des Februar 1934 die Volksfront-Bewegung ihre Sammlungspolitik unter dem Banner des "Antifaschismus“ betrieben, so begannen sich deren Gegner nun im Zeichen des „Antibolschewismus“ zu formieren. Die Phase des Wahlkampfes vor dem Mai 1936 war durch erbitterte Konflikte geprägt, die sich am Abessinienkrieg, am französisch-russischen Beistandspakt und an der Remilitarisierung des Rheinlandes entzündeten. Durch diese Debatten gerieten die Befürworter und Gegner der Volksfront immer mehr in den Sog der ideologischen Auseinandersetzung zwischen Kommunismus und Faschismus bzw. Nationalsozialismus. Die eigentlich außenpolitischen Konflikte wurden dabei auf den innerfranzösischen Gegner projiziert und in einem ideologischen Bürgerkrieg ausgetragen.

Das Schlagwort des Neopazifismus bezeichnet die außenpolitische Haltung der Volksfrontgegner. Dieser neue, ideologisch motivierte Pazifismus der Rechten unterschied sich von dem sozialistischen und bürgerlich-humanitären Pazifismus durch seine Feindschaft zum Bolschewismus und der daraus erwachsenden Verständigungsbereitschaft mit den Diktatoren Mussolini und Hitler ${ }^{1}$. Das innenpolitische Pendant fand seinen schlagenden Ausdruck in der Formel "Lieber Hitler als Blum", mit der sich die Wendung zur Kollaborationsideologie in den Kreisen der extremen Rechten vollzog². Die zentralen Themen dieses Bürgerkrieges waren bereits vor der Ernennung Léon Blums zum Ministerpräsidenten der Volksfront im Juni 1936 entwickelt. Zunächst geht es daher um die Konflikte, in denen sich die ideologischen Fronten herausbildeten, und den Standort, den die Jeune Droite und der Ordre Nouveau innerhalb des Radikalisierungsprozesses einnahmen.

Anhand von drei Ereignissen soll diese Entwicklung untersucht werden:

1. Der Abessinienkrieg zerstörte den außenpolitischen Konsens der Rechten: Die Extremisten distanzierten sich von dem Verbündeten England und setzten sich für die Bindung Frankreichs an Italien ein.

2. Die Debatten um die Ratifizierung des französisch-russischen Beistandspaktes im März 1936 bildeten den zweiten Schritt in der Neuorientierung der extremen Rechten: erstmals war ihre Entscheidung gegen die Sowjetunion unmittelbar an eine Option für das Dritte Reich geknüpft.

3. Diese Position wurde in der unmittelbar darauf folgenden Remilitarisierung des Rheinlandes noch bestärkt: Frankreich mußte nach Ansicht der extremen Rechten einen Krieg mit Deutschland um jeden Preis verhindern.

\footnotetext{
1 Vgl. hier und im folgenden Micaud, French Right, S. 51ff. Vaïsse, Der Pazifismus, S. 590-616; Ingram, The Politics of Dissent.

2 Rémond, L'image de l'Allemagne, S. 12. Vgl. Wirsching, Kollaborationsideologie, S. $55 \mathrm{ff}$.
} 


\section{Der Abessinienkrieg}

Mit der italienischen Offensive in Abessinien im Oktober 1935 gerieten Italien und Großbritannien in einen unerbittlichen Gegensatz. Die strategisch wichtige Position Großbritanniens am Suez-Kanal stand auf dem Spiel. Da Abessinien einen Sitz im Völkerbund hatte, konnte es das System der kollektiven Sicherheit in Gang setzen und - mit Unterstützung der Briten - Sanktionen gegen den Aggressor erwirken. Während die französische Linke die Sanktionspolitik vorbehaltlos unterstützte, ging auf der Rechten der außenpolitische Konsens zu Bruch, der mit dem Abkommen von Stresa (April 1935) konkrete Formen angenommen hatte. Das gegen Deutschland gerichtete Bündnis von Italien, England und Frankreich war an dem Interessengegensatz im Mittelmeer zerbrochen $^{3}$. Die Rechte spaltete sich in einen pro-britischen und eine pro-italienischen Flügel. Die traditionellen Nationalisten um Henri de Kerillis unterstützten die Sanktionspolitik und schlossen sich damit dem politischen Gegner auf der Linken an, während ein großer Teil der extremen Rechten vorbehaltlos die italienische Aggression verteidigte ${ }^{4}$.

Die Jeune Droite ergriff sofort die Position der von der Action française angeführten pro-italienischen Minderheit. Jean-Pierre Maxence gab der Konflikt Anlaß zu einem vehementen Bekenntnis zur „lateinischen Schwester". Auf einer Versammlung des französisch-italienischen Komitees im September 1935 beschwor er die Schicksalsgemeinschaft beider Länder: „[...] unsere gemeinsame Bestimmung ist es, die tausendjährige Vergangenheit und die römische Tradition zu retten". Er rief seine Landsleute auf, sich von England zu distanzieren und sich Mussolinis „Revolution“ zum Vorbild zu nehmen5. Dieses Bekenntnis fügte sich nahtlos in das von der Action française vertretene Konzept der „lateinischen Gemeinschaft“ ein. Aus dieser Sicht hatten Italien und Frankreich das Erbe der griechisch-lateinischen Antike angetreten und konnten für sich in Anspruch nehmen, die Bewahrer der universalen Prinzipien der abendländischen Kultur zu sein 6 . Eine Isolation oder Schwächung Italiens kam somit einem Angriff auf die Fundamente dieser Kultur gleich. Mit dem Hinweis auf die Verteidigung des europäischen Erbes legitimierte die Jeune Droite die Machtpolitik Mussolinis.

Maulnier begrüßte den Abessinienkrieg als zivilisatorische Mission Italiens gegenüber dem „barbarischen“ afrikanischen Staat. In der Action Française betonte er, die Abessinier sollten froh sein, daß ihnen auf diese Weise Kultur beigebracht werde. Er schloß mit der zynischen Bemerkung an die Adresse der Sanktionsbefürworter: moralische Fragen hätten in den Hintergrund zu treten, wenn es um den Fortbestand der europäischen Kultur gehe: „[...] auch wenn die Ziele der Eroberung, die vor unseren Augen stattfindet, rein materielle und wirtschaftliche Gründe haben, so dient sie letztendlich dem Wohl der gesamten Menschheit."7

${ }^{3}$ Höhne, Neuorientierung, S. 221ff., zur extremen Rechten siehe auch Micaud, French Right, S. 34ff.

${ }^{4}$ Höhne, Neuorientierung, S. 229; Micaud, French Right, S. 83.

${ }^{5}$ AN F7 12960 "Notes Jean", Bericht vom 11. Sept. 1935.

${ }^{6}$ Vgl. Sérant, Dissidents, S. 290-294.

${ }^{7}$ Maulnier, Les intellectuels juges de la civilisation, in: Action Française 24. 10. 1935, S. 3; ganz ähnlich seine Haltung im Courrier Royal: „Eine Intervention im Konflikt zwischen Italien und Äthiopien würde in der gegenwärtigen Situation einen Krieg entfesseln oder vorbereiten und damit die stärksten Traditionen und männlichsten Tugenden unserer Zivilisation aufs Spiel setzen“, 
Zudem warf Maulnier den Briten Heuchelei vor. Unter dem Deckmantel der moralischen Entrüstung würde ein kaltblütiger Zynismus die Entscheidung für Sanktionen bestimmen. In Wahrheit wollten die Briten Italien nur daran hindern, ein eigenes Kolonialreich aufzubauen, das zur Konkurrenz des Empire werden könne. Nach außen hin würden die Sanktionen als ehrlicher Pazifismus verkauft, während sie tatsächlich nur den eigenen Interessen dienten, für die England sogar einen Krieg in Kauf nehme ${ }^{8}$. Hiermit war ein zentrales Thema angesprochen, das die Argumentation der pro-italienischen Fraktion bestimmte: die Sanktionen kamen ihrer Ansicht nach einer Kriegserklärung gleich. Die Engländer und alle, die auf ihrer Seite standen, waren die eigentlichen Brandstifter. Die politischen Fronten schienen verkehrt zu sein: die Linke und mit ihr die probritische Minderheit der Rechten wurden der Kriegstreiberei beschuldigt, während die extreme Rechte plötzlich eine „pazifistische“ Position vertrat.

Mit dieser Haltung lag die Jeune Droite ganz auf der Linie der im Umkreis der Action française und ihrer Satelliten Gringoire, Je suis partout und Candide vertretenen Position'. Die extreme Rechte demonstrierte ihre Geschlossenheit in einem Manifest Henri Massis' „Für die Verteidigung des Abendlandes“, das auch die Unterschriften von Brasillach, Fabrègues, Francis, Maxence und Maulnier trug. Darin wurde Italiens Kolonialkrieg mit der Begründung gerechtfertigt, es gelte den kommunistischen Einfluß in Europa zurückzudrängen. Der „Sanktionskrieg“ war nach Ansicht der Unterzeichner ein kurzsichtiges und gefährliches Unterfangen, weil er Europa zugunsten des Bolschewismus schwächte. Der Völkerbund als Symbol der verhaßten Nachkriegsordnung und als Garant der kollektiven Sicherheit bewies in den Augen der extremen Rechten einmal mehr seine gefährliche Tendenz, Eigennutz und Zwietracht zu fördern und Konflikte zu entfachen statt sie einzudämmen ${ }^{10}$.

In dieser Situation traten die Differenzen zwischen den verschiedenen Gruppierungen der Rechten in den Hintergrund. Die Jeune Droite schloß sich den Veranstaltungen des Front National an, der sich aus den Ligen der Jeunesses Patriotes, der Solidarité française, der Action française und des Francisme gebildet hatte. Maulnier marschierte bei den Demonstrationen des Front National gegen die Völkerbundsanktionen mit ${ }^{11}$. Die Skrupel des Esprit-Kreises, der im Namen derselben christlich-abendländischen Kultur den brutalen Kolonialkrieg verurteilt hatte, tat die Jeune Droite als kleinlich ab: die Bruchlinie zwischen Anhängern und Gegnern des Kolonialkrieges verlief somit inner-

in: Courrier Royal 15, 12.10. 1935, S. 1. Zu diesem Zeitpunkt konnte er noch nicht wissen, daß diese „Kultur“ auf äußerst brutale Weise „vermittelt" wurde, nämlich mit Giftgas- und Bombenangriffen gegen die Zivilbevölkerung. Die Berichterstattung über die Kriegführung wurde am 4. Oktober 1935 vom Propagandaministerium untersagt. Doch auch später hat sich Maulnier nicht von der Grausamkeit der Kolonisatoren distanziert; vgl. Baer, Test Case, S. 18.

${ }^{8}$ Maulnier, L'opinion mondiale mystifiée, in: Combat, H. 1, 1936, S. $5 f$., vgl. Maulnier, Les trois grandes Démocraties, in: Combat, H. 18, 1937, S. 117.

${ }_{9}$ Micaud, French Right, S. 56f.; vgl. Milza, Fascisme italien, S. $221 \mathrm{ff}$.

${ }^{10}$ [Massis], Un manifeste d'intellectuels français pour la défense de l'Occident. Das Manifest ist am 4. 10. 1935 gleichzeitig in Le Temps, S. 2f. und in der Action française, S. 1f. erschienen. Die Liste in der AF enthält mehr Namen; vgl. Sirinelli, Intellectuels et passions françaises, S. $92 \mathrm{ff}$.

1 AN F7 13 983/ 14, Bericht vom Mai 1936; auch Maxence unterstützte die Aktivitäten der Front, F7 12965, Bericht vom 25.3. 1936. 
halb der nonkonformistischen Generation, sogar innerhalb des katholischen Lagers. Die politischen Präferenzen waren stärker als die gemeinsame Glaubensgrundlage ${ }^{12}$.

Angesichts der Bedrohung durch die Sowjetunion mahnte Fabrègues zur Geschlossenheit. Stalin wartete seiner Ansicht nach nur auf ein Zeichen der Schwäche, um Europa zu unterwerfen. Aus seiner Sicht nahm dieser Konflikt die Dimensionen eines Glaubenskrieges zwischen christlichem Abendland und heidnischem Materialismus an: „Ein totaler Krieg wird die Folge sein, in den die ganze westliche Zivilisation hineingezogen zu werden droht, in dem vor allem Frankreich alles zu verlieren hat. [...] In dem Moment, wo die kommunistische Revolution den Westen mit ihrem entfesselten Materialismus bedroht, ist nicht mehr nur das bloße Leben in Gefahr, sondern die geistige Bestimmung unseres Landes. Der totale Krieg im Westen bringt uns morgen den Bolschewismus." ${ }_{13}$ Diese Stellungnahme macht die ideologischen Dimensionen des Konfliktes deutlich. Der Bolschewismus war aus der Sicht der Jeune Droite eine fremde Macht aus dem fernen Asien, die den europäischen Kulturkreis auszulöschen drohte. Der Kolonialkrieg Italiens erschien angesichts dieser Gefahr als legitime Verteidigung der christlichabendländischen Wertegemeinschaft.

Besondere Bedeutung hatte der Konflikt, weil er die Weichen für künftige Entscheidungen stellte und das "große Schisma“ der Rechten zwischen den Anhängern einer traditionell an England orientierten Diplomatie und den Neopazifisten einleitete, die für Konzessionen gegenüber dem Diktator eintraten. Leichtfertig hatte die extreme Rechte auf den wichtigsten traditionellen Verbündeten Frankreichs verzichtet. Mit der rückhaltlosen Anerkennung der faschistischen Aggression stellten die extremen Rechten zumindest indirekt auch einen Freibrief für die territorialen Machtansprüche Hitlerdeutschlands aus ${ }^{14}$. Wie eng die Option für Italien mit derjenigen für Deutschland verbunden war, wird am Fall der Solidarité française besonders deutlich. Mit dem Ausbruch des Abessinienkonfliktes hatte Jean Renaud gleichzeitig eine nahezu vollständige Kehrtwende seiner Politik gegenüber Deutschland vollzogen. Hatte die Solidarité bis dahin eine strikt germanophobe Haltung eingenommen, so sprach sich Renaud nun für eine Allianz zwischen Frankreich, Italien und Deutschland gegen England und Rußland aus. Es ist auffällig, daß er seine Ansicht genau zu dem Zeitpunkt änderte, als Maxence sich im Direktionskomitee der Liga zu profilieren begann. Zudem lassen sich deutliche Parallelen in der Argumentation feststellen. Ähnlich wie Maxence bereits 1933 in der Revue française begründete Renaud seine Haltung mit der Notwendigkeit einer starken und stabilen Regierung in Frankreich. Hitler zu imitieren, bedeute zu verhindern, daß er Frankreich unterwerfen könne. Auch die Funktion Deutschlands als antibolschewisti-

\footnotetext{
12 Vgl. „Manifeste pour la justice et la paix“, in: Esprit, H. 38, 1935, S. 306-309, 307; auch die Polemik Pierre-Henri Simons gegen das Massis-Manifest: Petite note sur la vocation intellectuelle, in: ebenda, S. 303-306; Anfang 1936 waren die verschiedenen Vertreter des politischen Katholizismus auf Einladung der Dominikaner in Juvisy zusammengetroffen, um über den Abessinienkrieg zu diskutieren. In der Sache gab es allerdings keine Annäherung. Den Vorsitz hatte Gabriel Marcel, mit dabei waren Maulnier, Fabrègues, Maritain und Vertreter des Esprit-Kreises; vgl. Coutrot, Sept, S. 53; Rémond, Les catholiques, S. 94ff.; Fabrègues, Indépendance?, in: Combat, H. 2, 1936, S. 20.

${ }^{13}$ Fabrègues, La politique métaphysique n'est pas la politique chrétienne, in: Combat, H. 1, 1936, S. 6 f.

${ }^{14}$ Höhne, Neuorientierung, S. 230f., Micaud, French Right, S. $61 \mathrm{f} ., 64$.
} 
scher Schutzwall, auf die Renaud Wert legte, hatte Maxence schon zwei Jahre zuvor erkannt ${ }^{15}$.

Im Unterschied zur Jeune Droite distanzierte sich der Ordre Nouveau ausdrücklich und entschieden von der italienischen Aggression. Schon lange vor dem Beginn des Krieges hatte der Ordre Nouveau sich gegen jegliche Form von Kolonialismus ausgesprochen, weniger aus moralischen Gründen als vielmehr aus wirtschaftlichen. Dieses Expansionsstreben, so hatte Jacques Dalbon erläutert, sei die unvermeidliche Folge des Kapitalismus auf der Suche nach neuen Märkten ${ }^{16}$. Diesen Vorwurf richtete der Ordre Nouveau nun an Mussolini, der beschuldigt wurde, den liberalen Kapitalismus nicht entschieden genug bekämpft zu haben. Die gewaltsame Expansion stellte sich somit für den Ordre Nouveau als unausweichliche Folge einer wirtschaftlichen Zwangslage dar. Die Beherrschung des Mittelmeeres sei für den Diktator der Ausweg aus dem Bevölkerungsüberschuß und der wirtschaftlichen Misere, die sich noch durch die Aufrüstung verschärft habe. Diese Entwicklung lag nach Ansicht der Gruppierung in der Logik des kapitalistischen Staates, die in die kriegerische Konfrontation münde. „Die Rückkehr zum Angriffskrieg ist nichts anderes als die Rückkehr zum einfachsten Mittel. Krieg ist keineswegs ein unabwendbares Übel. Er ist auch kein heroischer Weg, der geeignet wäre, dekadenten Völkern ihre Lebenskraft zurückzugeben. Er ist lediglich ein anderer Ausdruck des Niedergangs." 17

Diese Stellungnahme, verbunden mit der Forderung nach einer föderalistischen Neuordnung Europas, zeigt deutlich den Einfluß sozialistischer Lehren aus der Schule Proudhons, die Arnaud Dandieu der Gruppierung vermittelt hatte ${ }^{18}$. Indem aber die Gründe für den Krieg ausschließlich dem kapitalistischen System angelastet wurden, negierte der Ordre Nouveau die Unterschiede zwischen liberalen Demokratien und diktatorischen Systemen. In der Tat verglich das Redaktionskomitee in einer Stellungnahme die zentralistische Politik Frankreichs gegenüber dem Elsaß mit der faschistischen Kolonisation Afrikas ${ }^{19}$. Aus dieser Perspektive mußte die Sanktionspolitik des Völkerbundes eine bloße Farce darstellen, ein scheinheiliges Disziplinierungsinstrument von Staaten, die derselben Logik unterworfen waren, sich jedoch noch nicht in einer vergleichbaren wirtschaftlichen Zwangslage befanden. Marc konstatierte: „Das Europa des Völkerbundes führt ebenso sicher zum Krieg wie das Europa der Faschisten. “20

Aus diesem Grund verurteilte der Ordre Nouveau nicht nur den Neopazifismus der extremen Rechten, sondern er distanzierte sich auch von den Sanktionsbefürwortern des Esprit-Kreises. Die Konsequenz der Interpretation, die der Ordre Nouveau dem Kon-

${ }^{15} \mathrm{Zu}$ Renaud vgl. Soucy, Second Wave, S. 80ff.; zu Maxence vgl. APP Ba 1960, Bericht vom 9.11. 1935.

${ }^{16}$ Dalbon, Les Colonies, le Capitalisme et l'Etat, in: ON, H. 2, 1933, S. 24-27.

17 Dupuis, Pourquoi la guerre?, in: ON, H. 26, 1935, S. 1-10, Zitat S. 9; ähnlich Marc, L'Etat contre les Nations, in: ON, H. 27, 1936, S.1-15, hier S. 3ff., und J. Chevalley/Dupuis, Le fascisme à bout de souffle, in: ON, H. 36, 1936, S. 14-20, hier S. 19 f.

18 Dupuis, Où en est l'Europe, in: ON, H. 24, 1935, S. 10; eine Sondernummer der Zeitschrift war ausschließlich diesem Thema gewidmet: „Par-dessus les frontières...vers le fédéralisme!“, in: ON, H. 15, 1934; zum Einfluß Proudhons auf die Theorien des Ordre Nouveau vgl. Voyenne, Histoire de l'idée fédéraliste, Bd. 3, S. 159ff.

19 Ordre Nouveau, De l'Ethiopie à l'Alsace, in: ON, H. 27, 1936, S. II.

${ }^{20}$ Marc, L'Etat contre les Nations, in: ON, H. 27, 1936, S. 11. 
flikt zugrunde legte, war ein Verzicht auf jegliche Parteinahme: „Weder Italien noch England“. Ohne eine grundsätzliche Überwindung des Kapitalismus und mit ihm des nationalstaatlichen Prinzips konnte nach Ansicht des Ordre Nouveau ein Krieg auf Dauer nicht verhindert werden. Als einziger Ausweg bot sich für Alexandre Marc eine "föderalistische Revolution“ in Frankreich an, die den übrigen europäischen Staaten als Vorbild dienen sollte ${ }^{21}$.

Italien wurde für den Ordre Nouveau zum warnenden Beispiel für die Außenpolitik eines autoritären Nationalstaats, mit dem zugleich die Schwäche des internationalen Systems der Friedenssicherung offenbar wurde. Ähnlich wie bei der extremen Rechten war das Urteil über Italien mit dem Blick auf Deutschland gefällt worden. Spätestens in zwei oder drei Jahren, so prophezeite Marc Anfang 1936, befände sich Deutschland in einer ähnlichen Situation wie Italien. Die Rüstungsindustrie, gegenwärtig noch der Motor der wirtschaftlichen Entwicklung in Deutschland, führe langfristig in den volkswirtschaftlichen Ruin, der nur durch Expansion aufgehalten werden könne. Wer das Verhalten Mussolinis legitimiere, der gebe auch Deutschland einen Freibrief für dessen Ausgreifen in Mitteleuropa ${ }^{22}$. Doch die Ansichten innerhalb der Gruppierung waren keineswegs so einhellig, wie dies in der Zeitschrift demonstriert wurde. In Sept bezog Daniel-Rops, der sich in Ordre Nouveau zu dem Konflikt nicht geäußert hatte, eine durchaus konträre Position. Er bescheinigte nämlich Italien grundsätzlich ein Recht auf koloniale Expansion. Er war sich darüber im klaren, daß er dieses Recht konsequenterweise dann auch Deutschland zugestehen mußte - in der Gewißheit, daß sich dessen Drang nach Osten richten werde. Er machte deutlich, daß ein Frieden in Europa vor allem davon abhänge, ob es Frankreich gelinge, sich mit Deutschland zu verständigen. Dafür war er bereit, die Bündnisverpflichtungen der kleinen Entente für nichtig zu erklären und die östlichen Verbündeten Frankreichs ihrem Schicksal zu überlassen ${ }^{23}$.

In einem Punkt allerdings war sich der Ordre Nouveau mit der Jeune Droite einig: in der Furcht vor den fatalen Konsequenzen eines europäischen Krieges, „der für Jahrhunderte unseren Kontinent ruinieren und zweifellos das Ende unserer westlichen Zivilisation bedeuten würde" ${ }^{24}$. Diese Haltung erwuchs jedoch noch nicht aus einer einseitigen Furcht vor der Sowjetunion, wie sie für die extreme Rechte charakteristisch war, sondern richtete sich gegen die beiden großen "materialistischen" Blöcke, die sich das Abendland unterwerfen wollten. Für Dupuis gab es zwei Möglichkeiten: „der Kolonisation Europas durch die Asiaten oder vielleicht durch die Amerikaner“"25.

Angesichts dieser unerfreulichen Perspektive und der geringen Aussicht auf eine revolutionäre Lösung steuerte der Ordre Nouveau letztlich auf einen Kompromiß zu, der demjenigen der linken Dissidenten ähnelte. Bergery, Déat und Doriot hatten ebenfalls die Aggression Italiens verurteilt, waren jedoch Zugeständnissen an Italien nicht prinzipiell abgeneigt. Sie lehnten militärische Sanktionen ab und plädierten für eine Verhand-

${ }^{21}$ Ebenda, S. 12ff.; vgl. Dupuis, Où en est l'Europe, in: ON, H. 24, 1935, S. 1 off.

22 Marc, L'Etat contre les Nations, in: ON, H. 27, 1936, S. 8; ders. [Scrutator], Les sept jours, in: Sept, H. 85, 1935, S. 2.

${ }^{23}$ Daniel-Rops, France-Allemagne, in: Sept, H. 101, 1936, S. 20.

${ }^{24}$ Dupuis, Où en est l'Europe, in: ON, H. 24, 1935, S. 11.

${ }^{25}$ Ebenda. 
lungslösung ${ }^{26}$. Auch sie kritisierten in erster Linie die kapitalistischen Ursprünge des Imperialismus und neigten auf diese Weise zur gleichen Überbewertung wirtschaftlicher Faktoren wie der Ordre Nouveau. Die Übereinstimmung ihrer Sichtweisen zeigte sich schließlich darin, daß sowohl Marc als auch Doriot das Argument des italienischen Bevölkerungsüberschusses ernst nahmen und darin den unmittelbaren Anlaß für die Expansion sahen ${ }^{27}$.

\section{Der französisch-russische Beistandspakt}

Die Ratifizierung des französisch-russischen Beistandspaktes Anfang 1936 stieß im Parlament und in der Öffentlichkeit auf einen bis dahin nicht gekannten Widerstand. Kaum ein Jahr zuvor, beim Abschluß des Paktes im Mai 1935, war er von Politikern und Presse noch überwiegend positiv bewertet worden. Die Verpflichtung zum gegenseitigen militärischen Beistand entsprach damals den Sicherheitsinteressen der meisten Franzosen, die sich durch die Aufrüstung und die Wiedereinführung der Wehrpflicht in Deutschland bedroht fühlten ${ }^{28}$.

Doch mit den Erfolgen der Volksfront hatte sich das politische Klima deutlich gewandelt. Nach wochenlangen zermürbenden Verhandlungen wurde der Pakt am 27. Februar 1936 schließlich mit einer schwachen Mehrheit von Sozialisten und Radikalen ratifiziert. Ein Großteil der traditionellen Rechten um Henri de Kerillis und Louis Marin hatte inzwischen seine Meinung grundlegend geändert: für sie war der Pakt nur mehr ein Mittel Stalins, um einen Kreuzzug gegen den „Faschismus“ zu führen, für den Frankreich seine Truppen liefern sollte ${ }^{29}$. Die Sowjetunion erschien selbst dem traditionell deutschfeindlichen Lager zumindest gleichermaßen bedrohlich wie der Nachbar jenseits des Rheins. Offensichtlich war dieser Umschwung ein Reflex auf die inzwischen deutlich veränderte innenpolitische Situation. Die Radikalen hatten auf ihrem Parteitag im Oktober 1935 ihre Bereitschaft zum Bruch mit der Nationalen Union signalisiert und ein Bündnis nicht nur mit den Sozialisten, sondern auch mit den Kommunisten anvisiert. Als sie Anfang 1936 unter Protest aus der Regierung Lavals ausschieden, war unübersehbar geworden, daß sie an der Seite der Volksfront in die Wahlen gehen und diese auch gewinnen würden ${ }^{30}$.

Unter diesen veränderten Vorzeichen drohte nach Auffassung der Rechten der Pakt eine ganz andere Bedeutung zu erhalten: Eine Volksfrontregierung mit Beteiligung der Kommunisten konnte - so fürchtete die Rechte - den Pakt in eine militärische Allianz umwandeln. Nachdem schon der Abessinienkrieg die einheitliche Haltung der Rechten unterminiert hatte, markierte die Ratifizierung des Beistandspaktes das offizielle Ende der Front gegen Deutschland und den Beginn des "großen Schismas". Nur ein harter Kern der traditionellen Nationalisten um Paul Reynaud blieb seiner germanophoben Haltung treu und stimmte für den Pakt mit der Sowjetunion. Doch war diese Gruppe innerhalb der Rechten isoliert und sah sich einer Mehrheit gegenüber, die den Pakt ab-

\footnotetext{
${ }^{26}$ Burrin, Dérive, S. $205 \mathrm{ff}$.

${ }^{27}$ Ebenda, S. 207; Marc, Etat, in: ON, H. 27, 1936, S. $2 f$.

${ }^{28}$ Scott, Alliance, S. $246 \mathrm{ff}$.

${ }^{29}$ Ebenda, S. $264 f$.

${ }^{30}$ Jackson, Popular Front, S. 49; Lefranc, Histoire, S. $98 \mathrm{ff}$.
} 
lehnte und zumindest eine abwägende Haltung gegenüber Deutschland einnahm. Innerhalb der Gegner des Paktes lassen sich zwei verschiedene Haltungen unterscheiden, die hier nach der Typologie Charles Micauds "bedingte“ und "resignierte" Nationalisten genannt werden. Die bedingten Nationalisten lehnten Zugeständnisse an die Sowjetunion und an Deutschland gleichermaßen ab. Ihre jeweilige Haltung war bestimmt vom Abwägen zwischen „brauner" und „roter" Gefahr. Ein Großteil der gemäßigten Rechten gehörte zu dieser Gruppe, die ein Gegengewicht gegen den Expansionsdrang Deutschlands durch die Wiederbelebung der Stresa-Front erreichen wollte.

Die resignierten Nationalisten - nach Micaud die extreme Rechte einschließlich der Action française - sahen in Deutschland primär einen Schutzwall vor dem Bolschewismus. Als radikale Feinde der Sowjetunion wollten sie Deutschland im Osten gewähren lassen, um selbst von einem möglichen Krieg zu profitieren - was im Zweifelsfall auch die Preisgabe der Sicherheitsgarantien für die Staaten der kleinen Entente bedeutete. Mit dem Widerstand gegen den Pakt hat ein Großteil der Rechten die Appeasementpolitik gegenüber Deutschland eingeleitet ${ }^{31}$.

Zugleich erhielt das Lager der resignierten Nationalisten Verstärkung von links: Jacques Doriot orientierte sich seit 1936 immer deutlicher zur extremen Rechten und plädierte, in der Hoffnung, auf diese Weise den gefährlichen Nachbarn zähmen zu können, für eine deutsch-französische Verständigung. Dagegen unterstützten Bergery und Déat den Beistandspakt mit Vorbehalten. Keinesfalls durfte er in eine militärische Allianz verwandelt werden, die zur Einkreisung Deutschlands führte. Vielmehr erhofften auch sie sich eine Rückkehr des Nachbarn an den Verhandlungstisch ${ }^{32}$.

Die Jeune Droite, die seit Anfang des Jahres 1936 über ein neues Organ mit dem Titel Combat verfügte, nahm die Ratifizierung mit Entrüstung auf. Sie machte die Hoffnungen auf die Orientierung Deutschlands nach Osten zunichte und weckte die Befürchtung, daß sich die Feindschaft nun auf den Nachbarn im Westen richten werde. Die Herausgeber Fabrègues und Maulnier nannten die Allianz „einen Pakt, der die gesamte französische Jugend bald einem unvermeidbaren Massaker preisgibt" ${ }^{33}$. Der Pakt war aus der Sicht der Jeune Droite nur ein geschickter Schachzug der Sowjetunion mit dem Ziel, die europäischen Staaten untereinander in einen Krieg zu verwickeln. Aus ihrer Sicht handelte es sich um ein Bündnis zwischen Staaten mit vollkommen gegensätzlichen Interessen. Blanchot betonte, das einzige Interesse Frankreichs sei die Bewahrung des Status quo, während die Sowjetunion sich Europa unterwerfen wolle. Blanchot fürchtete, daß die Sowjets mit der Allianz nur das Ziel verfolgten, Frankreich in eine Art Stellvertreterkrieg mit Deutschland zu verwickeln, um auf diese Weise Europa zu schwächen ${ }^{34}$.

Die jungen Rechten machten keinen Hehl aus ihrer Ansicht, daß Stalin im Vergleich mit Hitler der gefährlichere Feind war, und bekannten sich mit aller Deutlichkeit zu einer Haltung, die sie als resignierte Nationalisten auswies: Das Dritte Reich bildete den

31 Vgl. Micaud, French Right, S. $70 f f$.

32 Burrin, Dérive, S. $207 \mathrm{ff}$.

${ }^{33}$ Combat, La Dictature de l'infamie, in: Combat, H. 3, 1936, S. 35f. Auch innerhalb der Jeune Droite läßt sich der Klimawechsel deutlich ablesen; vgl. die Reaktion auf den Abschluß des Paktes im Mai 1935: Blanchot, Le dérèglement de la politique française, in: Revue du XXe siècle, H. 6, 1935, S. 57.

${ }^{34}$ Blanchot, La guerre pour rien, in: Combat, H. 3, 1936, S. 42. 
wirksamsten Schutzwall gegen den Bolschewismus. In der Folge ließen sie keine Gelegenheit aus, um die Gefährlichkeit der Kommunisten und den kurzsichtigen Eigennutz der übrigen Volksfront-Anhänger anzuprangern. „Wir dürfen nie vergessen, daß unsere Radikalen das Leben von Millionen Landsleuten für die kommunistische Wahlallianz aufs Spiel setzen, unsere Kapitalisten für die Hoffnung auf Aufträge aus der Sowjetunion." 35

Die kommunistische Weltrevolution war aus der Sicht der Jeune Droite nichts anderes als ein neues Vehikel des alten russischen Hegemonialstrebens, das sich immer schon gegen Europa richtete. „Es gibt eine bolschewistische Gefahr, aber die wahre Gefahr ist der Panslavismus, dem die Lehre von Marx und Engels neue Form und Gewalt gegeben hat. Nichts entkommt dem Zwang der Gegebenheiten. Revolutionen wandeln und beruhigen sich: Unter den äußerlichen Wandlungen bleibt das neue Rußland trotz allem das ewige Rußland. " ${ }^{36}$ Mit diesen Stellungnahmen blieb die Jeune Droite in dem Interpretationsrahmen, der durch ihr Herkunftsmilieu vorgegeben war und folgerichtig aus der Haltung zum Abessinienkrieg entwickelt werden konnte ${ }^{37}$.

Hatte der Ordre Nouveau den Abessinienkrieg zum mahnenden Beispiel des kapitalistischen Imperialismus erhoben, so vollzog die Gruppierung mit ihrer Haltung zur französisch-russischen Allianz einen deutlichen Stellungswechsel und fand sich auf der Seite der neopazifistischen Rechten wieder: „Dient die russische Allianz unserer Sicherheit? Wer das glaubt, muß so dumm sein wie ein Leser des Echo de Paris oder hörig wie ein Kommunist. [...] Stalin denkt nur daran, Frankreich als Schutzschild zu gebrauchen." ${ }^{38}$

Mit dieser Stellungnahme schloß sich Alexandre Marc der Auffassung an, daß die Allianz nur ein Mittel Stalins sei, um Frankreich in einen Krieg mit Deutschland zu verwikkeln. Aber nicht nur Marc, der durch seine persönlichen Erlebnisse mit dem Kommunismus geprägt war ${ }^{39}$, vertrat diese Ansicht. Denis de Rougemont hatte bereits vor der Bildung der Volksfront die Sympathisanten des Kommunismus der geistigen Abdankung bezichtigt und ihnen eine defätistische Haltung vorgeworfen ${ }^{40}$. Die Situation erschien nun um so bedrohlicher, als diese Haltung nicht mehr nur einige Schriftsteller betraf, sondern eine Bewegung, die alle Aussicht auf den Wahlsieg hatte. Robert Aron griff das zentrale Thema der Volksfront, den Kampf gegen den „Faschismus“, auf, und kehrte es in bezeichnender Weise um. Die Gefahr eines französischen Faschismus drohe der Volksfront vielmehr aus ihren eigenen Reihen: „Diese Fremdenlegion des Kommunismus wird beim ersten Fanfarenstoß - ohne es selbst zu bemerken - Fremdenlegion des Faschismus." ${ }^{41}$

Angesichts der sowjetischen Bedrohung galt der Nationalsozialismus eindeutig als das geringere Übel. Ausdrücklich räumte Marc dies ein: „Von allen Kriegstreibern und

${ }^{35}$ Combat, La Dictature de l'infamie, in: Combat, H. 3, 1936, S. 36.

${ }^{36}$ Saillenfest, Tamerlan 1936?, in: Combat, H. 3, 1936, S. 43; vgl. Fabrègues, Où sont vos principes?, in: Combat, H. 4, 1936, S. 54.; Wirsching, Kollaborationsideologie, S. $41 \mathrm{f}$.

${ }^{37} \mathrm{Vgl}$. Micaud, French Right, S. $72 \mathrm{f}$.

${ }^{38}$ Marc, Mériter la paix, in: ON, H. 33, 1936, S. 29-34, Zitat S. 30.

${ }^{39}$ Er war während der Oktoberrevolution in Moskau wegen konterrevolutionärer Tätigkeit festgenommen worden und nur durch einen Zufall der Hinrichtung entkommen; Rougemont, Journal d'une Epoque, S. 93.

${ }^{40}$ Rougemont, La Légion étrangère soviétique, in: ON, H. 2, 1933, S. 19-23, Zitat S. 19.

${ }^{41}$ Aron, Ecrivains révolutionnaires?, in: ON, H. 29, 1936, S. 7-9, Zitat S. 9. 
Pazifisten ist Stalin mit Sicherheit der gefährlichste."42 Stalin gefährlicher als Hitler, die Volksfront als Marionette Rußlands, der Bolschewismus als außereuropäische Macht mit dieser Einschätzung schloß sich der Ordre Nouveau dem Lager der resignierten $\mathrm{Na}$ tionalisten an. Ein Krieg mit Deutschland mußte auf jeden Fall verhindert werden, da dieser die Weltherrschaft des Kommunismus bedeutete. Damit akzeptierte der Ordre Nouveau auch die Rolle des Dritten Reiches als Bollwerk gegen den Bolschewismus. Allerdings distanzierte sich der Ordre Nouveau weiterhin von der eindeutigen Option für Italien und trat vielmehr für einen Ausgleich der Großmächte ein. Jegliche weitere Polarisierung der Großmächte mußte vermieden werden, da sie die Position Europas schwächte. Nach Ansicht Alexandre Marcs aber konnte Frankreich in der gegenwärtigen Lage zu diesem Ausgleich nur dadurch beitragen, daß es sich jeder Initiative enthielt ${ }^{43}$.

Diese Haltung lief letztlich auf einen Isolationismus hinaus, der für die Gruppierung seitdem bestimmend sein sollte. In dieser Situation war die Bewahrung des Friedens vor allem von der Rückbesinnung auf die Stärke des eigenen Landes abhängig. Wer sich, wie Léon Blum und Gaston Bergery, in einem solchen Moment für Abrüstung einsetze, begehe Verrat an seinem eigenen Land, betonte Alexandre Marc. Während sich ein großer Teil der Franzosen noch hinter der Maginot-Linie in Sicherheit wähnte, machte die Gruppierung auf Schwächen dieses Verteidigungssystems aufmerksam und forderte konkrete Schritte einer Heeresreform. Angeregt durch das Werk Charles de Gaulles über die Berufsarmee und durch persönliche Gespräche mit dem Autor, setzten sich die Mitarbeiter des Ordre Nouveau für die Umgestaltung der Wehrpflichtigenarmee in eine mobile und schlagkräftige Berufsarmee ein. Mit diesem Engagement gehörte die Gruppierung zu dem kleinen Kreis derjenigen, die bereits Mitte der dreißiger Jahre auf diese entscheidenden Schwächen hinwiesen. Gerade die extreme Rechte, die mit ihrer säbelrasselnden Rhetorik gerne nationale Stärke demonstrierte, erwies sich als ausgesprochen blind für die tatsächlichen Schwächen der militärischen Verteidigung, die sich 1940 als fatal erweisen sollten. Die Ideen de Gaulles fanden außer beim Ordre Nouveau auch im Milieu der nonkonformistischen Linken Gehör ${ }^{44}$.

42 Marc, Mériter la paix, in: ON, H. 33, 1936, S. 29-34, Zitat S. 30.

${ }^{43}$ Ebenda, S. 31ff.; ders. [Scrutator], Les sept jours, in: Sept, H. 113, 1936, S. 2. Mit einer ähnlichen Argumentation hatte Doriot, der zu diesem Zeitpunkt noch nicht in das Lager der extremen Rechten eingeschwenkt war, bereits die Sanktionen gegen Italien verurteilt. Eine Isolation Italiens würde es in die Arme Deutschlands treiben und damit dessen Revisionspolitik erst anstacheln; Burrin, Dérive, S. 207.

${ }^{44}$ Ebenda, S. 32. Das Projekt der Armeereform, das de Gaulle erstmals 1934 in seinem Werk Vers l'armée de metier formuliert hatte, wurde vom Ordre Nouveau entschieden unterstützt. Mit de Gaulle waren die Mitarbeiter der Gruppierung im Salon Daniel Halévys zusammengekommen; Aron, de Gaulle, S. 42; Rougemont, Journal d'une Epoque, S. 365. Darüber hinaus verfügte die Bewegung auch über langjährige Kontakte zu Emile Mayer, einem Bekannten und Kollegen de Gaulles; Brief Marcs an Sabine Aron vom 10. 10. 1984, Archives Rougemont, Neuchâtel, Correspondance. Vgl. die Artikel Emile Mayers in Plans und $O N$, Le danger aéro-chimique, in: Plans, H. 6, 1931, S. 115-120; ders., La défense du territoire français, in: Bulletin ON, Nr. 11, 1936, S. 4; Aron, L'armée dans la nation, in: ON, H. 26, 1935, S. 26-37. Zur Unterstützung des Projektes der Armeereform im Parlament vgl. Burrin, Dérive, S. 258f. und Brender, Kollaboration, S. 59; zur militärstrategischen Debatte vgl. Mysyrowicz, Anatomie d'une défaite, S. $201 \mathrm{ff}$., $245 \mathrm{ff}$. 


\section{Die Remilitarisierung des Rheinlands}

Die Ratifizierung des französisch-russischen Beistandspaktes im Februar 1936 nutzte Hitler als vordergründigen Anlaß, um den Vertrag von Locarno zu brechen und das Rheinland zu remilitarisieren. Hitler konnte darauf bauen, daß der Pakt nicht nur bei den Garantiemächten Großbritannien und Italien als Attacke auf die Abmachungen von Locarno angesehen wurde, sondern auch bei einem großen Teil der Franzosen selbst. Mit ihrer Agitation gegen den Pakt hatte die französische Rechte dem Diktator die Argumente bereitgestellt, mit denen er seine Aggression begründen konnte. Hitler brauchte nur noch das zu tun, was die Gegner des Paktes in ihren Schreckensprognosen prophezeit hatten. Zudem konnte Hitler als selbststilisierter „Retter vor dem Bolschewismus" nicht mit der Sympathie, aber zumindest mit der Duldung dieser Aggression bei den Feinden der Volksfront rechnen ${ }^{45}$.

Nach dem Einmarsch deutscher Truppen in das Rheinland trat die Jeune Droite die Flucht nach vorn an. Sie nahm die internationale Entrüstung über die deutsche Aggression zum Anlaß, von einer Verschwörung gegen das Dritte Reich zu sprechen. Alle Arten von "Vaterlandsverrätern" hatten sich nach Ansicht Maurice Blanchots zusammengefunden, um gegen Hitler Krieg zu führen: „Der Clan von alten Pazifisten, Revolutionären und emigrierten Juden ist zu allem bereit, um Hitler zu bekämpfen und gegen die Diktaturen vorzugehen. Neben der deutschen Ideologie gibt es eine weitere, die hartnäckig den Frieden durch ihre verkehrten Ansichten bedroht, Illusionen verbreitet und gegenwärtig Risiken vervielfacht. Das ist die Genfer Ideologie.“46

Wieder einmal kehrte die Jeune Droite in bezeichnender Weise den Vorwurf der Kriegstreiberei um. Deutschland erschien als das Opfer der Politik des verhaßten Völkerbundes. Unter dem Deckmantel des Pazifismus kaschiere die „Genfer Ideologie“ gerade das Gegenteil: einen ideologisch motivierten Krieg im Namen der Moral. Das System der kollektiven Sicherheit war Blanchot zufolge nichts anderes als die institutionalisierte Doktrin der liberalen Demokratien zur Durchsetzung ihres Hegemonialstrebens. Hitlers Coup mußte aus dieser Sicht als die unvermeidliche Folge dieser Art von Diplomatie begriffen werden, der sich Frankreich verschrieben hatte. Keinesfalls kamen daher Sanktionen gegen Deutschland in Frage, da sie die Kriegsgefahr noch gesteigert hätten. Mit der Forderung nach einer "realistischen“ Diplomatie unterstrich Blanchot die Allianz mit Italien als Alternative zum Völkerbundsystem der kollektiven Sicherheit. Eine Bündnis mit der „lateinischen Schwester", so unterstellte er, habe es Frankreich ermöglicht, Hitler ohne Kriegsgefahr am Bruch des Vertrages von Locarno zu hindern ${ }^{47}$.

Die Remilitarisierung des Rheinlands veranlaßte Brasillach zu einer grundsätzlichen Abrechnung mit der Versailler Nachkriegsordnung, die angeblich die Ursache von Frankreichs außenpolitischem Niedergang war: „der wirtschaftliche Irrsinn und Ruin, der Skandal der Reparationen, das Wiedererstarken Deutschlands, der langsame Abstieg Frankreichs auf den Rang eines Balkanstaats, die Machtergreifung Hitlers, der Niedergang der Vereinten Nationen" ${ }^{48}$. Folgerichtig interpretierte Brasillach, der hier erstmals

\footnotetext{
${ }^{45} \mathrm{Vgl}$. Wendt, Großdeutschland, S. 108, Jacobsen, Außenpolitik, S. $416 \mathrm{ff}$.

${ }^{46}$ Blanchot, Après le coup de force germanique, in: Combat, H. 4, 1936, S. 59.

${ }^{47}$ Ebenda; vgl. Micaud, French Right, S. 97.

${ }^{48}$ Brasillach, La machine à botter les culs, in: Combat, H. 9, 1936, S. 151.
} 
als politischer Journalist hervortrat, den deutschen Revisionismus als berechtigte Reaktion auf den Kriegsschuldartikel. Diese Schuldzuweisung war in seinen Augen der „moralische" Irrtum von Versailles. Frankreich sei mit seinen eigenen Mitteln geschlagen worden: im Namen der Moral beanspruche nun Deutschland das Recht auf Revision der Grenzen und auf Kolonien ${ }^{49}$. Trotz der neopazifistischen Attitüde blieb die Argumentation der Jeune Droite von einer Ambiguität geprägt: Auf der einen Seite rechtfertigte sie den Revisionismus des Dritten Reiches, um daran das Scheitern der französischen Außenpolitik zu demonstrieren. Auf der anderen Seite übersah sie nicht, daß das europäische Gleichgewicht bedroht war und insbesondere die nationalen Interessen Frankreichs verletzt wurden.

Der Ordre Nouveau zeigte sich von dem Einmarsch deutscher Truppen in das Rheinland wenig überrascht. Ohne Bedauern konstatierte René Dupuis, daß Hitler mit seinem Coup dem Versailler System endgültig den Todesstoß versetzt habe ${ }^{50}$. Und Alexandre Marc sah ähnlich wie Brasillach das Ereignis als eine notwendige Folge der Politik der kollektiven Sicherheit, die Deutschland in der internationalen Staatengemeinschaft isoliert habe: von dem Austritt Deutschlands aus dem Völkerbund über die Wiedereinführung der Wehrpflicht bis hin zum Abschluß des französisch-russischen Beistandspaktes: „Die unvermeidliche Folge dieser Reihe von ,Reaktionen“" "51 Unüberhörbar war auch hier der Tenor, der Nachbar habe nur auf eine äußere Bedrohung reagiert. Marc verknüpfte die „Ursachen“, nämlich die verfehlte Politik des Völkerbundes und Frankreichs, mit den jeweiligen "unvermeidlichen Folgen“, Deutschlands Aufrüstung und der Rheinlandbesetzung. Jedoch schenkte er den Friedensparolen Hitlers keinen Glauben, sondern war fest davon überzeugt, daß der Führer bei der nächsten Gelegenheit wieder die Konfrontation suchen werde. Letztlich konnte also nur ein starkes Frankreich den Diktator in seine Schranken weisen ${ }^{52}$. Seine kritische Distanz zum Nationalsozialismus veranlaßte ihn auch, den Kontakt zu Otto Abetz abzubrechen, nachdem dieser zum Frankreichbeauftragten der Ribbentrop-Dienststelle ernannt worden war ${ }^{53}$.

Doch gab es innerhalb der Gruppierung offensichtlich unterschiedliche Ansichten über die Aufrichtigkeit von Hitler. Dies wurde auf einer Konferenz deutlich, die einige Ordre Nouveau-Anhänger unter der Leitung Daniel-Rops' veranstalteten. Kennzeichnend für den Charakter dieser Konferenz war die Teilnahme von François Berge, der als aktives Mitglied des Sohlbergkreises für eine Politik der Verständigung mit Deutschland eintrat, die der Ordre Nouveau zu Beginn des Jahrzehnts entschieden bekämpft hatte. Nachdem es in Rethel 1931 zum Bruch zwischen dem Ordre Nouveau und dem Notre Temps-Kreis um Luchaire gekommen war, hatte Berge, der sich ebenfalls zu personalistischen Ideen bekannte, die französische Delegation des Sohlbergkreises auf dem Main-

\footnotetext{
${ }^{49}$ Brasillach, Morale, in: Combat, H. 13, 1936, S. 36; vgl. zur Politisierung und Radikalisierung von Brasillach durch den Aufstieg der Volksfront ders., Génération, S. 163; Hilary A. Footitt hebt indessen die Prägung durch den spanischen Bürgerkrieg hervor: Footit, Robert Brasillach, S. 123137.

${ }^{50}$ Dupuis, Le Mois, in: Bulletin ON, Nr.11, 1.5. 1936, S. 1.

${ }^{51}$ Scrutator [Marc], Les sept jours, in: Sept, H. 107, 1936, S. 2.

52 Ebenda; vgl. ders., L'Etat contre les Nations, in: ON, H. 27, 1936, S. 8.

${ }^{53}$ Gespräch mit Marc vom 4. 12. 1994; zu Abetz vgl. Jacobsen, Außenpolitik, S. 252ff.; Abetz, Das offene Problem, S. $41 \mathrm{ff}$.
} 
zer Treffen im März 1932 geleitet - jener Veranstaltung also, die als Reaktion auf den Frankfurter Plans-Kongreß organisiert worden war. Er verfügte seitdem über gute Kontakte zur Deutsch-Französischen Gesellschaft, der auch Otto Abetz angehörte, und arbeitete bei den Deutsch-französischen Monatsheften mit $^{54}$. Dieses gemeinsame Auftreten der ehemaligen Gegner kann nur als Geste der Versöhnung interpretiert werden. Einhellig verurteilten die Redner das Versagen der französischen Politiker und sahen insbesondere bei ihnen die Schuld für das Scheitern der deutsch-französischen Verständigung. René Dupuis zufolge hatte sich Frankreich nun in die paradoxe Situation hineinmanövriert, daß es, um den Frieden zu wahren, eigentlich Krieg führen müsse.

Eine entschieden prodeutsche Position vertraten Berge und Daniel-Rops. Berge betonte, daß auch nach diesem Vorstoß Hitlers in den Westen Frankreich nicht ernsthaft gefährdet sei. Hitlers Expansionsdrang richte sich weiterhin nach Osten. Die Franzosen sollten sich durch anderslautende Passagen in Mein Kampf nicht beunruhigen lassen: dieses Werk sei durch die historischen Umstände seiner Entstehung während der Ruhrbesetzung von antifranzösischen Ressentiments geprägt. Die wirklichen Feinde der Nationalsozialisten aber seien Habsburger, Juden und Bolschewisten. Dieser Haltung schloß sich Daniel-Rops an. Unerschütterlich hielt er an seiner Überzeugung von der Notwendigkeit einer deutsch-französischen Verständigung fest. Er verstieg sich zu der Behauptung, daß das Dritte Reich "gerechter und menschlicher" als das Kaiserreich unter Wilhelm II sei. Die Situation für Verhandlungen zwischen beiden Ländern erschien somit günstiger als vor dem Krieg. Daniel-Rops betonte sogar den aufrichtigen Friedenswillen des Diktators: „Meiner Ansicht nach könnte man dem deutschen Kanzler, dem es um den Frieden zwischen unseren Ländern geht, zum Beispiel sagen, daß sich das gegenwärtige Problem nicht in London, Berlin oder am Quai d'Orsay lösen läßt. Es geht vielmehr darum, die Menschen aus den künstlichen und mörderischen $Z$ wängen überholter Institutionen zu befreien und neue Institutionen zu schaffen, die die freie Entfaltung jedes einzelnen innerhalb seiner Bindungen an Boden, Familie und Beruf ermöglichen. " ${ }^{55}$ Daniel-Rops glaubte also offensichtlich nicht nur an eine Verständigung, sondern darüber hinaus auch an die Möglichkeit, eine grundsätzliche Übereinkunft zwischen Nationalsozialisten und Personalisten zu erzielen. Dieses Bekenntnis entsprach der bereits im „Brief an Hitler“ formulierten Überzeugung. Zugleich kam der Ordre Nouveau auf diese Weise den Bemühungen von Abetz entgegen, der in den Deutschfranzösischen Monatsheften den geistigen Austausch zwischen Personalisten und Nationalsozialisten förderte. In den Jahren 1936 und 1937 mehrten sich die Versuche, den Per-

${ }^{54}$ Die ON-Konferenz wurde in L'Euvre angekündigt und fand am 20.3.1936 im Musée Social statt. Neben Daniel-Rops und Berge sprachen noch Robert Aron, Claude Chevalley, Jean Jardin, Xavier de Lignac und René Dupuis, AN F7 12965, Bericht vom 21. 3. 1936; vgl. Ordre Nouveau, Mission ou Démission de la France, Paris 1936. François Berge arbeitete auch in den Deutschfranzösischen Monatsheften mit, die vom Comité France-Allemagne und seinem deutschen Pendant herausgegeben wurden, zu dem auch Otto Abetz gehörte; Berge, Die Ursprünge Frankreichs und die Entwicklung des nationalen Gedankens, in: DFM 3 (1936), S. 326-331; ders., Les Germains en France, in: DFM 4 (1937), S. 198-201. In diesem Artikel bekannte er sich zum „Personalismus"; siehe auch Abetz, Das offene Problem, S. 60ff. Zu François Berge vgl. auch Tiemann, Jugendbeziehungen, S. 129.

${ }^{55}$ AN F7 12965, Bericht vom 21.3. 1936. 
sonalismus als eine "geistige Erneuerungsbewegung" zu präsentieren und auf diese Weise die Parallelen zu Deutschland herauszustellen ${ }^{56}$.

Abgesehen von diesen Differenzen in der Bewertung der Verläßlichkeit Hitlers und der Aufrichtigkeit seiner Friedensbekundungen, stimmten Daniel-Rops und Alexandre Marc in ihrer neopazifistischen Grundposition überein. Mit der extremen Rechten teilten sie die Ansicht, daß das Dritte Reich eine zentrale Rolle bei der Verteidigung des Abendlandes vor der bolschewistischen Gefahr spiele. Von den Dissidenten der Linken unterschied sich der Ordre Nouveau durch die entschiedene Ablehnung des Parlamentarismus und seines außenpolitischen Pendants, des Genfer Systems der kollektiven Sicherheit. Bergery, Déat und Doriot nahmen zwar eine ebenso feindliche Haltung gegenüber der Sowjetunion ein und forderten eine Politik der nationalen Stärke, doch hielten sie an der Auffassung fest, daß eine Reform des Staates im Rahmen des Parlamentarismus und eine Lösung des internationalen Konfliktes innerhalb des Völkerbundes möglich $\operatorname{sei}^{\mathrm{5} 7}$.

\section{Revolutionärer Nationalismus: Jeune Droite}

\section{Combat}

Im Januar 1936, zu dem Zeitpunkt, als die Volksfront ihr erstes und einziges Wahlprogramm veröffentlichte, brachten Fabrègues und Maulnier die erste Ausgabe ihrer neuen Zeitschrift mit dem programmatischen Titel Combat heraus ${ }^{58}$. Daß sich diese Kampfansage vor allem gegen die Volksfront richten würde, machte das Manifest deutlich: „Das schreckliche Wort ,Sammlung' hat vor einigen Jahrzehnten einen schlechten Kompromiß zwischen übergeordneten Werten und politischen Interessen bezeichnet. Heutzutage sammeln sich wieder Intellektuelle in Parteien, das heißt, sie vergessen ihre eigentli-

56 Dazu war es Abetz gelungen, einen Beitrag von Emmanuel Mounier zu bekommen, Was ist der Personalismus?, in: DFM 3 (1936), S. 368-373; Rheiner/Hieronimi, Der Personalismus, eine geistige Erneuerungsbewegung in Frankreich, in: DFM 4 (1937), S. 58-63. Rougemont, um dessen Werk „Penser avec les mains“ es in der Besprechung von Hieronimi und Rheiner unter anderem ging, betonte in einem Leserbrief, daß die Unterschiede zwischen Nationalsozialisten und Personalisten in dem Begriff der „Person“ lägen, die nur bei letzteren Wirklichkeit werde. Ausdrücklich hob er aber hervor, daß es in der Jugend beider Länder Gemeinsamkeiten gebe, die mindestens ebenso bedeutend seien wie die Verschiedenheiten, in: DFM 4 (1937), S. 120.

${ }^{57} \mathrm{Vgl}$. Burrin, Dérive, S. $212 \mathrm{ff}$.

58 Zur Entwicklung der Jeune Droite seit 1936 gibt es zwei kürzere Abhandlungen: Leroy/Roche, Ecrivains, S. 61-72 und Leroy, Combat, S. 122-134; beide bleiben weitgehend an der Oberfläche und liefern keinerlei Informationen über Verbindungen und Hintergründe. Aus dieser Sicht bleibt die Zeitschrift in der Tradition der Action Française und zeichnet sich allenfalls durch ihren stärker ideologischen Charakter aus. Auch die Frage des Faschismus wird angesprochen, jedoch mit dem Hinweis auf die kritische Distanz zum Nationalsozialismus sogleich abgetan; vgl. ferner die von Verzerrungen nicht ganz freie Darstellung des ehemaligen Combat-Mitarbeiters Andreu, Revoltés, S. $121 \mathrm{ff}$. Der überwiegende Teil der Mitarbeiter war bereits zuvor in den Kreisen der Jeune Droite aktiv gewesen: Paul Amandry, Maurice Blanchot, Jean de Fabrègues, Hugues Favart, Robert Francis, Jean Loisy, Charles Mauban, Thierry Maulnier, Jean-Pierre Maxence, Marcel Noël, Claude Roy, Jean Saillenfest, Jacques-Marie Thomas, Emile Vaast, René Vincent. 
che Aufgabe und werden zu Parteianhängern. [...] Unparteilichkeit und Sammlung, Idealismus und Materialismus sind für uns Zeichen eines Niedergangs der Intelligenz, der gleichen Machtlosigkeit gegenüber der Realität." ${ }^{\text {"9 }}$

Das Manifest kehrte Bendas Intellektuellenkritik in programmatischer Weise um: nicht die nationalistischen Intellektuellen, sondern die linken Intellektuellen wurden der Pflichtvergessenheit bezichtigt: Sie hätten auf ihren Führungsanspruch verzichtet und sich selbst zu Mitläufern degradiert. Diese Polemik richtete sich insbesondere an die Adresse der verschiedenen Intellektuellenvereinigungen, die im Kampf gegen den „Faschismus" die Sammlungsbewegung der Volksfront unterstützt hatten: die Association des écrivains et artistes révolutionnaires (A.E.A.R.), das von Henri Barbusse ins Leben gerufene Comité de lutte contre la guerre et le fascisme, besser bekannt als Comité Amsterdam-Pleyel und das Comité de vigilance des intellectuels antifascistes (C.V.I.A.).60

Von den beiden Herausgebern prägte vor allem Maulnier den Charakter der Zeitschrift. Zusammen mit seinen Kollegen aus der ehemaligen Revue française, Maxence, Brasillach, Blond ${ }^{61}$ und Blanchot, bestimmte er den für eine Monatszeitschrift ungewöhnlichen aggressiven Stil: Scharfe Polemik verdrängte den weltanschaulich-kulturkritischen Ton, der bis dahin insbesondere in den von Fabrègues geleiteten Zeitschriften herrschte. Auch die neuen Mitarbeiter kamen aus dem Umfeld der extremen Rechten und unterhielten meistens schon längere Zeit Kontakte zur Jeune Droite. Mit Louis Salleron hatten Fabrègues und Maxence bereits 1924 in der Gazette française zusammengearbeitet. Er war ein Spezialist des agrarischen Korporatismus und wurde 1937 Professor für Wirtschaftspolitik am Pariser Institut Catholique. Als Chefredakteur des Courrier Royal stand er ohnehin in ständigem Kontakt mit den Redakteuren der Jeune Droite, die in der Zeitschrift des Grafen von Paris mitarbeiteten ${ }^{62}$. Ein weiterer Experte für Korporatismus war André Monconduit, der an einem Pariser Jesuitenkolleg unterrichtete ${ }^{63}$. Mit Pierre Andreu und Jean Le Marchand stießen die beiden Begründer des Front national-syndicaliste zum Redaktionsteam. Die Verbindung hatte Le Marchand hergestellt, der zusammen mit Fabrègues und Vincent zu den 1930 ausgeschiedenen AF-Anhängern gehörte und das Réaction-Manifest unterzeichnet hatte. Er leitete das Sekretariat des Combat.

Ähnlich wie die Vorgängerzeitschriften befand sich der Combat in einer prekären finanziellen Situation. Es gab keine Kapitaleinlage, die Sicherheit gewährt hätte, so daß die Zeitschrift anfangs nur mit dem Kredit des Druckers und durch Spenden existieren konnte. Die Mitarbeiter erhielten ebenso wie bei den übrigen Zeitschriften kein Honorar, sondern steuerten im Gegenteil noch Geld bei64. Doch trotz dieser Situation und der

59 Combat, Manifeste, in: Combat, H. 1, Jan. 1936, S. 3. Nach Angaben des Combat-Mitarbeiters Pierre Andreu hat Maulnier das namentlich nicht gekennzeichnete Manifest verfaßt: Andreu, Revoltés, S. 121.

${ }^{60} \mathrm{Vgl}$. Maxence, Après la peur, l'insulte, in: Combat, H. 3, 1936, S. 41; Ory/Sirinelli, Intellectuels, S. $96 \mathrm{ff}$.; Lefranc, Histoire, S. $41 \mathrm{ff}$., $45 \mathrm{ff}$.

${ }^{61}$ Brasillach und Blond verfügten über gute Beziehungen zur Action française und arbeiteten für Candide und Je suis partout; vgl. Brassié, Brasillach, S. 47; Dioudonnat, Rédacteurs, S.21, $23 \mathrm{f}$.

${ }^{62} \mathrm{Zu}$ Salleron vgl. Auzèpy-Chavagnac, Fabrègues, S. 108, 465; beim Courrier Royal arbeiteten mit: Fabrègues, Loisy, Mauban, Maulnier, Roy, Saillenfest, Vaast.

${ }^{63}$ Vgl. Auzèpy-Chavagnac, Fabrègues, S. 465.

64 Vgl. Combat, La quatrième année, in: Combat, H. 31, 1939, S. 4. 
problematischen Wirtschaftslage gelang es den Mitarbeitern, unterstützt durch Spenden von Sympathisanten, die Zeitschrift bis zum Juli 1939 zu publizieren ${ }^{65}$. Nach einem Jahr waren 1051 Abonnements des Combat in 42 Städten Frankreichs verkauft worden. 2000 wurden anvisiert für das Jahr 193766. Wenn man ähnlich wie bei den übrigen Zeitschriften dieser Größenordnung davon ausgeht, daß ungefähr die Hälfte der Exemplare frei verkauft wurde, so dürfte die Auflage zwischen 2000 und 4000 Stück betragen haben.

Der Kampf gegen die Volksfront erforderte nach Ansicht Blanchots den Einsatz von Gewalt. Einzig auf diese Weise glaubte er, das Volk aus seiner „Verblendung " befreien und zum Widerstand gegen eine Regierung bewegen zu können, die in seinen Augen für eine vollständige Blockade aller Reformen verantwortlich war. Unter dem Titel „Terrorismus, der Weg zum öffentlichen Wohl“ schrieb er: „Es ist notwendig, daß diese Revolution gewalttätig ist, weil man mit zurückhaltenden Maßnahmen einem so abgestumpften Volk wie dem unseren keine Kräfte und Leidenschaften für eine Erneuerung entlockt. Man rüttelt es nur mit blutigen Erschütterungen auf, mit einem Sturm, der alles umstürzt. "67

Der Sieg der Volksfront bestärkte den Kreis der Combat-Mitarbeiter in der radikalen Opposition gegen alle gemäßigten Kräfte. Maulnier sah die einzige Möglichkeit, die tiefen politischen Gräben zu überwinden, in einer "nationalrevolutionären“ Bewegung, die die antikapitalistischen Gewerkschaftskreise mit den nationalistischen Kräften vereinigte ${ }^{68}$. Die radikale Kritik am Parlamentarismus richtete sich in zunehmendem Maße auch gegen die traditionelle Rechte. Maulnier und Brasillach legten ihr gleichermaßen wie der Linken den Niedergang der Nation zur Last. Aus der Sicht der Jeune Droite führte jedes Bekenntnis zur Demokratie unweigerlich zu Kapitalismus und Klassenkampf. Der einzige Unterschied zwischen der bürgerlichen Linken und Rechten bestand darin, daß die einen auf der Seite der Arbeiter, die anderen auf der Seite der Patrons dieses Prinzip unterstützten.

Ein Wandel zeichnete sich jedoch in der Strategie ab: die Jeune Droite eröffnete nun die Offensive und versuchte, den Gegner auf seinem eigenen Terrain, der Wirtschaftsund Sozialpolitik, zu schlagen. Maulnier bedauerte, daß man der Linken schon viel zu lange diese Fragen überlassen habe. Jetzt sei es die Aufgabe der nationalen Rechten, sich dieser Themen zu bemächtigen und deutlich zu machen, daß nicht der Kampf der Klassen gegeneinander, sondern deren Versöhnung das Ziel der Politik sein müsse ${ }^{69}$. Anlaß für diesen Strategiewechsel war der enorme Zulauf, den sowohl die Kommunisten als auch die Gewerkschaftsbewegung in den Jahren der Volksfront verzeichneten. Die Mitgliederzahl der C.G.T. wuchs innerhalb weniger Monate nach der Wiedervereinigung mit der kommunistischen C.G.T.U. im März 1936 von 785000 auf rund vier Millionen. Die Kommunisten gewannen zudem rasch an Einfluß in den wichtigsten Sektoren: der

65 Vgl. Combat, Appel, in: Combat, H. 26, 1938, S. 4. Neben den seit 1937 steigenden Papierpreisen machten auch die Inflation und die höheren Kosten des Vertriebes den Zeitschriften zu schaffen, Combat, La quatrième année, in: Combat, H. 31, 1939, S. 4; vgl. Histoire générale de la presse française, Bd. 3, S. 456.

${ }^{66}$ Combat, La quatrième année, in: Combat, H. 31, 1939, S. 4.

${ }^{67}$ Blanchot, Le Terrorisme, méthode de salut public, in: Combat, H. 7, 1936, S. 106.

${ }^{68}$ Maulnier, Le seul combat possible, in: Combat, H. 6, 1936, S. 85f.; vgl. ders., A la recherche de l'Etat nouveau, Revue Universelle 66 (1936), H. 9, S. $368 f$.

${ }^{69}$ Brasillach, Lettre aux cocus de la droite, in: Combat, H. 3, 1936, S. 36; Maulnier, Les Conservateurs, in: Combat, H. 5, 1936, S.67f. 
Holz-, Bau- und Chemiebranche ${ }^{70}$. Die Strategie der „erhobenen Hand“ hatte sich bei den Volksfrontwahlen als erfolgreich erwiesen: Die Kommunisten hatten ihr Ergebnis im Vergleich zu den Wahlen von 1932 verdoppelt und damit sogar die Radikalen an Stimmen übertroffen ${ }^{71}$.

Die Streiks nach der Bildung des Volksfrontkabinetts im Juni 1936 boten die willkommene Gelegenheit, die Arbeiterbewegung gegen die Regierung auszuspielen. Sie waren schon durch ihr Ausmaß ein neuartiges Phänomen in der französischen Geschichte: auf dem Höhepunkt des Arbeitskampfes im Juni wurden 1,8 Millionen Streikende registriert, eine bis dahin nicht erreichte Größenordnung. Ungewöhnlich war auch ihr überwiegend spontaner Charakter, weitgehend unabhängig von den Kommunisten und der Gewerkschaft C.G.T., vor allem in Betrieben mit geringer gewerkschaftlicher Organisation wie der Metall-, Textil- und Nahrungsmittelbranche. Sie beschränkten sich zudem nicht auf Arbeitsniederlegung, sondern bedienten sich zum Entsetzen der Patrons erstmals in großem Umfang der Fabrikbesetzungen, um Aussperrungen zu verhindern 72 .

Im Unterschied zur traditionellen Rechten, die die Interessen der Arbeitgeber bedroht glaubte, begrüßte der Combat die Streiks ${ }^{73}$. Das weitgehende Fehlen gewerkschaftlicher Initiative bot die Gelegenheit, die Streiks als Ausdruck des „aufrichtigen“ Protests der Arbeiter zu werten. Brasillach sah darin einen spontanen Aufstand gegen die Volksfront, die gerade im Matignon-Abkommen (so benannt nach dem Sitz des Ministerpräsidenten) einen ersten Anlauf zur Durchsetzung lange geforderter Sozialreformen unternommen hatte $^{74}$. Die Combat-Redakteure setzten alles daran, den Keil zwischen Arbeiterschaft und Volksfront tiefer zu treiben. Die Maßnahmen des Abkommens, darunter die Einführung der 40-Stundenwoche und des bezahlten Urlaubs, gaben sie als einen schwachen Kompromiß aus, der auf Kosten der Arbeiter und der kleinen Patrons geschlossen worden sei. Die nach dem Matignon-Abkommen ausgehandelten Branchentarifverträge, in denen die Unternehmerverbände verlorenes Terrain wieder wettmachen konnten, prangerte Blanchot als Verrat am Wahlprogramm der Volksfront an: profitiert hätten wiederum nur die Kapitalisten und der Staat, eine wirkliche Sozialreform sei ausgeblieben. Während Blum außenpolitisch im Schlepptau der Internationale gefangen sei, mache er in der Wirtschaftspolitik gemeinsame Sache mit den Unternehmern. „Schöne Union, heilige Allianz, diese Verbindung von sowjetischen, jüdischen und kapitalistischen Interessen. Alle antinationalen und antisozialen Kräfte werden hier bedient. "75

\section{Comité National de Vigilance}

Die Volksfront hatte ihre Sammlungspolitik unter dem Banner des „Antifaschismus“ betrieben und bekämpfte damit insbesondere die rechtsextremen Ligen. Unmittelbar nach seinem Regierungsantritt löste Léon Blum gemäß seinem Wahlversprechen diese

70 Vgl. Prost, La C.G.T., S. 37, 152ff.

7 Racine/Bodin, Parti communiste, S. 209.

72 Borne/Dubief, Crise, S. 149ff.; Jackson, Popular Front, S. 87ff.; Lefranc, Histoire, S. $142 \mathrm{ff}$.

73 Ähnlich reagierten auch die extremen Nationalisten von JSP, die ihre Kampagne seit 1936 über die Mittelschichten und die Landbevölkerung hinaus auf die Arbeiter ausdehnte; vgl. Dioudonnat, Je suis partout, S. 245.

${ }^{74}$ Brasillach, Blum, in: Combat, H. 6, S. 89, ähnlich Maxence, Histoire, S. 358.

${ }^{75}$ Blanchot, Terrorisme, in: Combat, H. 7, S. 106; vgl. Borne/Dubief, Crise, S. $154 f$. 
Organisationen auf. Einzig La Rocque gelang es, von dem Verbot zu profitieren. Er gab vor, die Spielregeln des Parlamentarismus zu akzeptieren, und wandelte seine Feuerkreuzler in den Parti Social Français (PSF) um ${ }^{76}$. Der Kampf gegen die Ligen betraf unmittelbar auch eine Reihe von Aktivisten der Jeune Droite, die sich in der Action française und der Solidarité française engagierten: Brasillach, Maulnier, Maxence. Die Liga der Action française, die Camelots du Roi, war bereits im Februar 1936 verboten worden, nachdem einige ihrer Anhänger beinahe den Chef der Volksfront gelyncht hätten. Bei der Beerdigung Jacques Bainvilles, einem der einflußreichsten Denker der Action française, am 13. Februar trafen die Teilnehmer des Trauerzuges auf Léon Blum, der zufällig ihren Weg kreuzte. Sie zerrten ihn aus seinem Auto und begannen ihn zu verprügeln. Der Führer der Volksfront konnte schwerverletzt entkommen, nachdem ihm einige Arbeiter zur Hilfe geeilt waren, die an einer Baustelle in der Nähe arbeiteten?7.

Die Action française war somit als erste rechtsextreme Bewegung ihrer Massenorganisation beraubt. Dieser Schlag hielt Maurras und seine Getreuen nicht davon ab, weiter gegen die Volksfront zu hetzen. Im Gegenteil konzentrierten sich die Angriffe nun noch mehr auf die Person Léon Blums und schürten antisemitische Ressentiments. Von den Übergriffen der aufgelösten Camelots waren die Juden noch stärker betroffen als Kommunisten und Sozialisten ${ }^{78}$. Die Folgen dieses Verbots bekamen die beiden CombatMitarbeiter Brasillach und Maulnier unmittelbar zu spüren. Sie sollten als Redner bei einer Veranstaltung der aufgelösten Camelots auftreten, die unter dem Deckmantel des Instituts AF im Mai 1936 stattfinden sollte. Doch der Präfekt verbot das Treffen, nachdem bekanntgeworden war, daß die Action française einen Saal für 2500 Personen gemietet hatte. Dies war eine Größenordnung, die noch nie zuvor eine Veranstaltung des Instituts erreicht hatte, wohl aber die Treffen der Camelots ${ }^{79}$.

Als Reaktion auf die Auflösung der Camelots gründete ein Teil der Aktivisten der extremen Rechten mit Zustimmung Maurras' Anfang März ein „Nationales Wächterkomitee der Jugend gegen den Krieg“" (Comité national de Vigilance de la Jeunesse contre la guerre). Den Vorsitz hatten Thierry Maulnier und Jean Pierre Maxence zusammen mit Louis Darquier de Pellepoix, dem Präsident der „Vereinigung der Opfer des 6. Februar 1934“ (Association des blessés et victimes du 6 Février 1934), Dorgères, dem Chef der Landfront, sowie Robert Castille und Henri Charbonneau. Von der Zeitschrift Combat arbeiteten auch Jean Saillenfest, Kléber Haedens und Claude Roy mit ${ }^{80}$.

Mehrere Aktivisten des nationalen Wächterkomitees hatten bereits die Kampagnen gegen den Juraprofessor Gaston Jèze angeführt. Zur „Affäre Jèze“ kam es durch die Agitation der extremen Rechten gegen den Professor an der juristischen Fakultät der Sorbonne, der jüdischer Herkunft und Berater der abessinischen Regierung beim Völkerbund war. Zu Beginn des Jahres 1936 störten die Studenten seine Vorlesungen mit

\footnotetext{
${ }^{76}$ Soucy, Second Wave, S. $112 \mathrm{f}$.

77 Weber, Action française, S. $365 \mathrm{ff}$.

${ }^{78}$ AN F7 13 983/6, Bericht vom 20.5. 1936.

${ }^{79}$ Die Versammlung sollte am 18. 5. 1936 in Magic-City stattfinden. Die beiden Organisatoren waren Pujo und Castille, AN F7 13983/6, Berichte vom 15.5. 1936 und 20.5. 1936; APP Ba 1895, Schreiben des Direktors der Police Judicaire an den Procureur de la République vom 19.5 1936. ${ }^{80}$ Zu Saillenfest : AN F7 12 965, Berichte vom 27.3. 1936 und 28. 3. 1936; zu Haedens und Roy vgl. Charbonneau, Mémoires, S. $178 f$.
} 
Sprechchören, Streiks und Rauchbomben, woraufhin die Fakultät zeitweise geschlossen werden mußte. Innerhalb kurzer Zeit hatten die Unruhen das gesamte Quartier Latin erfaßt. Ein Großteil der Demonstranten gegen Jèze und späteren Anhänger des nationalen Wächterkomitees stammte aus den Fakultäten, in denen es ein traditionell starkes rechtsextremes Milieu gab. Neben der juristischen Fakultät waren dies vor allem die Ecole libre des Sciences Politiques, die Literaturwissenschaftler der Sorbonne und die medizinische Fakultät. Auch der Organisationsgrad der Studenten war hoch. Mehr als die Hälfte der Studenten, die bei einer Demonstration am 11. Februar festgenommen wurden, gehörte einer der folgenden Bewegungen an: Feuerkreuzler, Action française, Jeunesses Patriotes und Solidarité française ${ }^{81}$.

Aus dem Organisationskreis der rechtsextremen Studenten formierte sich das nationale Wächterkomitee. Zu den aktivsten Mitgliedern gehörte Robert Castille, Anwalt und Generalsekretär der Studentenorganisation der Action française, der der Polizei mehrfach wegen Raubes, Körperverletzung und Waffenbesitzes aufgefallen war ${ }^{82}$. Der Literaturstudent Henri Charbonneau, der der Polizei bereits mehrfach durch seine rechte Agitation aufgefallen war, beteiligte sich ebenfalls häufig an den Demonstrationen gegen Jèze ${ }^{83}$. Maxence leitete zu diesem Zeitpunkt die Studentenorganisation der Solidarité française ${ }^{84}$.

Die vom nationalen Wächterkomitee vertretenen Positionen entsprachen weitgehend der neopazifistischen Haltung der gesamten extremen Rechten. Wiederholt beschworen die Redner die Kriegsgefahr, die ihrem Land durch die Politik der Linken drohe: durch die Sanktionen gegenüber Italien, den Beistandspakt mit Rußland und das diplomatische Versagen Frankreichs gegenüber Deutschland. Nur eine Politik der nationalen Stärke konnte ihrer Ansicht nach die Stellung Frankreichs in Europa wiederherstellen und so einen dauerhaften Frieden garantieren ${ }^{85}$. Doch das Komitee verschonte auch das eigene Lager nicht von scharfer Kritik. Durch seine unerbittlich antiparlamentarische Haltung geriet es immer mehr in Konflikt mit den Ligen, die sich an die bürgerliche Rechte der Nationalen Union annäherten. Maxence trat im März von allen seinen Ämtern in der Solidarité française zurück, überzeugt davon, daß auch mit den Ligen der Umsturz nicht zu erreichen sei. Das Komitee wurde immer mehr zu einem Sammelbecken für radikal aktionistische Randgruppen ${ }^{86}$.

Der Leser des Combat erfuhr nichts über die Aktivitäten seiner Redakteure in dem Komitee, was insofern erstaunlich ist, als die Zeitschrift sonst über alle Konferenzen ih-

${ }^{81}$ Vgl. zum Verlauf der Affäre die Berichte in ANF 17 24604, Dossier personnel Gaston Jèze. Affaire Jèze. Zu den Demonstranten gegen Jèze gehörte auch der Student der Rechts- und Politikwissenschaften François Mitterrand, der bei den Nationalvolontären La Rocques organisiert war; vgl. Peán, Jeunesse, S. 25ff., $43 \mathrm{ff}$.

82 Castille hatte unter anderem den Führer der demokratischen Katholiken Marc Sangnier tätlich angegriffen, vgl. AN F7 13983/14, Bericht vom Mai 1936.

${ }^{83}$ AN F17 24 604, Bericht vom 29. 2. 1936; AN F7 13 983/14, Bericht vom Mai 1936.

${ }^{84}$ AN F17 24604, Berichte vom 11.2. 1936 und 29. 2. 1936; auch Maulnier war dort Ende Februar als Redner aufgetreten.

${ }^{85} \mathrm{Vgl}$. AN F7 12965, Berichte vom 27.3. 1936 und 28.3. 1936; APP Ba 1896, Bericht vom 24.4. 1936.

${ }^{86}$ AN F7 12 965, Bericht vom 23. 3. 1936; vgl. Maxence, Histoire, S. 323; Charbonneau, Mémoires, S. 179. 
rer Mitarbeiter informierte und die inhaltlichen Positionen weitgehend übereinstimmten. Auch Combat verteidigte die Position des Neopazifismus und polemisierte unerbittlich gegen die bürgerliche Rechte. Ebenfalls richtete sich die Zeitschrift an die nationalistischen Studenten und Absolventen der Hochschulen ${ }^{87}$. Doch diese wachsende Radikalisierung eines Teils der Jeune Droite stieß innerhalb der Zeitschrift auf Widerstand. Jean de Fabrègues beklagte sich in einem Brief an Maulnier über die Entwicklung des Combat zu einem polarisierenden Kampfblatt und erinnerte ihn an die gemeinsamen Ziele, die im Gründungsmanifest der Zeitschrift formuliert worden waren. Nach Ansicht Fabrègues' verengte sich der Adressatenkreis der Zeitschrift immer mehr auf eine kleine, extrem radikale Klientel, während die ursprüngliche Absicht gewesen sei, ein intellektuelles Forum der Rechten zu schaffen, das auch Feuerkreuzler und katholische Arbeiter erreichte ${ }^{88}$.

\section{Insurgé - Sprachrobr der Cagoule?}

Eine Spaltung der Jeune Droite konnte dadurch verhindert werden, daß der aktivistische Flügel Anfang 1937 ein eigenes Wochenblatt kreierte: Insurgé. Politique et social. Das Blatt gewann innerhalb der Presse der extremen Rechten schnell ein eigenes Profil durch seinen äußerst aggressiven Ton, populistische Vereinfachungen und schärfste Hetzkampagnen gegen Juden und Kommunisten. Ein Großteil der Redakteure stammte vom Combat und war vorher im nationalen Wächterkomitee aktiv gewesen: die beiden Herausgeber Maulnier und Maxence ebenso wie Jean Saillenfest, Kléber Haedens, Claude Roy und Robert Castille ${ }^{89}$. Zahlreiche weitere Combat-Mitarbeiter schrieben ebenfalls für den Insurgé: Dominique Aury ${ }^{90}$, Maurice Blanchot, Robert Francis, François Gravier und Jean Loisy. Gerade wegen dieser engen personellen Verflechtung legten beide Zeitschriften Wert darauf, ihre völlige Unabhängigkeit voneinander und von Dritten zu betonen. Im Fall des Insurgé hatten diese Beteuerungen aber noch einen weiteren Hintergrund. Die Zeitschrift dementierte damit das Gerücht, daß sie durch Geheimfonds aus den Kreisen der extremen Rechten unterstützt werde". Bestätigt wurde der Verdacht erst in den sechziger Jahren durch Henri Martin, einen ehemaligen Camelot, der 1930 aus der Action française ausgeschlossen wurde und einer der Drahtzieher der Geheimorganisation Cagoule war. Er versicherte, daß der Insurgé direkt von dieser Geheimorganisation finanziert worden sei ${ }^{92}$. Bei der Cagoule - ihr richtiger, aber weniger

${ }^{87}$ Vgl. AN F7 13 983/14, Bericht vom 26. 5. 1936.

${ }^{88}$ Ausdrücklich nannte er neben Maulnier selbst auch Maxence als Adressaten seiner Kritik; Brief Fabrègues' an Maulnier, o. D., Ende 1936, reproduziert bei Auzèpy-Chavagnac, Fabrègues, Annexe 63; vgl. ebenda, S. 467ff.

${ }^{89}$ Maxence hat sich daraufhin endgültig von Combat getrennt, während Maulnier weiterhin beide Zeitschriften leitete.

${ }^{90}$ Eigentlich Anne Desclos, Dozentin für Kunst der Pariser Abteilung der Columbia-Universität, später bekannt geworden als Pauline Réage, Autorin der „Geschichte der O.“; vgl. Auzèpy-Chavagnac, Fabrègues, S. 466; vgl. Sirinelli, Génération, S. 95.

${ }_{11}$ Insurgé, A nos camarades, in: Insurgé, H. 2, 1937, S. 1; Fabrègues/Maulnier, Combat - Insurgé, in: Combat, H. 12, 1937, S. II.

92 Aufgezeichnetes Gespräch mit Martin, abgedruckt bei Péan, Docteur, S. 96-99, hier S. 97; das Geld dürfte von Lemaigre-Dubreuil, dem Inhaber der Ölfabrik Lesieur, gekommen sein; vgl. 
bekannter Name lautete Organisme spécial d'action régulatrice nationale (O.S.A.R.N.) - handelte es sich um eine Abspaltung der Action française, die weniger durch eine spezifische Ideologie als vielmehr durch Terroranschläge und Attentate hervortrat: unter anderem gingen die Ermordung des kommunistischen Finanzberaters Boris Navachine und des Antifaschisten Carlo Roselli auf ihr Konto. $\mathrm{Zu}$ ihr gehörte auch die Geheimorganisation aus Kreisen der hohen Militärs mit dem Namen Réseaux Corvignolles ${ }^{93}$.

Es wäre verfehlt, sämtliche Mitarbeiter des Insurgé als Aktivisten der Cagoule zu verdächtigen. Die einen arbeiteten für die Öffentlichkeit, die anderen im Untergrund: diese Tätigkeiten schließen einander aus. Dennoch läßt sich eine Mittelsperson zwischen den beiden Kreisen ausmachen: Henri Charbonneau, einer der Aktivisten des nationalen Wächterkomitees, knüpfte 1937 Kontakte zu Eugène Deloncle von der Leitung der Cagoule und wurde während dessen Haft 1938 sein Privatsekretär ${ }^{94}$. Zumindest die Herausgeber der Zeitschrift mußten von der Herkunft des Geldes gewußt und damit letztlich nicht nur in die Ziele, sondern auch in die Methoden der Organisation eingewilligt haben. Wie Maurras später zugab, war der Hergang der Attentate bis in die Details hinein in der gesamten extremen Rechten bestens bekannt ${ }^{95}$. Maxence und Maulnier konnten daher kaum behaupten, nichts vom terroristischen Charakter der Organisation gewußt zu haben.

Ihre Bereitschaft zur Unterstützung von Terror und Gewalt haben die Insurgé-Mitarbeiter zumindest verbal hinreichend signalisiert. Maxence und Maulnier hatten sich bereits durch ihr Engagement bei der Solidarité als Sympathisanten einer faschistischen Bewegung zu erkennen gegeben. Blanchot hatte im Combat den Terrorismus als einziges Mittel zur Bekämpfung des Regimes propagiert. Auch Maulnier hatte sich dort zum Anwalt der Gewalt gemacht. „Wir lehnen Gewalt nicht ab, wir halten sie häufig für notwendig. Wir glauben, daß heute mehr denn je zuvor ein Kampf geführt werden muß."96 Zudem machte der Insurgé keinen Hehl aus der Absicht, an den Schaltstellen der Macht - in Polizei, Militär und Verwaltung - Sympathisanten zu gewinnen, während gleichzeitig Cagoule in Zusammenarbeit mit hohen Militärs einen Staatsstreich vorbereitete" Die Zeitschrift ließ kaum eine Gelegenheit aus, die Volksfront als das eigentliche Terrorregime darzustellen. Auf diese Weise suggerierte sie, daß die Regierung gleichfalls nur mit Gewalt bekämpft werden könne. Ausführlich wurden regelmäßig die heimlichen Waffenlieferungen der Volksfront an die spanischen Republikaner enttarnt, ergänzt

Weber, Action française, S. 511. Ein Polizeibericht vom 24.2. 1937 über eine Insurgé-Veranstaltung erwähnt nichts von möglichen finanziellen $\mathrm{Zuwendungen,} \mathrm{warnt} \mathrm{aber} \mathrm{vor} \mathrm{"möglichen} \mathrm{Zu}$ sammenstößen“, AN F7 12966.

${ }^{93}$ Durch die Auflösung der Ligen erhielt die Cagoule weiteren Zulauf, doch betrug die Zahl ihrer Anhänger niemals mehr als 1000; Freigneaux, Cagoule, S. 6-17. Der Artikel geht zurück auf eine memoire de maîtrise, in der der Autor neue Quellen vor allem aus den Archives de Paris auswertet; ferner Bourdrel, La Cagoule, S. 49ff.

${ }^{94}$ Charbonneau, Mémoires, S. 187.

${ }^{95}$ Im Juli 1945 bei einer öffentlichen Erklärung, Maurras, Au grand juge, S. 194; Weber, Action française, S. 397.

${ }_{96}$ Maulnier, Le seul combat possible, in: Combat, H. 6, 1936, S. 85f., Zitat S. 85; vgl. ders., Les deux violences, in: Combat, H. 2, 1936, S. 22.

97 Bertin [Maulnier], Nous voulons des agitateurs, in: Insurgé, H. 1, 1937, S. 5; Gravier, Le mythe du coup d'Etat, in: Insurgé, H. 10, 1937, S. 3; Guesclin, La faillite des ligues, in: Insurgé, H. 8, 1937, S. 3; zu Cagoule siehe Freigneaux, Cagoule, S. $12 \mathrm{ff}$. 
durch Berichte und Reportagen über französische Söldner, die angeblich ungehindert die Grenze passierten ${ }^{98}$. Diese Kampagne, die im Einklang mit der gesamten extremen Rechten geführt wurde, sollte die Verwicklung der Regierung Blum in den spanischen Bürgerkrieg belegen und deren öffentlich verkündete Nonintervention Lügen strafen. Der Vorwurf war unmißverständlich: Indem die Volksfront insgeheim die Republikaner unterstütze, mache sie sich zum Handlanger der Kommunisten und drohe Europa in einen Krieg zu verwickeln, aus dem nur der Bolschewismus als Sieger hervorgehen könne99. Diese Argumentationsweise war charakteristisch für die politischen Ansichten der Zeitschrift, die nicht müde wurde, die „Korruption“ der Regierung und die Gewalttätigkeit der Kommunisten anzuprangern. Ihre Strategie bestand hauptsächlich darin, die Opfer politischer Auseinandersetzungen der Volksfront anzulasten. „Kommunistische Mörder" lautete der Titel einer Meldung, in der die Regierung für den Tod von zwei Anhängern rechtsextremer Gruppierungen (PSF und PPF) verantwortlich gemacht wurde. Michel Lombard ging so weit zu behaupten, daß die Kommunisten in Algerien sogar von der Polizeipräfektur die Lizenz zum Töten erhalten hätten ${ }^{100}$.

Einen Höhepunkt erreichte die Eskalation der Gewalt in der Schießerei von Clichy am 16. März 1937. In dem Pariser Vorort, einer Hochburg der Kommunisten, schoß die Polizei auf Demonstranten, die gegen eine Kinoveranstaltung von La Rocques PSF auf die Straße gegangen waren. Es gab fünf Tote und rund 150 Verletzte ${ }^{101}$. Obwohl die Opfer zur extremen Linken gehörten, zögerte der Insurgé nicht, die Verantwortung der Volksfront zuzuweisen. Unter der Schlagzeile „Mörder, abdanken!“ zeigte eine Karikatur Léon Blum mit bluttriefenden Händen. Darunter stand: „Wer hat behauptet, ich hätte kein französisches Blut?" 102 Solche antisemitischen Attacken gingen einher mit dem Vorwurf an die Regierung, die Demonstranten mit ihrer Antifaschismus-Kampagne erst gegen den PSF aufgestachelt zu haben ${ }^{103}$.

Der Angriff gegen die Volksfront war von einem Appell an die Wählerschichten der Linksparteien begleitet, der ein bis dahin unbekanntes Ausmaß erreichte. Mehr als jedes andere Organ der extremen Rechten in Frankreich richtete sich Insurgé - mit dem erklärten Ziel, möglichst effektiv den Kommunismus zu bekämpfen - an die gewerk-

${ }^{98}$ Maulnier, Plus que jamais les volontaires vont passer en Espagne, in: Insurgé, H. 7, 1937, S. 1/8; Dallers, Sur les routes et sur mer, on passe en Espagne, in: Insurgé, H. 9, 1937, S. 5; ders., Armes et Miliciens continuent à passer en Espagne rouge, in: Insurgé, H. 10 bis, 1937, S. 8; H., De Marseille, des Armes et des hommes partent toujours pour l'Espagne, in: Insurgé, H. 13, 1937, S. 7; NN, Je suis un évadé, in: Insurgé, H. 39, 1937, S. 8.

99 Weber, Action française, S. 381 ff.; vgl. zur Haltung Frankreichs im spanischen Bürgerkrieg Warner, France, S. 306-326; Pike, Les Français, S. 71ff.

100 Lombard, Communistes assassins, in: Insurgé, H. 8, 1937, S. 1. Dieser Artikel hatte eine Durchsuchung der Redaktion zur Folge, ohne daß offenbar belastendes Material gefunden werden konnte; vgl. Maxence/Maulnier/Sopault/Haedens/Blanchot, Joyeuse Mi-Carême ou l'historique d'une perquisition, in: Insurgé, H. 9, 1937, S. 3.

101 Weber, Action française, S. 391; vgl. den Untersuchungsbericht der Sûrété AN F7 13 985. Mit der Schießerei wurde auch die Cagoule in Verbindung gebracht. Ein Beweis konnte aber nicht erbracht werden, vgl. Bourdrel, Cagoule, S. $173 \mathrm{ff}$.

102 Assassins, démission, in: Insurgé, H. 11, 1937, S. 1. Die Karikaturen stammten von Ralph Soupault, der ebenfalls für Action française und Je suis partout arbeitete.

${ }^{103}$ Maulnier, Ceux qui n'y étaient pas, in: Insurgé, H. 10 bis, 1937, S. 5; vgl. Maxence, Blum, démission!, ebenda. 
schaftlich organisierten Unter- und Mittelschichten ${ }^{104}$. Maurice Grandchamp sah das Haupthindernis eines nationalen Syndikalismus in der starken Präsenz kommunistischer Gewerkschaftler. Er rief dazu auf, zunächst diese „nationsfeindlichen“ Kräfte auszuschalten: „Mit einer konzertierten Aktion, geheim oder öffentlich, müssen die ausländischen Agenten in der Organisation vernichtet und die antifranzösischen Aktionen in den kommunistischen Zellen systematisch sabotiert werden. " ${ }^{105}$ Mit einer Sondernummer zum Tag der Arbeit, dem 1. Mai, unterstrich die Zeitschrift ihre Absicht, das Arbeitermilieu mit nationalistischen Ideen zu durchdringen (Umgekehrt hatten die Kommunisten im Vorjahr den Tag zu Ehren von Jeanne d'Arc am 10. Mai begangen.) ${ }^{106}$. Unter den Mitarbeitern gab es enge Verflechtungen zu verschiedenen Gewerkschaftsverbänden: François Gravier gehörte der christlichen Gewerkschaft an ${ }^{107}$, Jean Saillenfest war Mitglied der Union Corporative des Fonctionnaires ${ }^{108}$. Serge Jeanneret leitete die Union corporative des Instituteurs (U.C.I. ${ }^{109}$. Jean Le Cour-Grandmaison, Abgeordneter des Departements Loire-Inférieure, gehörte ebenso wie André Voisin den Métiers Français an, dem Berufsverband des Courrier Royal ${ }^{110}$. Louis Salleron war Mitglied der Confédération générale des syndicats des Classes moyennes und verfügte über gute Kontakte zu den Neosozialisten um Marcel Déat ${ }^{111}$. Auch zu dem kommunistischen Renegaten Jacques Doriot gab es Verbindungen. Maurice-Yvan Sicard und Henri Lauridan zählten zu den Anhängern des 1936 von Doriot gegründeten Parti Populaire Français (PPF) ${ }^{112}$.

Die außerordentliche Hetze gegen die Kommunisten als „Drahtzieher“ der Volksfront entsprach wiederum der Strategie der Cagoule. Mit Bombenattentaten auf zwei große Unternehmerverbände (Confédération générale du patronat français/Union patronale interprofessionelle) im September 1937 versuchte die Geheimorganisation ein kommunistisches Komplott vorzutäuschen und auf diese Weise die Intervention der Armee zu provozieren. Das Unternehmen scheiterte, obwohl die rechte Presse zunächst der falschen Fährte Glauben schenkte. Der Insurgé schrieb das Attentat der Polizei zu und beschuldigte die Volksfront und die Sowjetunion, ihre Finger dabei im Spiel zu ha-

104 Weber, Action française, S. 511; vgl. Maulnier, Le communisme, ce fantôme, in: Insurgé, H. 8, 1937, S. $1 / 8$.

105 Grandchamp, Lecteurs de L'Insurgé, à l'CEuvre dans vos syndicats!, in: Insurgé, H. 8, 1937, S. 2.

${ }^{106}$ Maulnier, Non, le 1er mai n'appartient pas au Jouhaux, in: Insurgé, H. 16 bis, 1937, S. 1f. Die C.G.T. hatte vergeblich versucht, das Erscheinen der Nummer zu verhindern.

107 Auzèpy-Chavagnac, Fabrègues, S. 465.

108 AN F7 13 983/14, Bericht vom Mai 1936.

109 APP Ba 1895, Brief Jeannerets an den Präfekten vom 6. 7. 1935 über die Gründung der Gewerkschaft, vgl. Bericht vom 26.10. 1938.

110 Vgl. Le Cour-Grandmaison, Discours à la Chambre, in: La Justice Sociale, H. 9, 1937, S. 4f.; Voisin, Le second congrès des Métiers Français, in: Insurgé, H. 26, 1937, S. 2.

111 Montagnon, De Jaurès à Blum, S. 163f.; vgl. Burrin, Dérive, S. 254 .

112 Lauridan war vormals Kommunist und Anhänger des syndikalistischen Zweiges der C.G.T., orientierte sich aber seit Mitte der zwanziger Jahre zunehmend nach rechts. Nach einem Engagement beim Faisceau und der Solidarité française gelangte er schließlich 1936 zum PPF; APP Ba 1945, Abschrift eines Flugblatts vom 3. 12. 1936, Ba 1960, Bericht vom 30. 1. 1936. Sicard schrieb seit 1936 regelmäßig für die Emancipation Nationale. 
ben. Doch die Militärs aus den Réseaux Corvignolles schreckten vor den Putschplänen schließlich zurück ${ }^{113}$.

Im Oktober stellte die Zeitschrift ihr Erscheinen ein, im November deckte der Innenminister Marx Dormoy die Hintermänner der Attentate auf. Ein Zusammenhang zwischen den Nachforschungen und der Einstellung der finanziellen Unterstützung läßt sich nicht nachweisen. Zumindest war auch der Insurgé auf Anweisung des Innenministeriums überwacht worden ${ }^{114}$. Maulnier reagierte auf die Entdeckung der wahren Täter mit einer Stellungnahme, die einerseits Distanzierung von der Cagoule, andererseits grundsätzliche Zustimmung signalisierte. Er forderte „ein Komplott gegen die Sicherheit des Staates, das diese Bezeichnung verdient", und prangerte die mangelhafte Vorbereitung des Attentats und die unzureichende Strategie der Cagoule an. Aber weder die brutale Vorgehensweise noch das Ziel eines Staatsstreichs stellte er in Frage. Vielmehr legte er seine Umsturzpläne dar, die in einer Koordination verschiedener Aktionen bestanden. Verbündete brauchte man Maulnier zufolge nicht nur beim Militär, sondern auch in der Verwaltung und in Regierungskreisen. Außerdem mußte dem Umsturz eine Mobilisierung der Öffentlichkeit vorausgehen, die durch die konsequente Mißachtung von Recht und Gesetz die Regierung in Zugzwang bringen sollte. Durch zivilen Ungehorsam und Generalstreiks von Arbeitern, öffentlichem Dienst, Ingenieuren und der Landwirtschaft sollte die Regierung zum Handeln gezwungen werden ${ }^{115}$. An dieser Stelle brachte Maulnier unverblümt zum Ausdruck, zu welchem Zweck die Gewerkschaftspolitik der extremen Rechten in erster Linie dienen sollte: nicht so sehr als Interessenvertretung, sondern als Instrument des politischen Kampfes. Im wesentlichen stellten diese Überlegungen eine Erweiterung der Cagoule-Pläne dar, für die ebenfalls der Gedanke der Provokation eine zentrale Rolle spielte. Die Regierung sollte gezwungen werden, als erste zu handeln, um sie auf diese Weise ins Unrecht zu setzen und den Umsturz als Maßnahme zur Aufrechterhaltung der Ordnung ausgeben zu können ${ }^{116}$. Selbst wenn der Insurgé von den Weisungen der Geheimorganisation unabhängig war, so ergänzten sich die Strategie der Zeitschrift und die Pläne der Cagoule. Propagandistisch bereitete der Insurgé den Weg für ein Klima der Gewalt und des Hasses, das die Voraussetzung für den Staatsstreich der Cagoule war.

Doch der Insurgé war weit davon entfernt, die Kräfte der extremen Rechten zu vereinigen. Zwar hatte die Zeitschrift bereits nach zwei Monaten 1000 Abonnenten gewonnen $^{117}$ und verfügte über sehr gute Verbindungen zu zahlreichen Gewerkschaftsverbänden, doch ihren Radikalismus empfanden selbst zahlreiche Anhänger der extremen Rechten als inakzeptabel. Programmatisch hatte sich der Insurgé so weit von dem elitä-

${ }^{113}$ Maulnier, Pour la croisade antifasciste fraiche et joyeuse, in: Insurgé, H. 36, 1937, S. 1/8. Nachdem die Cagoule in Verdacht geraten war, die Attentate begangen zu haben, betonte Maulnier, es sei egal, ob Faschisten oder Antifaschisten dahintersteckten, die Drahtzieher seien in erster Linie Ausländer: Bertin [Maulnier], Trois attentats fascistes ou antifascistes commis chez nous en une semaine par des étrangers, in: Insurgé, H. 38, 1937, S. 1/3; Freigneaux, Cagoule, S. 11f.; Weber, Action française, S. $396 f$.

114 Daumas, Dormoy se dérobe et fait intercepter notre courrier, in: Insurgé, H. 38, 1937, S. 8.

115 Maulnier, Pour un complot contre la sûreté de l'Etat digne de ce nom, in: Combat, H. 20, 1937, S. $148 \mathrm{f}$.

116 Zur Strategie der Cagoule vgl. Freigneaux, Cagoule, S. 1 of.

117 Insurgé, Pour repondre aux poursuites abonnez vous, in: Insurgé, H. 9, 1937, S. 1. 
ren Mittelstandsdenken der Action française abgewandt, daß Maurras in einem Brief an Maulnier seine Beunruhigung über ein Abgleiten in den Staatssozialismus ausdrückte und zur Mäßigung mahnte ${ }^{118}$. Aber Maurras war auch der Aktionismus der Cagoule ein Dorn im Auge. Seit dem Sommer 1936 warnte die Action française vor den schlecht vorbereiteten und unverantwortlichen Handlungen der Organisation, die nach Maurras' Ansicht ähnliche Strukturen wie die verhaßten Freimaurerlogen entwickelt hatte ${ }^{119}$. Colonel La Rocque distanzierte sich wegen der fortgesetzten Angriffe der Zeitschrift gegen den Legalitätskurs seines PSF, der mit seinen über 700000 Anhängern nicht nur die größte Gruppierung der Rechten bildete, sondern auch die größte Partei überhaupt ${ }^{120}$. Der Konflikt gipfelte in einer angeblichen Morddrohung aus den Reihen des PSF gegen die Frau des Insurgé-Herausgebers Maxence, Hélène Colomb ${ }^{121}$.

Neben der polarisierenden Polemik, wie sie der aktivistische Flügel der Jeune Droite schätzte, gab es andererseits durchaus Ansätze zum Dialog mit benachbarten oder sogar feindlichen Gruppierungen. Besonders Jean de Fabrègues bemühte sich angesichts nivellierender Propaganda um eine differenzierte Auseinandersetzung. Er setzte sich konstruktiv mit den Katholiken Maritain und Mounier oder mit marxistischen Autoren wie Lefebvre und Guterman auseinander ${ }^{122}$. Zusammen mit Gabriel Marcel unternahm er in der Zeitschrift Civilisation (1938-1939) den Versuch, die antirepublikanischen Intellektuellen zur Verteidigung der französischen Kultur zu versammeln. Doch dazu fehlte dem Organ letztlich das Profil. Außer Literaturbesprechungen veröffentlichte die Civilisation häufig Nachdrucke, etwa Maulniers Artikel aus dem Combat, oder ebenso grundsätzliche wie unverbindliche Stellungnahmen mit Titeln wie „Muß man sich noch mit dem Liberalismus auseinandersetzen?". ${ }^{123}$

Im Combat trafen die unterschiedlichen Auffassungen aufeinander. Sie kamen in den Spannungen zwischen den beiden Herausgebern zum Ausdruck, die Fabrègues bereits in seinem Brief an Maulnier angesprochen hatte. Maulnier und der Kreis der InsurgéMitarbeiter wollten den Staatsstreich und waren bereit, ihn auch mit Gewalt zu unterstützen. Fabrègues hingegen gab der „Wiederbelebung intellektueller und geistiger Standpunkte" den Vorzug, während er eine direkte Verwicklung in die Politik entschieden ablehnte ${ }^{124}$. Er verstand sein intellektuelles Engagement als Resultat einer Aufgabenteilung zwischen der Macht und der Kritik an der Macht. Er postulierte eine Doppelmoral: die des christlichen Humanismus für die Intellektuellen und die der Macht für die Politiker. Engagement bedeutete für ihn zwar durchaus politische Stellungnahme und publizistische Aktivität, es war aber unvereinbar mit dem Wechsel zur Partei der Macht. Dieser Einstellung war er seit den Februarunruhen 1934 treu geblieben. Trotz

${ }^{118}$ Brief Maurras' an Maulnier, ohne Datum, abgedruckt bei Massis, Maurras et notre temps, S. $275 f$.

119 Weber, Action française, S. $397 f$.

120 Soucy, Second Wave, S. 114.

121 Ein Photo der angeblichen Morddrohung wurde in Insurgé veröffentlicht: La menace anonyme, in: Insurgé, H. 32, 1937, S. 6.

122 Fabrègues, Indépendance? Oui, sauf de la vérité, in: Combat, H. 2, 1936, S. 20f.; ders., L'homme petit, in: Combat, H.5, 1936, S. 70f.; ders., Apologie de la nuance, in: Combat, H. 7, 1936, S. 102f.; vgl. Vincent, Bernanos le visionnaire, ebenda, S. $75 f$.

${ }^{123}$ Salleron, Faut-il encore parler du libéralisme?, in: Civilisation, H. 10/11, 1938, S. 26-30.

124 Brief Fabrègues' an Maulnier [Ende 1936], Auzèpy-Chavagnac, Fabrègues, Annexe 63. 
gegensätzlicher politischer Ansichten unterschied sich Fabrègues in diesem Punkt nicht von Julien Benda ${ }^{125}$.

Ein weiterer Unterschied zwischen den beiden Combat-Herausgebern läßt sich in der Haltung zur sozialen Frage feststellen. Maulnier sympathisierte mit dem revolutionären Syndikalismus der französischen Arbeiterbewegung, der bis zum Ersten Weltkrieg die dominierende Strömung innerhalb der französischen Gewerkschaftsbewegung gebildet hatte. Durch seine doppelte Frontstellung, einerseits gegen die internationale Arbeiterbewegung, andererseits gegen den reformistischen Kurs der C.G.T., ließ er sich zumindest argumentativ für die Ziele der radikalen Nationalisten einspannen. Maulnier berief sich hierbei auf das Experiment des Proudhon-Kreises (1912-1914), in dem seiner Ansicht nach erstmals die Synthese von revolutionärem Syndikalismus und integralem $\mathrm{Na}$ tionalismus verwirklicht worden war ${ }^{126}$.

Die kurze Existenz des vom damaligen AF-Wirtschaftsredakteur Georges Valois ins Leben gerufenen Kreises genügte, um die Hoffnung auf einen Zusammenschluß der beiden Lager zu nähren. Durch den Einfluß von Pierre Andreu, der 1936 von den Neosozialisten zur Doriot-Bewegung gewechselt war ${ }^{127}$, wurde die Episode des ProudhonKreises zu einer Art Gründungsmythos einer national-syndikalistischen Bewegung. Andreu entwickelte im Combat seine These von den spezifisch französischen Ursprüngen des italienischen Faschismus - einem Faschismus als Synthese aus dem Syndikalismus Sorels und dem Nationalismus Maurras', wie sie der Proudhon-Kreis erstmals formuliert hatte ${ }^{128}$. Die Sympathie für die Formen des syndikalistischen Kampfes, Generalstreik und "direkte Aktionen“ (Aufmärsche und Fabrikbesetzungen), gründete auf einer (allerdings einseitigen) Auslegung von Sorels Reflexions sur la violence. Sie verband sich mit dem Versuch, die lokalen, unabhängigen Arbeiterorganisationen für die eigenen politischen Ziele zu instrumentalisieren. Das Bemühen um eine basisdemokratische Interessenvertretung lag den Vertretern dieses nationalen Syndikalismus hingegen fern ${ }^{129}$.

125 Vgl. Fabrègues, Les conditions d'une action efficace, in: Combat, H. 6, 1936, S. 84. Zu Benda vgl. die Analyse von Benjamin, Standort des französischen Schriftstellers, S. 782f.

126 Maulnier, Les deux violences, in: Combat, H. 2, 1936, S. 22; ähnlich Saillenfest, Fascisme, in: Combat, H. 8, 1936, S. 139f.; vgl. Schöttler, Syndikalismus, S. 419-476.

127 Vgl. seine Artikel in der Emancipation Nationale seit Mai 1936.

128 Andreu, Fascisme 1913, in: Combat, H. 2, 1936, S. 23f.; ders., Demain sur nos tombeaux..., in: Combat, H. 4, 1936, S. 55; vgl. Andreu, Rouge, S. 96ff. Genau diese These liegt auch den Werken von Sternhell zugrunde. Sternhell hat diese Faschismus-Konzeption der französischen extremen Rechten weitgehend übernommen, den Einfluß des vermeintlichen „revolutionären Syndikalismus" Sorels noch stärker betont und daraus seine "Faschismus"-These entwickelt. Mit dieser These, die Sternhell in seinen Werken La droite révolutionnaire und Ni droite, ni gauche entwikkelt, ist er zu Recht scharf angegriffen worden. In diesem Zusammenhang hat vor allem Jacques Julliard darauf hingewiesen, daß der revolutionäre Syndikalismus lange Zeit auf seinen angeblichen Theoretiker Sorel reduziert worden ist, obwohl er als genialischer Außenseiter nur sehr lockere Verbindungen zur Bewegung hatte und seine Ideen an der Basis kaum rezipiert wurden; vgl. Julliard, Fascisme imaginaire, in: Annales 39 (1984), S. 852ff. Zum Proudhon-Kreis vgl. Douglas, Fascism, S. 28-33 und Mazgaj, Action Française, S. 170-193.

129 Maulnier, complot, in: Combat, H. 20, 1937, S. 149 und Maulnier, Violences, in: Combat, H. 2, 1936, S. 22; vgl. Roth, The Cult of Violence. 
Diesem Kreis stand derjenige um Fabrègues gegenüber, der sich zum Anwalt des „sozialen Status quo" machte ${ }^{130}$. Auch er begründete seinen Standpunkt nicht mit wirtschaftlichen Argumenten, wie Fabrègues' Ansichten über Pierre-Joseph Proudhon deutlich machen. Fabrègues würdigte in Proudhon nicht so sehr den Theoretiker des Frühsozialismus, sondern eher den Apostel einer neuen Arbeitsmoral. Was ihn an dem Autor interessierte, waren nicht seine Thesen zur Selbstverwaltung der Arbeiter, die auf eine Emanzipation gegenüber den Patrons zielten. Er begriff Proudhon vielmehr als einen Prediger der neuen Harmonie von Arbeitgebern und Arbeitnehmern. Proudhon hatte Fabrègues zufolge den "heroischen“ Charakter der Arbeit hervorgehoben und der Wohltätigkeit eine quasireligiöse Weihe verliehen ${ }^{131}$. Diese Vorstellungen gründeten zweifellos auf einer einseitig verzerrten Auslegung der Theorien Proudhons im Sinne eines paternalistischen Korporatismus. Anstatt den Forderungen nach mehr Rechten der Arbeiter Nachdruck zu verleihen, betrachtete Fabrègues die Verbesserung der Arbeitssituation als Akt patronaler Güte und Nächstenliebe. Mit seiner nostalgischen Verklärung von Wert und Würde der Arbeit lenkte er ab von der Suche nach Lösungen zur Überwindung der Wirtschaftskrise und den berechtigen Interessen der Arbeitnehmerorganisationen $^{132}$.

In der Rolle, die beide Kreise der Arbeiterbewegung zugedacht hatten, treten die unterschiedlichen Strategien deutlich hervor: auf der einen Seite der Versuch, neue Anhänger zu mobilisieren und die Dynamik der Arbeiterbewegung für einen Umsturz zu nutzen, auf der anderen Seite das Bemühen, das revolutionäre Potential der Bewegung durch den Appell an Moral und Solidarität zu dämpfen. In beiden Fällen war das Interesse an der sozialen Frage nicht durch klassenkämpferische Ideen motiviert, sondern zielte auf die Überwindung des Klassenbegriffs und die Wiederherstellung des nationalen Konsenses. Die grundsätzliche Feindschaft zum Kommunismus vereinte die beiden Kreise der Jeune Droite. Ihr auffälliges Interesse an der sozialen Frage war von dem Bemühen bestimmt, die Arbeiterbewegung dem Einfluß der Kommunisten zu entziehen und sie für ihre nationalistischen Ziele zu gewinnen.

Die Furcht vor den Kommunisten trieb die Jeune Droite in das Lager von deren erbittertstem Feind: Jacques Doriot. Der ehemals kommunistische Bürgermeister von SaintDenis hatte sich nach einer Phase der tiefen Desillusionierung von der Ideologie der Partei distanziert und sich zu einem haßerfüllten Antikommunisten entwickelt. Zugleich blieb er, was seine Kampfstrategie anbetraf, ein Kommunist, der den Kommunismus mit seinen eigenen Mitteln, mit Fanatismus, totalitärem Politikverständnis und Gewalt, bekämpfte. Mit dem im Juni 1936 gegründeten Parti Populaire Français (PPF) hatte sich Doriot das entsprechende Kampfinstrument geschaffen, das in seiner doppelten Feindschaft zum Kommunismus und zur traditionellen Rechten eindeutig faschistische Züge trug ${ }^{133}$.

${ }^{130}$ Fabrègues, La Pensée esclave, règne de l'opinion, in: Combat, H. 20, 1937, S. 149f., Zitat S. 150.

131 Fabrègues, Un nouvel idéalisme héroique, in: Combat, H. 34, 1939, S. 9. Zu Proudhon vgl. Bravo, Frühsozialismusforschung, S. 553ff.

132 Vgl. Fabrègues, Le prolétariat vivant, in: Combat, H. 16, 1937, S. 87f.; ders., Intégrer le Prolétariat, in: Combat, H. 17, 1937, S. 101f. Der Kreis um Fabrègues hielt sich ganz aus der syndikalistischen Diskussion heraus: Vincent, Vaast, Monconduit, Le Marchand.

133 Doriot war 1934 einer der entschiedensten Befürworter der Volksfrontpolitik gewesen und hatte versucht, seine Strategievorstellungen gegen Moskau durchzusetzen. Er wurde aus der Partei 
Mitte 1937 näherten sich die Jeune Droite und Doriots PPF einander an. Zwei Mitglieder des Zentralkomitees des PPF schrieben für den Combat: Pierre Drieu la Rochelle und Bertrand de Jouvenel bekundeten mit ihren Beiträgen im Combat die Absicht, die Jeune Droite für eine nationale Sammlungsbewegung zu gewinnen ${ }^{134}$. Umgekehrt schrieben die Intellektuellen der Jeune Droite für Doriots Parteiorgan Emancipation Nationale: zu den Sympathisanten und gelegentlichen Mitarbeitern gehörten neben dem bereits erwähnten Andreu auch Brasillach, Blond und Maulnier. Noch einen Schritt weiter ging Fabrègues: er trat der Bewegung bei ${ }^{135}$. Seine Artikel, die er zwischen Juli und Dezember 1937 regelmäßig in der Emancipation Nationale veröffentlichte, unterschieden sich inhaltlich nicht von denjenigen, die er für den Combat schrieb: in seinen Stellungnahmen machte er sich für eine Politik der Versöhnung der Klassen und der nationalen Einigung stark ${ }^{136}$.

Wie tief die Furcht vor den Kommunisten saß, verdeutlicht folgende Überlegung Maulniers. Wenn ein Krieg ausbräche - so schrieb er im April 1937 -, dann dürfe kein national gesinnter Franzose mehr für sein Land kämpfen. Denn im Falle eines Krieges würden die französischen Kommunisten die Allianz mit Rußland sofort zu einem militärisches Bündnis ausweiten und auf diese Weise Europa unterwerfen. So kam es, daß ein überzeugter Nationalist zum Verfechter eines entschiedenen Defätismus wurde: „Ein Sieg Frankreichs droht zur Niederlage der Menschheit zu werden. "137

\section{Nationaler Sozialismus: Ordre Nouveau}

\section{Zwischen den Fronten}

Zu Beginn des Jahres 1936 war der Ordre Nouveau weitgehend isoliert von den ehemaligen Verbündeten. Obwohl sich über den Neopazifismus deutliche Anknüpfungspunkte zur extremen Rechten ergeben hatten, distanzierte sich die Gruppierung entschieden von deren Demonstrationen der Macht. In ihrer Haltung zum spanischen Bürgerkrieg unterstützte sie zwar die Strategie der Nonintervention, deren Einhaltung von der extre-

ausgeschlossen, nachdem Moskau eine taktische Kehrtwendung vollzogen hatte und nun die französischen Kommunisten auf den vorher von Doriot befürworteten Kurs verpflichtet hatte. Seine Hoffnungen auf die Führung der PCF waren damit durchkreuzt. An seiner Stelle übernahm Maurice Thorez als treuer Vasall die PCF; vgl. zur Entwicklung Doriots: Brunet, Doriot, Paris 1986, S. 145ff. und 500ff., zum faschistischen Charakter des PPF S. 245ff.; Burrin, Dérive, S. 26, 278ff.; Wolf, Doriot-Bewegung, S. $115 \mathrm{ff}$.

${ }^{134}$ Drieu la Rochelle, Mesure et Démesure dans l'esprit français, in: Combat, H. 17, 1937, S. 104f.; B. de Jouvenel, Le Mort saisit le Vif, in: Combat, H. 19, 1937, S. 136f.; vgl. Wolf, Doriot, S. 222f., Anmerkung 1.

135 Vgl. Wolf, Doriot-Bewegung, S. 163f. Darunter fanden sich zahlreiche Mitarbeiter von Je suis partout; vgl. auch die Liste der Parteimitglieder und Sympathisanten in: Emancipation Nationale, 14. 1. 1938; Brasillach, Avant-guerre, in: ders., CEuvres complètes, Bd. 6, S. 277f. Falsch ist die Datierung von Fabrègues' Engagement für Doriot auf den Juni 1936 (nur diesen Monat!) bei Auzèpy-Chavagnac, Fabrègues, S. 479.

136 Vgl. Fabrègues, Les barbares à l'intérieur, in: EN 58, 6. 8. 1937, S. 2; ders., Si elle veut vivre encore la Nation devra surmonter les antagonismes, in: EN 72, 12.11. 1937, S.7.

137 Maulnier, Il faut refaire un nationalisme en dépit de la nation, in: Combat, H. 14, 1937, S. 51. 
men Rechten immer wieder angemahnt wurde. Jedoch war diese Haltung weitaus weniger durch die Sympathie für die Anführer der Militärrevolte motiviert als vielmehr durch die Furcht vor einer Ausweitung des Konfliktes zugunsten der Kommunisten ${ }^{138}$.

Nach Ansicht Arons begnügte sich die extreme Rechte mit der Aufstachlung zur Gewalt, ohne dadurch die gesellschaftlichen Verhältnisse wirklich zu verändern. Die Exaltation verbaler und physischer Gewalt konnte Aron zufolge nicht darüber hinwegtäuschen, daß der extremen Rechten weitgehend positive Ziele fehlten. Ebensowenig wie den italienischen Faschisten könne es den Ligen gelingen, Kapitalismus und Liberalismus zu überwinden. Diesen Vorwurf richtete Aron im besonderen an die Intellektuellen der Jeune Droite, die sich in der Solidarité française engagierten. „Sind sich Robert Francis, Jean-Pierre Maxence und Thierry Maulnier darüber im klaren, daß sie mit der Akzeptanz des Partisanenkampfes in Zukunft möglicherweise ebenfalls die falsche und abstrakte Gewalt militärischer Abenteuer akzeptieren?" 139

Aber auch eine neuerliche Annäherung an die linken Dissidenten Déat und Bergery war vorläufig ausgeschlossen, da diese ihre Pläne eines alternativen Rassemblement mittlerweile aufgegeben und sich der Volksfront angeschlossen hatten. Obwohl das im Januar verkündete gemeinsame Wahlprogramm hinter den von Bergery geforderten wirtschaftlichen Strukturreformen zurückblieb, hatte der Chef des Front social seine Beteiligung aufrechterhalten. Auch Déat hatte sich auf dem konstituierenden Kongreß der USR im November 1935 für die Volksfront ausgesprochen und damit auf die Verwirklichung seiner planwirtschaftlichen Ziele vorläufig verzichtet. Selbst Doriot hatte sich mit dem Argument, die Volksfront vor dem Einfluß der Kommunisten bewahren zu wollen, zunächst auf eine kritische Unterstützung der Sammlungsbewegung eingelassen ${ }^{140}$.

Die Ablehnung von Parlamentarismus und Volksfront brachte den Ordre Nouveau schließlich auch in einen politischen Gegensatz zu Esprit. Mouniers Zeitschrift hatte von ihrer Fundamentalkritik Abstand genommen und signalisierte seit Mitte 1935 ein wachsendes Interesse an der Volksfront. Auch wenn sie sich von der „Antifaschismus“-Kampagne distanzierte und aus ihrer Ablehnung des Stalinismus keinen Hehl machte - im Juni 1936 veröffentlichte Esprit die aufsehenerregenden Berichte von Victor Serge über die Terroristenprozesse in Moskau -, so wurde seit Anfang 1936 deutlich, daß sie zu einer konstruktiven Kritik an der Regierung von Léon Blum bereit war ${ }^{141}$. Der Ordre Nouveau erneuerte hingegen unmittelbar vor den Wahlen die entschiedene Absage an die parlamentarische Demokratie: in der Aprilausgabe des Organs mit dem Titel „Wählt nicht!" erinnerte Denis de Rougemont noch einmal an den Kampf gegen den Parlamentarismus, wie ihn der Ordre Nouveau in der Formel "weder rechts noch links" zum Ausdruck gebracht hatte: „Die Staatsnation ist der wahre Feind. Und dabei ist es unerheblich, ob es sich um einen rechten Pseudofaschismus oder einen linken Pseudodemo-

138 Marc, Le Stalinisme et les événements d'Espagne, in: ON, H. 35, 1936, S. 62-64; vgl. Bernecker, Krieg in Spanien.

${ }^{139}$ Aron, Vapeurs d'huile, in: Bulletin ON, Nr. 6, 15. 11. 1935, S. 2.

${ }_{140}$ Burrin, Dérive, S. $196 \mathrm{ff}$.

141 Winock, Esprit, S. 119ff.; Hellman, Mounier, S. 100ff.; Serge, Lettres à Madeleine Paz et à André Gide, in: Esprit, H. 45, 1936, S. 435-440. 
kratismus handelt, ob dies mit der Unterstützung des Stahlkomitees ${ }^{142}$ oder Moskaus geschieht: Angesichts der personalistischen Mission Frankreichs sind dies verwandte Irrwege. [...] Wir sind für den kommunalistischen Föderalismus, für die Ausübung der Autorität vor Ort, durch Menschen mit Verantwortungsbewußsein, nach Maßgabe des Menschen - wir würden sagen, für die einzig wahre ,Demokratie', wenn der Begriff nicht so mißbraucht wäre. " ${ }^{143} \mathrm{Da}$ allerdings Rougemont zufolge die einzig "wahre“ Form der Demokratie nur auf kommunaler Ebene verwirklicht werden konnte, schloß er eine demokratische Verfassung für Staaten von der Größe Frankreichs kategorisch aus.

Die innenpolitische Auseinandersetzung bestimmte das Leitmotiv des Antikommunismus. Léon Blum - und mit ihm der französische Sozialismus - war mit seinem Experiment der Sammlung gescheitert, wie der Ordre Nouveau immer wieder unterstrich. Claude Chevalley und René Dupuis stellten einen Zusammenhang zwischen dem Siegeszug des Republikanismus und dem Niedergang des Sozialismus her ${ }^{144}$. In der Volksfront war ihrer Ansicht nach eine spezifisch nationale Tradition der Arbeiterbewegung an die kommunistische Internationale verraten worden. In dem Regierungsbündnis mit den Kommunisten hatte der französische Sozialismus den Tiefpunkt einer Entwicklung erreicht, deren Ursprünge auf den Beginn der Dritten Republik zurückgingen. Schritt für Schritt belegten Chevalley und Dupuis, wie die französische Arbeiterbewegung, die unter dem Einfluß der Theorien Babeufs, Saint-Simons, Blanquis und Proudhons stand, durch den Marxismus „kontaminiert" worden war. Erst durch ihn sei die revolutionäre Praxis der "direkten Aktion" zu einem reformistischen Kurs umgebogen worden. Für die beiden Autoren zeigte sich der Einfluß des Marxismus in der Demokratisierung der Arbeiterbewegung. Das Scheitern der Pariser Commune in den Wahlen von $1870 \mathrm{führ}$ ten sie darauf zurück. Auch die Präambel des Sozialistischen Parteiprogramms von 1878 hielten Chevalley und Dupuis für „rein marxistisch inspiriert, insbesondere die Berufung auf den historischen Determinismus und die Anerkennung des taktischen Wertes des allgemeinen Wahlrechts"145. Durch diesen Strategiewechsel hatten sich die Sozialisten nach Ansicht der beiden Autoren zum Legalitätskurs bekannt und sich auf den Kampf um die Macht eingelassen, dessen Spielregeln vom Gegner, dem kapitalistischen Bürgertum, bestimmt wurden. Eine erfolgreiche Revolution konnte somit nur durch einen rigorosen Bruch mit dem "reformistischen“ Marxismus und die Rückbesinnung auf die nationale Tradition der Arbeiterbewegung eingeleitet werden, die auch innerhalb der C.G.T. unterdrückt worden sei. Chevalley bezichtigte die C.G.T., nach dem Kongreß von Amiens 1906 ihren ursprünglichen Kurs verlassen zu haben. An die Stelle eines Dachverbandes der autonomen lokalen Syndikate sei ein zentralistischer Machtapparat getreten, der sich die marxistische Theorie des Klassenkampfes zu eigen gemacht habe ${ }^{146}$.

142 Comité des Forges, ein einflußreicher Zusammenschluß von Großunternehmern aus der Stahlindustrie, dessen Präsident François de Wendel war; vgl. Jeanney, François de Wendel.

${ }^{143}$ Rougemont, Plébiscite et démocratie, in: ON, H. 30, 1936, S. 21-25, Zitat S. 25.

${ }^{144}$ Chevalley/Dupuis, Déclin du socialisme, in: ON, H. 35, 1936, S. 11-17.

145 Ebenda, S. 14.

146 Chevalley, Politique syndicale, in: ON, H. 32, 1936, S. 21-27, hier S. 22f.; vgl. Marc, Georges Sorel et le syndicalisme, in: ON, H. 38, 1937, S. 58-60; vgl. Lefranc, Le mouvement syndical. 
Ähnlich wie die Jeune Droite und ein Teil der extremen Rechten begrüßte auch der Ordre Nouveau die Streiks vom Juni 1936 als Signal zum Aufbruch autonomer Bestrebungen gegen den Legalitätskurs der C.G.T. Die „direkte Aktion“ der Streiks und Fabrikbesetzungen wertete die Gruppierung als ein Anzeichen für das Wiedererwachen der anarchistischen Tradition des revolutionären Syndikalismus ${ }^{147}$.

Den Mitarbeitern des Ordre Nouveau war nicht entgangen, daß sie die Sympathie für den radikalen Flügel der Arbeiterbewegung vorwiegend mit der extremen Rechten teilten, während die ehemals radikale Linke einen reformistischen Kurs einschlug. Albert Ollivier konstatierte dieses scheinbare Paradox der verkehrten Fronten und bemühte sich nachzuweisen, daß die Sympathie der extremen Rechten für den Syndikalismus auf einem Mißverständnis beruhe. Anhand von Georges Sorel, dem Autor der Reflexions sur la violence, und seinen Rezipienten erläuterte Ollivier den unterschiedlichen Gewaltbegriff von Syndikalismus und extremer Rechter. Er vertrat die Auffassung, daß es nicht genüge, mit der „direkten Aktion“ die Massen für einen Staatsstreich zu mobilisieren. Ein solcher Umsturz sei nicht im Sinne Sorels, weil er nur die Staatsmacht in andere Hände übergebe und letztlich den Staat selbst weiter stärke. Dies widerspreche den Zielen des revolutionären Syndikalismus, der den Staat selbst überwinden wolle. Gerade diese anarchistische Tendenz Sorels aber sei der extremen Rechten entgangen, weil sie ganz der autoritär-etatistischen Denkweise Maurras' verpflichtet sei. Unter Gewalt verstehe Sorel weniger physische Brutalität der mobilisierten Massen als vielmehr die doktrinäre Unnachgiebigkeit der revolutionären Führungsgruppen. Diese Elite der Bewegung sollte sich in kleinen, straff organisierten Zellen in Betrieben und Gemeinden organisieren und durch gezielte Aktionen den Staat von innen heraus zersetzen. Erst im letzten Moment sollte der revolutionäre Funke überspringen und die Massen zum Umsturz mobilisieren. „Darin liegt vielleicht der entscheidende Schritt der Revolution, ein irrationaler Schritt, dessen Dynamik beinahe notwendigerweise der Geschichte entgeht. " 148

An diesem Vorbild des anarchistischen Syndikalismus orientierte sich ausdrücklich die Organisationsform des Ordre Nouveau: Sie setzte sich zusammen aus „Zellen“, die ihren Charakter eines spontanen Zusammenschlusses durch den Verzicht auf jegliche Satzung und feste Hierarchie betonten. Das Ziel der Gruppierung war es, durch die Aktivität der Zellen wachsenden Einfluß auf die Gesellschaft zu gewinnen und sie schließlich umzugestalten. Deutlich traten in dieser Organisation die Züge einer konspirativen Gemeinschaft hervor, deren koordinierendes Zentrum das Direktionskomitee der Zeitschrift bildete ${ }^{149}$.

Die Strategie des Umsturzes bestand in der Subversion: dem Stärken der Opposition gegen den Staat und der Entwicklung eigener Herrschafts- und Kommunikationsstrukturen, mit deren Hilfe der Staat bekämpft werden konnte. Ausführlich hat sich Chevalley mit dieser Strategie befaßt. Sein Mißtrauen gegen jede Form von staatlicher Ordnung entsprang der Vorstellung, daß eine lebendige Gesellschaft nicht in eine feste Struktur eingezwängt werden dürfe und sich daher in einem Zustand der permanenten Revolution befinden müsse. Er begriff die revolutionäre Aktion ganz in der anarchistischen

${ }^{147}$ Aron/Chevalley/Dupuis/Hayon, Après les grèves, in: ON, H. 33, 1936, S. 1-28, hier S. 7ff., 28. 148 Ollivier, Violence collective, in: ON, H. 32, 1936, S. 14-20, Zitat S. 18.

149 Vgl. Chevalley/Glady [Marc], La mort des Partis, in: ON, H. 4, 1933, S. 19-27, und NN, Comment est né l'Ordre Nouveau, in: ON, H. 9, 1934, S. II-III. 
Tradition als ein ständiges Zerbrechen etablierter Herrschaftsformen. Sie sei ihrer Natur nach illegal und richte sich gegen jegliche Form der Institutionalisierung in Bürokratie, Parlament und Parteien. Der Ordre Nouveau sah sich innerhalb der subversiven Gruppen als "revolutionäre Avantgarde“, der aufgrund ihrer "geistigen Autorität" die Führungsrolle zukam: sie sollte im höchsten Rat (conseil suprême) über die Einhaltung der revolutionären Prinzipien wachen ${ }^{150}$.

Im Vergleich zum eher statischen Verfassungsentwurf von 1934 traten nun die dynamischen Elemente in der radikalen Entstaatlichung deutlich in den Vordergrund. Dies entsprach der Auffassung, daß der Zusammenbruch der Dritten Republik in greifbare Nähe gerückt sei. Im November 1935 hatte der Ordre Nouveau proklamiert: „Die Übergangszeit hat begonnen." ${ }^{151}$ Die Gruppierung reagierte damit auf die Mobilisierung der Arbeiterbewegung durch die Volksfront und versuchte, das revolutionäre Potential von der Sammlungsbewegung „abzuwerben“. Seit April 1936 folgten regelmäßig Aufrufe zur Gründung weiterer Zellen, die sich an der revolutionären Umgestaltung beteiligen sollten. Mit der Anhängerschaft wuchs auch der Umfang der Zeitschrift von 32 auf 48 Seiten. Das Bulletin de liaison, ursprünglich ein internes Organ, öffnete sich seit Mai für Sympathisanten ${ }^{152}$. Auf zahlreichen Vortragsreisen warben die Mitarbeiter um neue Anhänger. Ein „Aktionszentrum“ koordinierte die Aktivitäten der verschiedenen Gruppen und bereitete eine Neuauflage des Arbeitsdienst-Experimentes vor, das der Ordre Nouveau nach dem positiven Echo des vergangenen Jahres in einem größeren Rahmen wiederholen wollte ${ }^{153}$. Doch der Erfolg stellte sich nicht ein: Die Planungen des Arbeitsdienstes wurden durch das Matignon-Abkommen, durch das der bezahlte Urlaub tariflich garantiert wurde, hinfällig. Schließlich brachten die zahlreichen Aktivitäten die Gruppierung in finanzielle Schwierigkeiten, woraufhin auch eine weitere VergröBerung als utopisch erschien ${ }^{154}$.

Im Frühjahr 1937 hatte sich jedoch ein Mäzen gefunden, der die Publikation einer Wochenzeitschrift ermöglichte: A nous la liberté $e^{155}$. Damit konnte der Ordre Nouveau unter der Leitung Arons und Dupuis' das Werben um die revolutionär-syndikalistischen Kreise auf breiterer Basis fortsetzen. Aron griff den C.G.T.-Chef Léon Jouhaux wegen seiner Unterstützung der Volksfront an und forderte die Rückbesinnung der Gewerkschaftsbewegung auf die revolutionären Ursprünge ${ }^{156}$. Allerdings distanzierten sich die Mitarbeiter der Zeitschrift von den fortgesetzten Attacken der extremen Rechten auf den Volksfront-Chef. Alexandre Marc beschuldigte die Rechte, Léon Blum zum Sün-

${ }^{150}$ Chevalley, Révolution permanente, in: ON, H. 31, 1936, S. 6-11, Zitat S. 10.

151 NN, La Période de transition est ouverte, in: ON, H. 25, 1935, S. 1.

152 Bulletin de liaison, Nr.11, 1.5. 1936; darunter Paul Flamand, der dem Unternehmerverband U.C.F. nahestand, vgl. dessen Beiträge in Justice Sociale, 28. 10. 1937 - 19.5. 1938.

153 ON, H. 32, 1936, S. III; ON, H. 35, 1936, S. III.

154 NN, A nos amis, in: ON, H. 30, 1936, S. 49; Brief Arons an Rougemont vom 16. 7. 1936, Archives Rougemont, Neuchâtel: ON-Correspondance; vgl. Andreu, Echec pratique et grandeur réelle de l'Ordre Nouveau, in: La Nation française, 21.3. 1962, S. 10.

155 Den Hinweis auf den Mäzen gab mir Alexandre Marc, Gespräch vom 4. 12. 1994. Chefredakteur war Robert-Philippe Millet, der vorher das Bulletin de liaison geleitet hatte.

156 Aron, Lettre à Léon Jouhaux, in: ANLL, H. 1, 1937, S. 5; ders., Seconde lettre à Léon Jouhaux, in: ANLL, H. 3, 1937, S. 5. 
denbock für die Fehler einer Politik zu machen, die sie selbst mitzuverantworten hatte ${ }^{157}$.

Die Redakteure von $A$ nous la liberté prangerten die Staatsverschuldung an und erneuerten die Forderung des Ordre Nouveau nach Ablösung des liberalen Kapitalismus durch eine gemischte Planwirtschaft. Zu den weiteren - bereits an früherer Stelle formulierten - programmatischen Zielen gehörte die Beteiligung der Arbeiter am Produktivvermögen der Unternehmen, die Auflösung der Aktiengesellschaften (sociétés anonymes) und die Garantie eines Existenzminimums ${ }^{158}$. An dem Unternehmen beteiligten sich auch Sympathisanten aus dem Umfeld des Ordre Nouveau, darunter Christian Pineau, der Gründer der Nouvelles Equipes und Mitarbeiter der Zeitschrift Syndicats, Roger Leenhardt von Esprit und Georges Valois, der Gründer des Faisceau, der seit 1934 die technokratische Zeitschrift Nouvel Age herausgab. Doch nach kurzer Zeit waren die finanziellen Ressourcen oder die Geduld des Mäzens erschöpft: mit der zehnten Ausgabe mußte die Zeitschrift ihr Erscheinen bereits im April wieder einstellen.

Der Versuch des Ordre Nouveau, mit einem speziellen Organ in der Gewerkschaftsbewegung Fuß zu fassen, entsprach den Bemühungen des aktionistischen Flügels der Jeune Droite, der zum gleichen Zeitpunkt mit dem Insurgé Arbeiter für die Bewegung gewinnen wollte. A nous la liberté richtete sich an die gleiche Klientel, die auch das Wochenblatt der Jeune Droite erreichen wollte. Beide Gruppierungen verfolgten dieselbe Strategie, nämlich die Arbeiterbewegung dem Einfluß der Volksfront zu entziehen, um sie für die eigenen revolutionären Ziele zu gewinnen. Unmißverständlich machte $A$ nous la liberté diesen Anspruch mit dem Wechsel des Untertitels geltend: an Stelle von bebdomadaire personnaliste lautete er ab Nr. 4 bebdomadaire d'action et d'ordre révolutionnaire.

Beide Gruppierungen vereinte zudem die Feindschaft zum Kommunismus: nicht der Sieg einer Klasse über die andere, sondern die Aufhebung der Klassenunterschiede sollte am Ende der Revolution stehen. Während jedoch die Jeune Droite versuchte, die Arbeiterschaft mit nationalistischen Parolen zu mobilisieren, bediente sich der Ordre Nouveau wirtschaftspolitischer Argumente, die speziell an den Interessen der städtischen Unter- und Mittelschichten ausgerichtet waren. Auch im Stil unterschied sich $A$ nous la liberté durch eine primär sachbezogene Kritik deutlich vom Insurgé: Beleidigende Attacken und Aufrufe zur Gewalt fehlten ebenso wie der aggressive Nationalismus und die antisemitische Hetze. Vor allem aber war der anarchistische Antietatismus des Ordre Nouveau kaum vereinbar mit dem Ruf der Jeune Droite nach einem starken Staat. Am ehesten läßt sich dieser Gegensatz folgendermaßen beschreiben: während die Jeune Droite mit einem autoritären politischen Regime sympathisierte, das den Wirtschaftsinteressen ihrer Bürger weitgehend freien Lauf ließ, tendierte der Ordre Nouveau umgekehrt zu einem politisch schwachen Staat, der in der Wirtschafts- und Sozialpolitik jedoch zentrale Kompetenzen besaß. In dieser Hinsicht bewahrte die personalistische Gruppierung ihre Affinitäten zur Linken, während die Jeune Droite ebenfalls ihrer Herkunft verpflichtet blieb und den Sozial- und Wohlfahrtsstaat bekämpfte.

157 Sillargues [Marc], Plaidoyer pour Léon Blum, in: ANLL, H. 3, 1937, S. 6.

${ }^{158} \mathrm{NN}$, Il faut en sortir, in: ANLL, H. 3, 1937, S. 3. 


\section{Orientierung zur Linken}

Diese Orientierung des Ordre Nouveau bestimmte auch die Wahl der Verbündeten. Rougemont setzte sich dafür ein, die Zusammenarbeit mit Esprit zu intensivieren und die Zeitschrift wieder den Ideen des Ordre Nouveau näherzubringen. Ein deutliches Zeichen gab er Mounier in einer Besprechung von dessen Werk Manifeste au service du personnalisme: "Worauf es uns vor allem ankommt, ist, daß wir bei Esprit unsere Konzepte wiederfinden: das Existenzminimum, den Arbeitsdienst (hier öffentlicher Dienst genannt), das Unternehmen (und nicht die Genossenschaft), den höchsten Rat und schließlich die Unterscheidung zwischen Autorität und Macht. " 159

Doch erst nachdem die wachsenden Spannungen innerhalb der Volksfront die Fortsetzung der Reformen blockierten und Blum daraufhin im Februar 1937 die „Pause“ seines sozial- und wirtschaftspolitischen Programms verkünden mußte, bahnte sich eine neue Kooperation an. Ende des Monats verkündeten Mounier und Rougemont die Gründung gemeinsamer Presseklubs. Auch der Front social Bergerys, vertreten durch den Chefredakteur von La Flèche, Jean Maze, beteiligte sich an dem Unternehmen. Die Organisatoren wollten mit den Klubs eine Art Gegenöffentlichkeit schaffen, die als Ergänzung und Korrektur der Massenmedien dienen sollte. Sie hatten sich zum Ziel gesetzt, die Meinungsmanipulation der Tagespresse zu entlarven und ihre Abhängigkeit von Markt und Mäzenen offenzulegen: gezielte Fehlinformationen sollten ebenso angeprangert werden wie das Verschweigen von Informationen ${ }^{160}$. Weniger als vier Monate später hatten sich bereits rund 100 Clubs in Frankreich, Belgien und der Schweiz gebildet und ein eigenes Informationsnetz aufgebaut. Ein wöchentlich erscheinendes Bulletin verzeichnete Informationen, die das Redaktionsteam von Esprit, des Ordre Nouveau und des Front social für zutreffend und wichtig hielt ${ }^{161}$.

Die Zusammenarbeit überdauerte das Ende der Zeitschrift Ordre Nouveau, die im Juni 1937 ihr Erscheinen nicht zuletzt wegen der Erhöhung der Druck- und Papierkosten aus finanziellen Gründen vorläufig einstellen mußte. (Im Sommer 1938 erschienen noch einmal drei Ausgaben.) Ein hektographiertes Rundschreiben informierte im Dezember die Anhänger der Gruppierung über die Fortsetzung der Aktivitäten. Weiterhin setzte der Ordre Nouveau auf eine Kooperation mit Esprit. Ebenso sollten die Kontakte mit den syndikalistischen Kreisen aus der C.G.T. und dem Front social aufrechterhalten werden. Das Rundschreiben enthielt einen Gründungsaufruf für eine neue Organisation in Form einer "Arbeiterkooperative der Produktion" (Société ouvrière de cooperative de production) ${ }^{162}$.

Nach dem Verlust ihres eigenen Organs konnten die Anhänger des Ordre Nouveau auf diese zahlreichen informellen Beziehungen zurückgreifen und ihre Arbeit in benachbarten Zirkeln und Gruppierungen weiterführen. Rougemont intensivierte seine Zusammenarbeit mit Esprit und wurde im März 1937 Chefredakteur der Nouveaux

${ }^{159}$ Rougemont, Manifeste au service du personnalisme par E. Mounier, in: ON, H. 34, 1936, S. 64; vgl. Notizen von Rougemont auf Brief Arons vom 16. 7. 1936; Archives Rougemont, Neuchâtel: ON-Correspondance.

160 AN F7 12966, Bericht vom 25.2. 1937 über Konferenz vom Vortag; Millet, Pour une information indépendante et vraie, in: ON, H. 38, 1937, S. 62-64.

161 Sandahl, Les clubs de presse, in: Esprit, H. 57, 1937, S. 51 of.

162 NN, Aux abonnés et amis de l'Ordre Nouveau, in: Bulletin ON, Dez. 1937, S. 1-3. 
Cabiers, einem Zusammenschluß aus neoliberalen Industriellen und reformistischen Syndikalisten. Der Kreis um die Nouveaux Cabiers existierte bereits seit dem Februar 1934 und war von Auguste Detœf, dem Vorsitzenden des Verwaltungsrats der Alsthom, der größten französischen Elektrizitätsgesellschaft, ins Leben gerufen worden. Die Mitarbeiter distanzierten sich ausdrücklich von jeglicher Parteipolitik, doch verfolgten sie im Unterschied zu den nonkonformistischen Kreisen des Ordre Nouveau und der Jeune Droite die Entwicklung der Volksfront mit Sympathie und unterstützten deren sozialund wirtschaftspolitisches Reformprogramm ${ }^{163}$. Daniel-Rops und Alexandre Marc setzten ihre politischen Aktivitäten vorwiegend innerhalb der katholischen Presse fort. Nachdem die Berichterstattung über den Abessinienkrieg und den spanischen Bürgerkrieg innerhalb von Sept zu unüberbrückbaren Spannungen geführt und die Zeitschrift daraufhin ihr Erscheinen eingestellt hatte, erschien seit November 1937 die Nachfolgerin Temps présent - diesmal in der Hand eines laizistischen Redaktionskomitees, zu dem auch Daniel-Rops gehörte ${ }^{164}$. Marc redigierte - wie schon bei Sept - die politische Chronik und die Zeitschriftenschau.

Beide schrieben zudem in der neosozialistischen Tribune de France, die im Februar 1939 von Max Bonnafous und Marcel Déat gegründet worden war. Auch zwei weitere ehemalige Mitarbeiter des Ordre Nouveau engagierten sich dort: Jacques Lassaigne und Eugénie Hélisse ${ }^{165}$. Die Tribune war ein relativ offenes Organ des nonkonformistischen Milieus, in dem gelegentlich auch Beiträge von Anhängern der C.G.T. und der Sozialisten erschienen, unter anderem auch von Pierre-Olivier Lapie, der inzwischen unabhängiger Abgeordneter der Sozialisten war. Mit diesem Sammelbecken verfolgte Déat ein weiteres Mal den Versuch, eine Mehrheit für die innere Reform zu gewinnen. Auf diese Weise hoffte er, der wachsenden außenpolitischen Bedrohung durch ein starkes und geeintes Frankreich begegnen zu können ${ }^{166}$. Die Kontakte zum Front social hielt Robert Aron aufrecht. Nachdem sich Bergery zu einem militanten Antikommunisten entwikkelt hatte und sich Anfang 1938 von der Volksfront zu distanzieren begann, entschloß sich Aron, der Bewegung beizutreten ${ }^{167}$.

${ }^{163}$ Ein weiteres Ziel der Gruppe war es, die Kluft zwischen den Wirtschaftskreisen und den Intellektuellen zu überbrücken. Zu diesem Zweck engagierte die Zeitschrift überwiegend Vertreter der Linken: Angehörige des „antifaschistischen“ C.V.I.A. wie Henri Bouché und Paul Rivet, der Trotzkist Boris Souvarine, die linke Katholikin Simone Weil, Paul-Ludwig Landsberg und Henri Marrou von Esprit, Jacques Maritain und Gabriel Marcel; vgl. die Selbstdarstellung in: Nouveaux Cahiers (NC), H. 11, 1937, S. 2f. und in: NC, H. 20, 1938, S. 13-18.; Villey, Les Nouveaux Cahiers, in: Esprit, H. 65, 1938, S. 668-679; Brun, Technocrates, S. 44ff.; zu Detœe siehe Kuisel, Detœf, S. 149-174; Barnaud war im Aufsichtsrat der Banque Worms, vgl. Jeanney, L'argent caché, S. 277f.

${ }_{164} \mathrm{Zu}$ den Hintergründen der Spaltung vgl. Coutrot, Sept, S. 287ff.; zu Daniel-Rops vgl. Annuaire de la presse française 1938, S. 831.

${ }^{165}$ Auch ein Gespräch mit Rougemont erschien dort: Hélisse, Du mythe de Tristan et Iseult à l'hitlérisme avec Denis de Rougemont, in: Tribune de France, H. 24, 1939, S. 4.

166 Bergounioux, Néo-socialisme, S. 411; Burrin, Dérive, S. 274f.; Lapie, La Chambre protectrice de la pensée française, in: Tribune de France, H. 22, 1939, S. 4.

167 Aron, Conditions d'un rassemblement français, in: Flèche, H. 104, 1938, S. 1f.; Burrin, Dérive, S. 229; vgl. Claude Mauriac, Espaces imaginaires, Bd. 2, S. 21. 


\section{Antisemitismus und Antiliberalismus}

Dieses Kapitel weicht von der bisher üblichen Praxis der Darstellung ab. Die Orientierung am Gang der Ereignisse tritt hier zugunsten einer ideengeschichtlichen Betrachtung zurück. Zugleich aber fügt sich die Thematik in die Argumentationskette ein: Sie bildet eine notwendige Ergänzung des Blickwinkels des vorausgegangenen Volksfrontkapitels. Das Thema Antisemitismus wurde bisher ausgespart, obwohl während der Regierungszeit von Léon Blum die Agitation ein Ausmaß erreichte, das allenfalls mit demjenigen der Dreyfus-Affäre vergleichbar ist ${ }^{168}$. Da jedoch eine Untersuchung über die Verbreitung dieser Ressentiments bei den nonkonformistischen Intellektuellen bislang nahezu völlig fehlt, erschien es mir notwendig, diesem Thema ein eigenes Kapitel zu widmen ${ }^{169}$.

Der Versuch einer Standortbestimmung durch den Antisemitismus wird in einem zweiten Schritt erweitert: hier werden die Zusammenhänge zwischen den Vorurteilen gegenüber Juden und dem Antiliberalismus analysiert. Schließlich wird der Beweis angetreten, daß die ideologische Auseinandersetzung mit dem Liberalismus das Denken beider Gruppierungen entscheidend bestimmte und der Kampf gegen den Kommunismus, auch wenn er die Phase der Volksfront prägte, für die Genese der nonkonformistischen Ideen zweitrangig war.

Als Begründer des modernen französischen Antisemitismus gilt Edouard Drumont, der mit seinem 1886 erschienenen Werk La France juive erstmals die zentralen Argumentationsstränge in populärer Form vereinigt hatte: christlichen Antijudaismus, Antikapitalismus, Antirepublikanismus, Rassismus und Nationalismus ${ }^{170}$. Mit der Revision des Dreyfus-Prozesses erreichte die Agitation gegen die Juden einen ersten Höhepunkt. Die Angriffe der nationalistischen Rechten auf die Verteidiger des Hauptmanns waren stark befrachtet mit antisemitischen Ressentiments. Die Dreyfusards, denen man vorwarf, im Namen der Gerechtigkeit das Schicksal eines Individuums über die Interessen der Nation gestellt zu haben, wurden des Landesverrats bezichtigt. Ihr Eintreten für die universalen Menschen- und Bürgerrechte trug ihnen den Vorwurf ein, abstrakten Idealen anzuhängen und die Prägung des Menschen durch Blut, Boden und Geschichte zu ignorieren. In der gegenrevolutionären Verschwörungstheorie der extremen Rechten galten die Juden als Drahtzieher der Französischen Revolution. Auf diese Weise konnten sie die Agitation gegen die republikanischen Ideale mit derjenigen gegen die Juden verknüpfen und im Namen von Ordnung, Autorität und Nation die Vernunft, Wahrheit und Gerechtigkeit als Erfindungen „jüdischer Intellektueller" bekämpfen ${ }^{171}$.

An dieser Stelle ist es notwendig, einen Blick auf die besondere Form des französischen Antisemitismus zu werfen. Pierre Birnbaum hat auf die Rolle des Staates hingewiesen, die den Ressentiments in Frankreich im Vergleich mit Deutschland, England und den USA ihre spezifisch politische Stoßrichtung gab. Der ausgeprägte Zentralismus des republikanischen Systems und die starke Integration der Juden in den Staat prägten

168 Vgl. Schor, L'antisémitisme en France, S. 169ff.

${ }^{169}$ Eine Ausnahme bildet die Untersuchung der Ambiguitäten von Mouniers Philosemitismus bei Birnbaum, Mythe politique, S. 244ff.

170 Winock, Nationalisme, S. $117 \mathrm{ff}$.

171 Vgl. Winock, Les Affaires Dreyfus, S. 19-37. 
die Argumentationsstruktur, mit der die nationalistische Rechte die angebliche Vorherrschaft der Juden bekämpfte ${ }^{172}$. Die universalistischen Prinzipien des republikanischen Bürgerrechts ermöglichten es den Juden, einen großen Teil der hohen politischen Ämter in der Dritten Republik zu besetzen. Gefördert durch die staatliche Elitenrekrutierung, gelangten viele von ihnen in leitende Positionen in Politik und Verwaltung. Die staatliche Integration förderte auf der anderen Seite die außerordentlich starke Identifikation der Juden mit dem republikanischen Ideal einer laizistischen, liberalen Gesellschaft. Genau durch diese Identifikation von diesem bei Birnbaum als "stark“ bezeichneten Staat mit den Juden erhielt der französische Antisemitismus seine spezifische Kontur, die im Mythos der „jüdischen Republik“ ihren Ausdruck fand.

Vor 1936 spielten antisemitische Ressentiments in den Debatten der Jeune Droite nur eine untergeordnete Rolle. Es gibt einzelne Hinweise auf die Existenz solcher Denkfiguren bei Fabrègues und Chenut, doch läßt sich von der Gruppierung bis 1935 nicht sagen, sie habe den $\mathrm{Haß}$ gegen die Juden angestachelt ${ }^{173}$. Daß antisemitische Ressentiments dennoch präsent waren, wird in der Auseinandersetzung mit dem Nationalsozialismus deutlich. Maulnier stand zwar der Rassenlehre ablehnend gegenüber, weil sie in einem biologischen Determinismus gründete, jedoch war er von der Existenz von Rassenunterschieden und der Notwendigkeit einer "Auslese“ überzeugt. „Man kann es nicht oft genug wiederholen: Die Rasse steht nicht am Anfang, sondern sie entsteht erst im Verlauf einer historischen Entwicklung, die Reinheit des Blutes ist niemals durch den Zufall gegeben, sie ist im Gegenteil das Ergebnis einer sehr langen Perfektion, durch dieselbe künstliche Auslese wie bei Hunden und Pferden. [...] Eine Rasse ist eine menschliche Schöpfung, die französische Rasse ist eine Schöpfung der französischen Nation, sie wurde im Laufe der Jahrunderte gereinigt und geformt durch eine unermüdliche politische und geistige Arbeit. " 174 Maulnier kehrte den nationalsozialistischen Rassismus geradezu um und stellte dessen deterministisches Grundprinzip radikal in Frage. Die Rasse war nicht der Ursprung, sondern das Ergebnis eines Ausleseprozesses. Sie war seiner Ansicht nach der physische Ausdruck einer geistigen Schöpfung, ein Triumph des Willens, dessen Krönung die Nation bildete. Maulnier führte somit die Differenz von Franzosen und Juden nicht auf die Rasse, sondern auf die nationale Identität bzw. ihr Fehlen zurück.

Mit dem Sieg der Volksfront wurden die Attacken der Jeune Droite auf die Juden zahlreicher und aggressiver. Bereits die Tatsache, daß sie jederzeit abrufbar waren, macht deutlich, wie stark die Argumentationsmuster der Judenfeindschaft in der Tradition der Rechten verankert waren. In dieser Hinsicht zeigten sich die jungen Intellektuellen ih-

172 Birnbaum, Mythe, S. 13ff., 30ff.; vgl. ders., „La France aux Français“, S. $300 f f$.

${ }^{173}$ Fabrègues vertrat bereits 1928 in einer Konferenz vor der U.C.F. die These, Juden seien die Drahtzieher der russischen Revolution. Ähnliche Gedanken hat er im Etudiant français wiederholt, vgl. Auzèpy-Chavagnac, Fabrègues, S. 256ff.; Chenut, La crise et l'usure, in: Réaction, H. 8-9, 1932, S. 49f. Im weiteren Umfeld der Jeune Droite fanden sich auch radikale Antisemiten wie Robert Vallery-Radot (Revue française 1930-1931, Réaction 1930, Revue du siècle 1933), 1935 Vizepräsident der „Union Anti-Maçonnique“, und Pierre Loyer (Revue du XXe siècle 1934-1935), Sekretär der antisemitischen „Union Sociale des Ingénieurs catholiques“, vgl. Kingston, Anti-semitism, S. $51 \mathrm{ff}$.

174 Maulnier, Conditions d'un reveil, in: Action Française 30.3. 1933, S. 3; vgl. Maxence, Jeunesse française et Jeunesse allemande, in: Revue Française, H. 4, 1933, S. 597. 
rem Herkunftsmilieu deutlich verpflichtet. Ihre Kritik fixierte sich auf den Führer der Volksfront, den Juden Léon Blum. Für Maxence verkörperte er den Typus des entwurzelten Intellektuellen. „Entwurzelt vom nationalen Boden, von seinem Ursprungsland, das ihm Gemeinschaftssinn geben könnte. Entwurzelt ebenfalls vom Volk. Denn wie der Großteil der wichtigen Anhänger der deutschen Sozialdemokratie gehört Léon Blum zu jener intelligenzia, die zu Niederlagen, zum Exil und der kampflosen Flucht verurteilt ist, einer intelligenzia, die nach dem Faschismus ruft und ihn vorbereitet, die mit einem Schlag die Interessen der Proletarier und die der Nation verrät." 175

Eine vergleichbare Kritik am Typus des bürgerlich-linksliberalen Intellektuellen hatte sich zuvor hauptsächlich an Benda entzündet. Der Autor der Trabison des clercs gehörte als Kritiker des politischen Engagements zu den traditionellen Feinden des nonkonformistischen Lagers. Seit 1936 mischten sich in die Vorwürfe gegen Benda deutlich antisemitische Töne. René Vincent beschuldigte ihn, mit seinem Einsatz für die Rechte der Juden alle Nichtjuden zu diskriminieren. Bendas neues Werk Jeunesse d'un clerc (1936) bezeichnete er als ein „rassistisches Buch “ ${ }^{176}$, das er unter Zuhilfenahme der Topoi des Antiintellektualismus, die seit der Dreyfus-Affäre zum antisemitischen Repertoire gehörten, verriß: „Dies zeigt die Entfaltung eines bestimmten idealistischen und abstrakten Semitismus (zu dem sich übrigens Benda auf jeder Seite bekennt), der durch seine Mißachtung der Realität die Intelligenz fehlleitet und Katastrophen herbeiführt. “177

In derselben Manier richtete Blond den Vorwurf des Rassismus gegen die Juden. Seiner Ansicht nach wurden alle zentralen Positionen des öffentlichen Lebens von Juden kontrolliert. Der überwiegende Teil der Ärzte und nahezu das gesamte öffentliche Leben - Kino, Theater und Presse - seien bereits in ihrer Hand. In Anspielung auf die Hetzparole von der „jüdischen Republik“ behauptete er, das französische Volk werde durch eine "totalitäre Plutokratie“ der Juden unterdrückt ${ }^{178}$. Die Vorstellungen Blonds trugen durchaus paranoide Züge. Er sah bereits die Weltherrschaft der „weißen Rasse“ durch den Siegeszug der republikanischen Ideale bedroht. Der seiner Ansicht nach von Philosemiten geführte Kampf für Liberalismus, Egalitarismus und Demokratie mußte sich zwangsläufig gegen die weiße Rasse richten, weil sie sie auf eine Stufe mit den anderen stelle ${ }^{179}$. Die Überlegenheit der weißen Rasse stellte für ihn jedoch eine unbestreitbare Tatsache dar, die er mit dem Hinweis auf deren kolonisatorische "Leistung" in Afrika begründete. Blond machte unmißverständlich klar, daß die Emanzipation der unterdrückten Völker für ihn gleichbedeutend war mit dem Rückfall der Welt in die Barbarei. Um dies zu verhindern, mußten die Ergebnisse der Französischen Revolution entschieden bekämpft werden ${ }^{180}$. Als symptomatisch für das Ausmaß der Agitation kann

\footnotetext{
175 Maxence, Histoire de dix ans, S. 364.

176 Vincent, Benda: Jeunesse d'un clerc, in: Combat, H. 11, 1937, S. 15.

177 Ebenda; vgl. Winock, Affaires, S. 24f.

178 Blond, Ordre et liberté, in: Combat, Sondernummer, Aug./Sept. 1936, S. 122f. Zitat S. 122.

179 Blond, Un noir vaut un blanc, in: Combat, H. 27, 1938, S. 10.

180 Ebenda. Blond unterstützte auch direkt die nationalsozialistische Propaganda. Er verfügte über gute Kontakte nach Deutschland, schrieb in den Deutsch-französischen Monatsheften von Abetz und übersetzte und kommentierte 1938 eine Zusammenstellung von Texten Hitlers für das französische Publikum; Blond, Das wahre Antlitz Frankreichs, in: DFM 4 (1937), S. 110 113; Hitler, Ma doctrine. Übersetzt und kommentiert von Georges Blond und François Dauture, Paris 1938.
} 
das Ende 1937 erschienene Pamphlet Bagatelles pour un massacre angesehen werden, mit dem sich Louis-Ferdinand Céline als maßloser und fanatischer Antisemit offenbarte. Céline kann nicht als besonders pathologischer Einzelfall betrachtet werden. Er berief sich auf verbreitete Ressentiments und gebrauchte Stereotype, die in der antisemitischen Literatur seiner Zeit geläufig waren ${ }^{181}$.

Der radikale und subjektive Ton der Bagatelles sorgte jedoch auch für eine Polarisierung innerhalb der extremen Rechten, die schließlich zum Bruch zwischen dem Combat und Je suis partout führte. Gerade dieser Streit um Ziele und Grenzen des Antisemitismus berührte einen Punkt, an dem sich ein fundamentaler Unterschied zwischen der extremen Rechten in der Tradition der Action française und der Jeune Droite abzeichnete. Während die Redaktion von Je suis partout, die seit Juni 1937 von Brasillach geleitet wurde, die Bagatelles mit Enthusiasmus aufnahm und in Auszügen nachdruckte ${ }^{182}$, distanzierte sich der Combat scharf von Célines Antisemitismus. Für René Vincent waren die Bagatelles der Ausdruck eines „delirierenden Subjektivismus ohne den geringsten Funken von Wahrscheinlichkeit" ${ }^{183}$. Mit den Bagatelles schoß Céline seiner Ansicht nach über das Ziel hinaus und brachte die Auseinandersetzung auf die Ebene des persönlichen Hasses und der maßlosen Polemik, die der „Sache“ selbst, nämlich dem „berechtigten“ Antisemitismus, schade. Und dies war Vincent zufolge um so schlimmer, als es genügend Gründe gebe, die Juden zu bekämpfen. An erster Stelle nannte er die „rassistische Diktatur, die Frankreich gerade hinter sich gebracht hatte“184. In einem herablassenden und beleidigenden Ton reagierte Lucien Rebatet, leitender Redakteur von Je suis partout, auf diese Polemik und machte deutlich, daß er die Kritik an Céline als direkten Angriff auf seine Zeitschrift verstand. Er bezeichnete Vincent als „kleingeistigen“ Journalisten, der durch seinen "gehörnten Liberalismus“ den Juden noch Hilfe bei ihrer Verteidigung leiste ${ }^{185}$.

Die Schärfe, mit der dieser Streit zwischen zwei Redaktionen geführt wurde, zwischen denen enge persönliche Verbindungen bestanden ${ }^{186}$, legt die Vermutung nahe, daß es um wesentlich mehr ging, als in der Debatte bisher zur Sprache kam. Deutlich wird dies, wenn man die Kampagne betrachtet, die Rebatet nach dem Erscheinen des Buches entfachte. Von Ende Januar bis März 1938 veröffentlichte er eine Serie von sechs Artikeln über die Emigranten in Frankreich, die seine These einer jüdisch-bolschewistischen Verschwörung belegen sollten. Nach seinem Dafürhalten diente das kommunistische Komitee Ernst Thälmann als Sammelbecken für Emigranten, die, wie Rebatet betonte, in der Mehrheit Juden waren und politisch zur extremen Linken zählten. Zu den gehei-

181 Die Ansicht von Thalmann, Céline sei ein Einzelfall, ist durch die Forschungen von Schor und Kingston widerlegt; vgl. Thalmann, L'antisémitisme, S. 134-158, S. 152; Kingston, Anti-semitism, S. 51ff., 75ff.; Schor, Antisémitisme, S. 169ff.; Winock, Nationalisme, S. 374ff.; Wirsching, Kollaborationsideologie, S. 32f.

182 Dioudonnat, Je suis partout, S. 224f.; Vitoux, Vie de Céline, S. 320. Auch Léon Daudet hatte in der Action française das Erscheinen der Bagatelles begrüßt.

183 Vincent, Les aveux du juif Céline, in: Combat, H.23, 1938, S. 13.

${ }^{184}$ Ebenda.

${ }^{185}$ Rebatet, Juifs et catholiques, in: JSP, H. 384, 1938, S. 8.

186 Folgende Personen haben gleichzeitig für die Jeune Droite (Combat/Insurgé) und Je suis partout gearbeitet: Blond, Brasillach, Pierre Gaxotte, Kléber Haedens, Jean Héritier, Maulnier, Claude Roy, Louis Salleron, René Vincent. 
men Hintermännern des Komitees, dem Intellektuelle wie André Gide, André Malraux, Paul Langevin, Henri Barbusse und Romain Rolland angehörten, erklärte er die deutschen Juden. Anknüpfend an Célines Bagatelles sah Rebatet hinter den Kommunisten die Juden als die eigentlichen Drahtzieher einer neuen, globalen Revolution ${ }^{187}$. Diese Überzeugung Célines und Rebatets hatte ihren geistigen Nährboden, wie Andreas Wirsching gezeigt hat, in der katholisch-gegenrevolutionären Verschwörungstheorie der Action française. Die durch den Sieg der Volksfront entfachte Furcht vor einem jüdischbolschewistischen Komplott bildete die Grundlage für diese neue, radikalisierte Form des Antisemitismus. Mit dieser entschieden antibolschewistischen Reaktion sprengte die Rechte letztlich die Paradigmen des katholisch-gegenrevolutionären Antisemitismus der Dreyfus-Affäre188.

Zugleich hatte die extreme Rechte mit dieser aus der französischen Tradition inspirierten Denkfigur die ideologische Voraussetzung für die Annäherung an Deutschland geschaffen. Hitler erschien der extremen Rechten in dem Maße als natürlicher Verbündeter, wie sie sich selbst durch die jüdisch-bolschewistische Weltrevolution bedroht fühlte. Gerade Hitlers Vorgehen gegen die Juden war aus dieser Sicht "genuiner Antibolschewismus" ${ }^{189}$. Diesen ideologischen Schulterschluß mit Deutschland vollzog Rebatet mit seiner Kampagne, mit der er sich erstmals öffentlich der Sichtweise der nationalsozialistischen Propaganda anschlo ${ }^{190}$. Eine Je suis partout-Sondernummer über „die Juden“ im April 1938 bekräftigte diese Haltung. Rebatet bekannte sich zu den „Erkenntnissen" der Rassenlehre und dem politischen Wert von ethnischen Differenzierungen. An der nationalsozialistischen Lehre von der "nordischen Rasse“ kritisierte er in erster Linie, daß sie den Boden der "seriösen“"Wissenschaft verlassen habe ${ }^{191}$.

Diese Haltung forderte wiederum Maulnier zu einer grundsätzlichen Darlegung eines „vernünftigen Antisemitismus" heraus ${ }^{192}$. Ganz offensichtlich saßen die Adressaten dieser Abrechnung in der Redaktion von Je suis partout, auch wenn er die Zeitschrift mit keinem Wort erwähnte. Erneut kritisierte er die auf das Kriterium der Rasse gegründete pauschale Verurteilung der Juden und gab vor, die "wahren" Gründe des Antisemitismus zu kennen. „Der entmythifizierte Antisemitismus hat seine Ursprünge in zwei Wesenzügen, die das jüdische Element ausmachen: seine wachsende Stärke und seine unüberwindbare Fremdartigkeit. " ${ }^{193}$ Maulnier unterstrich somit die Vergeblichkeit jeglicher Assimilationsbestrebungen: als „ewiger Fremder" sei der Jude gewissermaßen die Verkörperung des schlechthin Antinationalen. Wo es ihm aber gelinge, die Macht an sich zu reißen, mußte die Nation Schaden nehmen. Als Belege für den „schädlichen“ Einfluß der Juden nannte er die „zurückgebliebenen“ Länder Polen und Rußland. Maulnier sah in dem hohen Anteil von Juden an der Bevölkerung den Grund dafür, daß diese Länder

\footnotetext{
${ }^{187}$ Rebatet, Peut-on éviter le pogrom?, in: JSP, H. 380, 1938, S. 4; vgl. Céline, Bagatelles, S. 51. 188 Wirsching, Kollaborationsideologie, S. 45ff.; vgl. zum Paradigma der Dreyfus-Affäre Winock, Affaires, hier S. 26ff.

${ }^{189}$ Ebenda, S. 52f., Zitat S. 53; vgl. zu Hitler Nolte, Faschismus, S. $490 f$.

${ }^{190}$ Den Hinweis auf den Zusammenhang liefert Rebatet selbst in dem Artikel: La France, repaire de la juiverie allemande, in: JSP, H. 377, 1938, S. 5; vgl. Belot, Rebatet, S. $214 f$.

191 Rebatet, Les juifs et l'antisémitisme, in: JSP, H. 386, 1938, S. 2.

192 Maulnier, Notes sur l'antisémitisme, in: Combat, H. 26, 1938, S. 5.

${ }^{193}$ Ebenda, S. 6.
} 
allenfalls verspätet an der westeuropäischen Entwicklung zu Kapitalismus und Demokratie teilgehabt hätten. Dies klingt paradox, gehörten doch der ausbeuterische Kapitalist und der Anhänger republikanischer Ideale zu den antisemitischen Topoi. Aber nach Auffassung Maulniers war das zentrale Wesensmerkmal der Juden ihre Rückwärtsgewandheit. „Sie profitieren von der historischen Situation mehr, als daß sie sie gestalten würden. "194 Umgekehrt verdankte Frankreich Maulnier zufolge seinen Aufstieg zur führenden westlichen Nation nur der Tatsache, daß es verhältnismäßig wenige Juden beherberge. Ohne dies direkt auszusprechen, operierte Maulnier mit dem Bild von Parasiten, die den staatlichen „Organismus" befielen und auszehrten ${ }^{195}$. Wenn man den Rassismus nicht auf die pseudobiologischen Lehren beschränkt, sondern ihn als Zuweisung konstanter physischer und psychischer Eigenschaften an eine Abstammungsgemeinschaft versteht, so müssen auch diese Gedanken Maulniers als Rassismus verstanden werden ${ }^{196}$. Das Fehlen jeglicher Eigeninitiative führte aber die Verschwörungstheorie ad absurdum. Eine Gemeinschaft, deren zentrales Wesensmerkmal in der Passivität gesehen wurde, konnte unmöglich eine Revolution anzetteln. Auch die Französische Revolution war nach Maulniers Ansicht nicht das Werk der Juden, sondern der Engländer und Protestanten gewesen ${ }^{197}$.

Deutlich unterschied sich dieser Antisemitismus der Jeune Droite von demjenigen der Je suis partout-Redakteure durch das Fehlen einer vergleichbaren "reaktionären Dynamik“. Der radikalisierte Flügel der extremen Rechten, zu dessen Sprachrohr sich Je suis partout entwickelt hatte, bekämpfte mit seiner Verschwörungstheorie das Grundprinzip der Revolution. Sein Denken war im wörtlichen Sinne reaktionär, es erhielt seine Radikalität aus der vermeintlichen Bedrohlichkeit des Gegners ${ }^{198}$. Mit dieser extremen Rechten, aus deren Gedankenwelt nahezu alle Redakteure der Jeune Droite stammten, teilten sie zwar die Ablehnung der Folgen der Revolution, also von Liberalismus, Demokratie und Kapitalismus. Der Einfluß der Juden war jedoch aus der Sicht Maulniers nur eine Folge, keineswegs aber die Ursache des nationalen Niederganges. Daher mußten auch nicht die Juden, sondern der Staat bekämpft werden: „Das jüdische Problem läßt sich fast vollständig lösen, wenn man das demokratische Staatswesen und die kaufmännische Gesellschaft zerschlägt. " 199

Das revolutionäre Prinzip als solches verurteilte die Jeune Droite niemals, es bildete vielmehr die Grundlage ihrer eigenen Weltanschauung. Nur durch eine Revolution konnten ihrer Ansicht nach die Folgen von 1789 überwunden werden. Aus diesem Grund konnte und wollte die Jeune Droite den Juden keine revolutionären Absichten unterstellen. Nicht die Revolution mußte bekämpft werden, sondern nur ihr Ergebnis, die liberale Gesellschaft, die aus ihr hervorgegangen war ${ }^{200}$. Mit der Infragestellung des gegenrevolu-

\footnotetext{
194 Ebenda.

195 An anderer Stelle sprach er aber vom Bürgertum als parasitärer Macht: Maulnier, Examen, in: Combat, H. 23, 1938, S. 4.

196 Von zur Mühlen, Rassenideologien, S. 12.

${ }_{197}$ Maulnier, Notes, S. 6.

198 Vgl. Wirsching, Kollaborationsideologie, S. 36f.; Nolte, Faschismus, S. $61 \mathrm{ff}$.

${ }^{199}$ Maulnier, Notes, S. 6.

200 Vgl. Maulnier, Réalités et représentations révolutionnaires, in: Combat, H. 13, 1937, S. 37f.; Fabrègues, Une révolution justifiée, in: Combat, H.21, 1938, S.6f.
} 
tionären Dogmas haben sich die Combat-Redakteure der Häresie gegenüber der Lehre der Action française schuldig gemacht. Selbst die Redaktion von Je suispartout, die sich in ihrer Haltung zu Deutschland ebenfalls weit von Maurras entfernt hatte, hielt an diesem Dogma fest. Brasillach und Blond zogen daraus die Konsequenzen und stellten nach dem Erscheinen von Maulniers Artikel ihre Mitarbeit beim Combat ein ${ }^{201}$.

Aus diesen häretischen Ideen entwickelte Maulnier 1938 seine Theorie des neuen Nationalismus. In seinem Werk Au-delà du nationalisme - dessen Titel er in Anlehnung an Hendrik de Mans $A u$-delà du socialisme gewählt hatte - kündigte er den Beginn einer neuen Epoche an, in der die Nation wieder zum zentralen Integrationsbegriff aller Klassen werden sollte. Die ersten Symptome dieses Wandels sah er in den „nationalen Revolutionen" in Italien und Deutschland. Für Maulnier waren dies freilich unzulängliche Versuche, den Begriff der Nation von seiner Vereinnahmung durch das Bürgertum zu befreien und wieder zu dem zu machen, was sie seiner Ansicht nach verkörperte: das „natürliche" Organisationsprinzip der auf einer historischen Gemeinschaft von Blut, Boden und Sprache beruhenden europäischen Kulturen ${ }^{202}$.

Den liberalen Nationalismus erklärte er zum Verteidigungsreflex einer sozialen Schicht, die ihre Privilegien bedroht sah. Er konnte nur durch eine Umgestaltung der sozialen Verhältnisse wirksam bekämpft werden. Die nationale Revolution mußte in erster Linie den Kapitalismus überwinden. Die Triebkraft der politischen und sozialen Umgestaltung konnte seiner Ansicht nach nur der Klassenkampf sein - ein Klassenkampf, der von der Vereinnahmung durch die Linke und der Verurteilung durch die Rechte befreit war: „Die Ansicht, eines der interessantesten sozialen Phänomene unserer Epoche sei das Ergebnis einer durch die Juden, Intellektuelle oder den Zufall provozierten Katastrophe, und die Ansicht, es handle sich bei diesem Phänomein um ein universelles $\mathrm{Ge}$ setz der Geschichte - diese beiden Ansichten sind zwei gleichermaßen absurde Formen des politischen Fetischismus. “203

Antisemitische Verschwörungstheorien und materialistische Dialektik begriff er als komplementäre Seiten derselben Reaktion auf die soziale Tatsache der Klassenspaltung, die der liberale Kapitalismus geschaffen hatte. Auch der Marxismus konnte Maulnier zufolge die Verhältnisse nicht verändern, da er selbst auf dem geistigen Boden des Liberalismus entstanden war und die Prämisse der Klassenherrschaft mit ihm teilte - mit dem einzigen Unterschied, daß an Stelle des Bürgertums das Proletariat die Führung übernehmen sollte. Eine wirkliche Revolution aber müsse die Klassenkämpfe überwinden und die ursprüngliche nationale Gemeinschaft wiederherstellen ${ }^{204}$. Maulnier setzte seine Hoffnungen auf eine Überwindung des linken und rechten Determinismus. Der reaktionäre Nationalismus eines Barrès war seiner Ansicht nach nur die umgekehrte

201 Allerdings schrieben Maulnier und Claude Roy noch bis 1940 für das literarische Feuilleton der Zeitschrift von Je suis partout; Dioudonnat, Rédacteurs, S. 63, 80.

202 Maulnier, Nationalisme, S. 25, 62, 226. Zahlreiche Thesen des Werkes hatte Maulnier zuvor in Combat veröffentlicht. Das Werk fand auch in Deutschland Beachtung. In der Abhandlung von Karl-Heinz Bremer über den französischen Nationalismus seit 1789 nahm die Auseinandersetzung mit Maulniers Thesen den zentralen Platz ein. Er würdigte Maulnier als den Theoretiker des „revolutionären Konservativismus“; Bremer, Nationalismus, S. 124.

${ }^{203}$ Maulnier, Nationalisme, S. 42.

${ }^{204}$ Ebenda, S. 44. 
Form des marxististischen Determinismus: er verneine die Freiheit des Willens und des Denkens und damit die Möglichkeit des Fortschritts überhaupt. Auf diese Weise erkenne er die wirtschaftliche Vorherrschaft des liberalen Bürgertums an und mache sich zu dessen Komplizen ${ }^{205}$.

Der Syndikalismus schließlich war durch seinen reformistischen Kurs mit den republikanischen Prinzipien „kontaminiert" worden. Durch eine Rückbesinnung auf seine ursprünglich revolutionären Ziele konnte er jedoch die treibende Kraft im Kampf gegen das liberale Bürgertum werden. Er befürwortete ein Bündnis zwischen der revolutionären Linken und der nationalen Rechten als Voraussetzung für einen Sieg über Liberalismus und Demokratie: „Nationalistischer und revolutionärer Wille treffen sich im historischen Schöpfungsakt, durch den eine Gemeinschaft die Möglichkeit erhält, sein Geschick in die Hand zu nehmen und in einer neuen Synthese der sie zersetzenden Antagonismen zu triumphieren. Die Nation kann nur in der befreienden Metamorphose wiedergefunden oder erneuert werden. " 206 Die Haltung des führenden Theoretikers der Jeune Droite war somit in erster Linie antiliberal und nicht antimarxistisch. Mit seiner Theorie des Neonationalismus näherte er sich von der entgegengesetzten Seite den Thesen Hendrik de Mans an: dieser hatte mit der Revision des Sozialismus den Vorrang der nationalen Einheit vor den Interessen des Proletariats formuliert. Mit seiner Revision des Nationalismus verknüpfte Maulnier die Versöhnung der Klassen mit der Entmachtung des liberalen Bürgertums ${ }^{207}$.

Während sich bei der Jeune Droite ein latenter Antisemitismus feststellen ließ, der jederzeit aktivierbar war, beschränkten sich die Ressentiments beim Ordre Nouveau nur auf Einzelfälle. Es fällt zudem auf, daß derartige Gedanken ausschließlich außerhalb der eigenen Zeitschrift veröffentlicht wurden. Die Vermutung liegt also nahe, daß solche Bemerkungen innerhalb des Direktionskomitees auf Widerstand stießen und unterdrückt wurden ${ }^{208}$. Jedoch stammen auch die im folgenden untersuchten Äußerungen aus der Kerngruppe des Ordre Nouveau: von Daniel-Rops, Rougemont und Dupuis.

Daniel-Rops nahm den Zustrom deutscher Emigranten nach Frankreich 1933 zum Anlaß, seinen Ressentiments gegen die Asylsuchenden Ausdruck zu verleihen. Trotz der im Vergleich zu anderen Immigrationsströmungen aus Italien, Spanien und Polen wesentlich geringeren Zahl deutscher Emigranten reagierte Daniel-Rops, ähnlich wie ein großer Teil der Rechten, in diesem Fall besonders sensibel. Ohne daß er dies offen auszusprechen brauchte, war unüberhörbar, daß sich seine Vorwürfe primär gegen Juden richteten, die mit rund 80 Prozent den bei weitem überwiegenden Teil der deutschen Emigranten ausmachten ${ }^{209}$. Daniel-Rops behauptete, die meisten der Emigranten seien

${ }^{205}$ Ebenda, S. 203ff.; vgl. zu Barrès Curtius, Barrès, S. 121ff., Sternhell, Barrès, S. $254 \mathrm{ff}$.

${ }^{206}$ Maulnier, Nationalisme, S. 201, Zitat S. 227.

207 Vgl. de Man, Marxisme; Dodge, Beyond Marxism, S. $90 f f$.

208 Einen besonderen Anlaß dazu dürften Aron und Marc gehabt haben, die selbst jüdischer Herkunft waren.

209 Zumal er sich unmittelbar vorher gegen den Philosemitismus einiger Linksintellektueller gewandt hatte, Daniel-Rops, Jeune Allemagne, jeune France, in: Le Correspondant, H. 105, 1933, S. 266-296. Vgl. Thalmann, Immigration allemande, S. 149-172. Diese Untersuchung wertet erstmals das französische Archivmaterial aus, vor allem aus dem Außenministerium, dem Nationalarchiv und der Pariser Polizeipräfektur. Von Mai bis Ende 1933 stieg die Zahl der Emigranten von 4000 auf 20-25000 und blieb danach bis 1936 weitgehend konstant. Zum Vergleich die Im- 
bereits in Deutschland arbeitslos gewesen und hätten nur einen Vorwand gesucht, um in Frankreich Hilfeleistungen anzunehmen, die sie in Deutschland nicht mehr bekommen hätten. Er unterstellte ihnen damit in kaum verschlüsselter Form, arbeitsscheu zu sein und von einem fremden Sozialsystem profitieren zu wollen, ohne nach möglichen Gründen für ihre Arbeitslosigkeit in Deutschland zu fragen. Er vertrat zudem die Meinung, daß der Zustrom der Fremden eine Gefahr für den sozialen Frieden darstelle: „Diese neuen Elemente werden sich kaum assimilieren, und wir haben vielleicht derzeit kein dringendes Bedürfnis, die Zahl unserer Arbeitslosen ansteigen zu lassen." 210 Dieses Argument der sozialen Unverträglichkeit fand - angefacht durch die Propaganda der deutschen Dienststellen - in Frankreich ein breites Echo bei der französischen Rechten $^{211}$. Ansätze zu einer Verschwörungstheorie fehlen aber bei Daniel-Rops vollständig.

Bei Rougemont finden sich Anhaltspunkte für Ressentiments gegenüber Juden, die einerseits seiner antiliberalen Haltung entstammten, andererseits auf religiösen Vorbehalten beruhten. Für Rougemont verkörperten die Juden spezifisch bürgerlich-liberale Werte. In dieser Auffassung hatte ihn besonders sein Lektorat in Frankfurt 1935-1936 bestärkt, über das er im Journal d'Allemagne berichtete. In dieser Stadt mit ihrer bedeutenden und reichen jüdischen Gemeinde sah er sich mit Vertretern des jüdischen Großbürgertums konfrontiert. „Der Jude, von dem ich spreche, entspricht weitgehend dem Typus des europäischen Liberalen. “212 Daneben entdeckte Rougemont auch einige, die mit marxistischen oder stalinistischen Ideen sympathisierten ${ }^{213}$. „Aber der Großteil214 derjenigen, die man in einem Café am Opernplatz beobachten kann, scheint tatsächlich den schlichten Parolen der nationalsozialistischen Propaganda zu entsprechen. Dickbäuchig und beringt, die Zigarre mitten im Mund, repräsentieren sie den ordinären Typus des hochmütigen Kapitalisten. “215 Diese Juden waren somit die Nutznießer eines Systems, das der Ordre Nouveau entschieden bekämpfte: des liberalen Kapitalismus. Es ginge zu weit, aus diesem Hinweis jeglicher Kritik am Liberalismus eine antisemitische Tendenz zu unterstellen, doch macht er deutlich, daß diese Konnotationen durchaus angelegt waren ${ }^{216}$. Zumindest betonte Rougemont in diesem Punkt sein Einvernehmen mit der nationalsozialistischen Propaganda und verlieh seiner Überzeugung Ausdruck, daß im Antisemitismus letztlich ein wahrer Kern stecke. Jedoch muß man hinzufügen, daß Rougemont in demselben Werk auch von seinen jüdischen Freunden sprach und die Maßnahmen des NS-Systems gegen die Juden mißbilligte.

migration aus anderen Ländern im selben Zeitraum: Polen: 518000 , Spanier: 490000 , Italiener: 800000 ; vgl. Schor, Opinion française, S. $613 \mathrm{ff}$.

${ }^{210}$ Daniel-Rops, Jeune Allemagne, S. 286f., dieser Auszug erschien auch in: Union pour la vérité, H. 1-2, 1933, S. $15 f$.

211 Thalmann, Immigration allemande, S. 156; vgl. Peterson, Emigranten, S. 888.

212 Rougemont, Journal d'Allemagne, S. 20.

213 Über die jüdischen Stalinisten schrieb er: „Sie begrüßen einen Anti-Führer, der sie mehr noch als der Führer ausgrenzt." Rougemont, Journal, S. $20 \mathrm{f}$.

214 In der zweiten Auflage von 1968 ersetzte Rougemont „la plupart" durch „beaucoup“, ders., Journal d'une Epoque, S. 297; zu den Modifikationen Rougemonts am Journal d'Allemagne im Journal d'une Epoque vgl. Ackermann, Rougemont, Bd.2, S. $999 f f$.

${ }^{215}$ Rougemont, Journal d'une Epoque, S. 21.

216 Vgl. dazu Sternhell, Roots, S. 103-134. 
Eine weitere Quelle seiner Ressentiments speiste sich aus religiösen Vorbehalten. Rougemont war engagierter Protestant und hatte in seiner Zeitschrift Hic et nunc ein erstes Forum für die frankophone Karl-Barth-Rezeption geschaffen. Er prägte damit maßgeblich die Calvinismus-Renaissance, die für seine Vorstellung vom persönlichen Engagement von zentraler Bedeutung war ${ }^{217}$. Im Anschluß an Ernest Renans Histoire du peuple d'Israël kritisierte Rougemont die strikte Ausrichtung des jüdischen Glaubens auf das Jenseits, die seiner Ansicht nach jeglichen Sinn für die diesseitige Wirklichkeit verstellte. Diese attentistische Haltung führe wiederum zu geistiger Verengung und mangelnder Tatkraft, kurzum zur Kapitulation vor den Aufgaben dieser Welt ${ }^{218}$. Dieser Vorwurf der Kapitulation bildete auch die Folie der Intellektuellenkritik, wie Rougemont sie namentlich in seinen beiden Hauptwerken des Personalismus, Politique de la Personne (1934) und Penser avec les mains (1936), formuliert hat. Sein Vorwurf an die Intellektuellen, für den Niedergang der abendländischen Kultur im zwanzigsten Jahrhundert maßgeblich verantwortlich zu sein, richtete sich keineswegs ausschließlich gegen die Vertreter jüdischen Glaubens, jedoch gerade gegen diejenige Haltung, die seiner Ansicht nach im Glauben angelegt war: die Abdankung vor den Forderungen der Gegenwart. Eines der Grundprinzipien des Personalismus forderte das politische Engagement der Intellektuellen, die neue Ethik des Denkens verpflichte ihn zum Handeln ${ }^{219}$.

Zumindest diese religiös motivierten Ressentiments modifizierte Rougemont später und schwächte sie ab. In einem Beitrag für den Sammelband Les Juifs, der 1937 in der von Daniel-Rops geleiteten Reihe Présences erschien, bezog er eine vermittelnde Position gegenüber dem jüdischen Glauben. Im Anschluß an seine theologischen Überlegungen von 1935/36 bemühte er sich, die vermeintlichen Antagonismen zwischen jüdischem und protestantischem Glauben aufzulösen und den gemeinsamen Ursprung im Alten Testament hervorzuheben. Er betonte deutlicher als vorher den Glauben an eine Berufung, an den missionarischen und charismatischen Charakter des jüdischen Glaubens, und sah hierin Parallelen zum Protestantismus - insbesondere in seiner kalvinistischen Form. Den Vorwurf des Intellektualismus, des abstrakten, realitätsfernen Denkens, beschränkte Rougemont auf diejenigen jüdischen Intellektuellen, die von dem Glauben an ihre Berufung abgefallen waren ${ }^{220}$.

Als entschiedener Antisemit entpuppte sich Dupuis in einem Beitrag in demselben Sammelband Les Juifs, der sich mit der nationalsozialistischen Judenpolitik beschäftigte ${ }^{221}$. Dieser Artikel war trotz seines sachlichen Stils und seiner zutreffenden Belege in seiner Tendenz so dezidiert antisemitisch, daß selbst Rebatet in Je suis partout Beifall

${ }^{217}$ Reymond, Théologien, S. 24 und 62ff.; Balmand, Rougemont, S. 53f.; vgl. auch Archives Rougemont Neuchâtel, Hic et nunc.

${ }^{218}$ Rougemont, Penser, S. $49 \mathrm{ff}$.

219 Vgl. Rougemont, Politique, S. 9f.; ders., Penser, S. 13ff.; zu den jüdischen Ursprüngen vgl. das Kapitel "L'Arche de l'Alliance“, Penser, S. 49-56.

${ }^{220}$ Rougemont, Vocation et destin d'Israël, in: Les Juifs, S. 156ff. Doering führt diesen Wandel Rougemonts auf den Einfluß Maritains zurück, dessen Kreis in Meudon er regelmäßig frequentierte, Doering, Maritain, S. 165.

${ }^{221}$ Dupuis, Hitler et les Juifs, in: Les Juifs, S. 26-43. 
spendete $^{222}$. Zumindest innerhalb des nonkonformistischen Milieus hatte Dupuis hiermit den einzigen Versuch unternommen, den nationalsozialistischen Antisemitismus einer umfassenden ideologischen und historisch-politischen Analyse zu unterziehen. In dem Kenntnisreichtum und der analytischen Schärfe ragt er weit über das Niveau der sonstigen antisemitischen Hetze in Frankreich hinaus. Mit dieser Art von Untersuchung betrat Dupuis Neuland: Erst zwei Jahre später erschienen die Werke von Gustav Warburg und Konrad Heiden, die sich erstmals in systematischer Weise mit der Frage des Judentums in Deutschland befaßten ${ }^{223}$.

Es ging ihm darum, die historischen Gründe für den spezifisch deutschen Antisemitismus darzulegen. Dabei hatte er die Tendenz, mit sachlich weitgehend zutreffenden Argumenten eine unausweichliche Notwendigkeit dieser Entwicklung zu konstruieren, durch die der Antisemitismus gewissermaßen seine Legitimation in den historischen Umständen fand. So nannte er die Ruhrbesetzung als Auslöser einer Welle des Antisemitismus und folgerte: „Umwälzungen wie diese appellieren bei Betroffenen beinahe automatisch an einen Verteidigungsreflex und eine instinktive Auflehnung, wie sie sich in der Suche nach einem Sündenbock äußert." ${ }^{224}$ Auch wenn er das Ausmaß der Beschuldigungen gegenüber den Juden für unangemessen hielt, so war für ihn das deutsche Vorgehen gegen die exponierte Stellung der Juden „eine natürliche Abwehrreaktion des deutschen nationalen Organismus“225.

Durch die Weimarer Verfassung weitgehend assimiliert, hätten die Juden in der Nachkriegszeit innerhalb kurzer Zeit zahlreiche politische Ämter besetzt. Auch in den freien Berufen seien sie überproportional vertreten gewesen. Diese - nach Ansicht Dupuis' unverhältnismäßig starke Präsenz der Juden im politischen wie im wirtschaftlichen Leben sei die Ursache für den Antisemitismus, den die Wirtschaftskrise ausgelöst habe. Für Hitler bot diese Situation die Grundlage seines Rassismus, den Dupuis im folgenden anhand der deutschen - ungekürzten - Erstausgabe von Mein Kamp $f$ darlegte, ohne jedochauf die jüdisch-bolschewistische Verschwörungstheorie einzugehen. Er zeigte auf, wie Hitlers Antisemitismus aus seinen persönlichen Erlebnissen in Wien erwacht war und daraufhin sein Nationalismus auf der Basis des Rassegedankens an Kontur gewonnen hatte. Das „Bewußtsein“ von der Andersartigkeit der Juden und die Wahrnehmung einer spezifisch deutschen Identität waren seiner Ansicht nach bei Hitler nicht zu trennen $^{226}$.

Besonders aufschlußreich sind die Überlegungen Dupuis' zu den Konsequenzen der antisemitischen Politik nach der Machtergreifung. Sie geben Einblick in die Entwicklungsmöglichkeiten, die ein sehr gut informierter Beobachter des Nachbarlandes 1937 für denkbar und, was in diesem Fall noch wichtiger ist, für undenkbar hielt. Dupuis urteilte in genauer Kenntnis einerseits der deutschen Rassentheorien von der Gobineau-

222 Rebatet, der den von Daniel-Rops herausgegebenen Band als Machwerk der "roten Katholiken“ bezeichnete, nahm ausdrücklich den Artikel über die deutschen Juden aus. Dupuis hat "die logische und insgesamt kluge Konzeption des Status der Juden in Hitlers Deutschland aufgezeigt “". Rebatet, Juifs et catholiques, in: JSP, H. 384, 1938, S. 8.

${ }^{223}$ Vgl. Kulka, Geschichtsschreibung, S.607f.

${ }^{224}$ Dupuis, Hitler et les Juifs, in: Les Juifs, S. 27.

225 Ebenda, S. 28.

226 Ebenda, S. $31 \mathrm{ff}$. 
Rezeption über Houston Stuart Chamberlain bis zu Alfred Rosenberg und andererseits der nationalsozialistischen Gesetzgebung vom sogenannten Arierparagraphen bis hin zu den Nürnberger Gesetzen. Merkwürdigerweise erwähnte er mit keinem Wort die Existenz der Konzentrationslager, von denen er als gut informierter Beobachter unweigerlich gewußt haben muß. Bereits 1935 war die französische Übersetzung eines Berichtes erschienen, in dem ein geflohener KZ-Häftling von seiner Gefangenschaft berichtete ${ }^{227}$.

In Hitlers Stellungnahmen sah Dupuis zwei Wege angelegt: die „radikale" Lösung zielte auf eine massive Vertreibung der Juden aus Deutschland, die andere auf ihre Isolation im öffentlichen und privaten Leben. Eine systematische und massenhafte Vernichtung konnte er sich wie die meisten seiner Zeitgenossen zu diesem Zeitpunkt nicht vorstellen, obwohl er selbst eine Passage zitiert hatte, in der Hitler - legt man eine intentionalistische Deutung des Holocaust zugrunde - diesen Gedanken zumindest angedeutet hatte. „Hat Hitler nicht in Mein Kampf konstatiert, ,daß es keine Verfolgung [der Juden] gibt, die in ihrer definitiven Vernichtung mündet'. Es scheint, daß diese radikale Lösung nie praktisch umgesetzt werden sollte. “228 Zumindest deutete Dupuis die Möglichkeit an, daß Hitler den Holocaust theoretisch erwogen hatte 229 .

Aber selbst an eine vollständige Vertreibung aus Deutschland konnte Dupuis nicht glauben, da sie auf unüberwindbare äußere wie innere Widerstände stoßen würde ${ }^{230}$. Hingegen sah er die zweite, weniger radikale Lösung seit der Machtergreifung in die Wege geleitet und mit den Nürnberger Gesetzen 1935 verwirklicht: Dupuis sprach in Anlehnung an den zynischen Begriff der Nationalsozialisten von einer "Koexistenz" von Juden und Ariern. „Man kann diese Konzeption - und diese Praxis - empörend, unmenschlich und barbarisch finden. Doch es wäre völlig falsch, in dem Begriff der ,Koexistenz' einen Euphemismus zu sehen, der nur eine brutale Tyrannei verdecken soll." ${ }^{231}$ Dupuis ging es vorwiegend darum, die Vorwürfe gegen die nationalsozialistische Judenpolitik zu entkräften. Er bezeichnete sie als ein aufrichtiges ${ }^{232}$ Mittel, um die „Benachteiligung" der Arier gegenüber den Juden aufzuheben und somit die wachsenden Konflikte zwischen beiden Rassen zu vermeiden. „Die Nationalsozialisten haben unzweifelhaft dazu beigetragen, diesen Konflikt zu verschärfen, dies läßt sich nicht leugnen. Doch sie haben eine Lösung entwickelt, besser gesagt, sind sie gerade dabei, eine Lösung zu entwickeln oder vielmehr den Versuch einer Lösung. " 233 Dupuis verglich die Situation in Deutschland mit einem Rückfall ins Mittelalter, einer Wiederkehr des Ghettos ${ }^{234}$. Jedoch

${ }^{227}$ Langhof, Les soldats du marais. Das Buch war im selben Verlag, Plon, erschienen wie der Sammelband Les Juifs. ON-Mitarbeiter Pierre Prévost berichtet, er habe im Frühjahr 1937 von der Existenz des KZ Dachau erfahren, Prévost, Rencontres, S. 23.

${ }^{228}$ Dupuis, Hitler et les Juifs, in: Les Juifs, S. $39 f$. Hervorhebung von mir. Zu den Forschungskontroversen um die Deutung des Holocaust vgl. Hildebrand, Das Dritte Reich, S. $202 \mathrm{ff}$.

229 Der Gedanke der intendierten Vernichtung war erstmals 1939, also nach den Novemberpogromen, in den systematischen Analysen der nationalsozialistischen Rassenpolitik von Konrad Heiden und Gustav Warburg formuliert worden; vgl. Kulka, Geschichtsschreibung, S. 608.

${ }^{230}$ Dupuis, Hitler et les Juifs, S. 39 f.

231 Ebenda, S. 41.

232 "indiscutablement sincère“, ebenda, S. 43.

233 Ebenda.

${ }^{234}$ Eine Vorstellung, die auch von bedeutenden jüdischen Historikern geteilt wurde, vgl. Ringelblum, Notes from the Warsaw Ghetto, S. 82. 
entließ er die Nationalsozialisten weitgehend aus der Verantwortung, indem er das , jüdische Problem" vom Produkt der Propaganda zu objektiver Geltung erhob. Das Interpretationsschema, das Dupuis dem Konflikt zugrunde legte, trägt deutlich die Spuren seiner Herkunft aus den französischen Debatten. Die These von der Überrepräsentation der Juden im öffentlichen Leben und in der Politik bildete das Leitmotiv der antisemitischen Agitation, die die Hetzpropaganda von der „jüdischen Republik“ nährte. Durch diese scheinbare Parallele der französischen Situation in der Phase der Volksfront mit derjenigen in Deutschland konnte wiederum die nationalsozialistische Judenpolitik, die Dupuis zumindest als Lösungsansatz gewürdigt hatte, eine Orientierung für das eigene Land bieten.

Die antisemitischen Äußerungen beschränkten sich beim Ordre Nouveau auf solche Einzelfälle. Insgesamt ist die Gruppierung während der Volksfront nicht von der Radikalisierung erfaßt worden. Größeres Gewicht erhalten die genannten Beispiele allerdings dadurch, daß sie von drei Mitgliedern des Direktionskomitees stammten, die maßgeblich an der Ausarbeitung der Ideologie der Gruppierung beteiligt waren. Eine zweifellos zentrale Bedeutung kam dem Gedanken des Föderalismus im Denken des Ordre Nouveau zu. In der folgenden Analyse wird keineswegs die These vertreten, der Föderalismus der Gruppierung sei antisemitisch gewesen. Jedoch soll gezeigt werden, daß er als Gegenentwurf zum Liberalismus zugleich die obengenannten Elemente der Kritik an den Juden in sich aufnahm.

Wiederholt hat der Ordre Nouveau neben den historisch-kulturellen und den geographischen Faktoren auch die ethnische Zugehörigkeit als konstitutives Element der regionalen Gemeinschaft hervorgehoben. Die Region (patrie) als konstitutives Element des personalistischen Föderalismus bildete zugleich eine zentrale Bezugsgröße des Menschen: in der Bindung an die heimischen Sitten und Bräuche, an die Geschichte, die Landschaft und die Abstammungsgemeinschaft sollte der Mensch seine jeweils unverwechselbare Identität finden. Als eine „organisch“ über Jahrhunderte hin gewachsene politische, wirtschaftliche und soziale Gemeinschaft formte sie nach Auffassung des Ordre Nouveau die Menschen nicht nur in geistig-kultureller, sondern eben auch in physischer Hinsicht. „Dieses Streben - das sich in der Religion, der Sprache, den Künsten, den Wissenschaften und der Lebensart ausdrückt - ist ebenso vielfältig wie das Klima und das Land. Es ist in gewisser Weise Ausdruck des Kontaktes des Menschen mit seiner Umwelt. Dieser Kontakt kann nur dann wirklich fruchtbar sein, wenn der Mensch seinem Boden und seiner ursprünglichen Gemeinschaft verbunden bleibt. " 235

Die Formulierung einer ethnischen Gemeinschaft war nur eines unter mehreren Kriterien. Daher führt die von John Hellman ohne nähere Begründung gebrauchte Charakterisierung des Föderalismus von Ordre Nouveau als „völkisch“ in die Irre ${ }^{236}$. An keiner Stelle wurde die Rassenzugehörigkeit zum konstitutiven Element einer Volksgemeinschaft erhoben oder die Überlegenheit einer Rasse über eine andere behauptet. Wiederholt distanzierten sich die Ordre Nouveau-Redakteure von den pseudobiologischen Im-

${ }^{235}$ Dupuis, Le problème de l'Europe et la question de l'Etat, in: Plans, H. 7, 1931, S. 13f.

${ }^{236}$ Hellman, Mounier, S. 62; vgl. weitere Belege: L'action, in: Plans, H. 10, 1931, S. 154; Marc/Chevalley, in: Revue du siècle, H. 2, 1933, S. 4; Dupuis/Marc, Le Fédéralisme révolutionnaire, in: Esprit, H. 1, 1932, S. $318 f$. 
plikationen der Rassenlehre ${ }^{237}$. Diese Vorstellungen wurzelten vielmehr im Patriotismus eines Maurice Barrès und Charles Péguy, die dem Gedanken an die Prägung durch die Vorfahren und die heimatliche Erde Ausdruck verliehen hatten. Für Marc war das Vaterland „die Erde, in der Toten ruhen und auf der die Lebenden die ,Rasse“ der Verstorbenen fortbestehen lassen“238. Unübersehbar bezog sich diese Vorstellung auf den vergangenheitsorientierten Kult „der Erde und der Toten“, wie ihn Barrès in Les Déracinés begründet hatte 239 .

In dieser Gedankenwelt waren die über Jahrhunderte gewachsenen Bindungen konstitutiv für die Identität des Menschen und bildeten das Fundament einer funktionierenden solidarischen Gemeinschaft. Diese „organische“ Ordnung wurde durch die „abstrakten“ Ideale des Liberalismus bedroht, die den Menschen seiner natürlichen Bindungen berauben und zur bloßen Zahl in einer anonymen Masse degradieren. Der Zerfall des sozialen Konsenses und die „Entwurzelung“ des Menschen galten nur als zwei Seiten desselben Phänomens, das in der Revolution seinen Ausgang genommen hatte. Unter Berufung auf Péguy richtete Daniel-Rops seine Kritik gegen das republikanische System, das auf dem Boden dieser Ideen gediehen war: „An Stelle der Zivilisationen, die den Menschen von seinen Ursprüngen trennen, wie Péguy gesagt hätte, die sein Vaterland in seiner abstraktesten und zentralisiertesten Form begreifen, suchen wir nach einer stärkeren Verwurzelung des Menschen in seiner Region, das heißt im sinnlichen Rahmen seiner menschlichen Erfahrung. “240 Mit der Betonung der vielfältigen Bindungen des Menschen waren dem Freiheitsideal Grenzen gesetzt. In Anlehnung an die Kritiker des „entwurzelten“ Intellektualismus, Barrès und Péguy, legte auch der Ordre Nouveau Wert auf die Relativierung der Idee von der Freiheit des Willens und des Denkens. Alle schöpferische Tätigkeit blieb demnach abhängig von dem Kontext, in dem sie entstanden war: von Herkunft, Milieu und Mentalität ${ }^{241}$.

Trotz dieser deutlichen Anknüpfungspunkte erschöpften sich die Vorstellungen des Ordre Nouveau nicht in einer Neuauflage von Barrès' Nationalismus. Die Relativierung des Freiheitsbegriffes richtete sich zwar ausdrücklich gegen ein Grundprinzip von 1789, sie führte aber nicht in den für Barrès typischen Determinismus, der die Unveränderlichkeit dieser Bindungen behauptete, die jeden Versuch des Ausbrechens unweigerlich zum Scheitern verurteilten. Dieser resignierte Pessimismus war dem Ordre Nouveau ebenso fremd wie der vergangenheitsfixierte Revanchismus mit seinen machtstaatlichen

${ }^{237}$ Dupuis, Révolution et patrie, in: Plans NS, H. 2, 1932, S. 8-11, hier S. 9; Chevalley/Glady [Marc], Mort des partis, in: ON, H. 4, 1933, S. 24.; vgl. die Kritik am nationalsozialistischen Rassismus: Chevalley, Destin de l'Etat ou Mission de la France, in: ON, H. 11, 1934, S. 9f.; ders., Distinctions nécessaires, in: ON, H. 25, 1935, S.4f.

${ }^{238}$ Marc, Patrie - Nation - Etat, in: ON, H. 32, 1936, S. 28-42, hier S. 30.; ähnlich Aron/Dandieu, Décadence, S. $185 \mathrm{ff}$.

${ }^{239}$ Ausdrücklich verweist Daniel-Rops auf Barrès als Vorbild in: Années tournantes, S. 221ff.; vgl. Curtius, Barrès, S. 136f.; Sternhell, Barrès, S. 282ff.; Barral, La patrie, S. 109ff.; Rossi-Landi, La région, S. $83 \mathrm{f}$.

${ }^{240}$ Daniel-Rops, Positions générales, in: Revue française, H. 4, 1933, S. 492.

${ }^{241}$ Der Begriff der Mentalität wurde von Barrès als Gegenkonzept zu dem des „freischwebenden“ Intellektuellen geprägt, vgl. Raulff, Geburt, S. 50-68. 
Forderungen ${ }^{242}$. Der personalistische Föderalismus erschöpfte sich nicht in dem Rückblick in die Vergangenheit, sondern bezog daraus seinen Impuls zur Veränderung der Verhältnisse. Er betonte stärker die wechselseitigen Einflüsse von Mensch und Gesellschaft und setzte die Möglichkeit zur Veränderung voraus. Die Energie, die der Mensch aus seinen vielfältigen Bindungen schöpfte, sollte der Revolution die notwendige Dynamik verleihen und eine erneute gesellschaftliche Erstarrung verhindern.

Dieser Föderalismus betonte die Verschiedenheit der regionalen Gemeinschaften. Nach Absicht seiner Schöpfer sollte er einen Gegenentwurf zum republikanischen Zentralismus bilden, der als institutionalisierte Form des Gleichheitsgedankens die historisch gewachsene Vielfalt der sozialen Beziehungen unterdrückte. Daniel-Rops zufolge hatte die Republik den Menschen seiner "natürlichen“ Lebensgrundlagen - Familie, Beruf und Herkunft - beraubt und ihn zu einem gesichts- und geschichtslosen Bürger gemacht. Die Entfremdung zwischen Mensch und Staat sei mit der Einführung des Gleichheitspostulats in den Menschenrechten eingeleitet worden: „Der Mensch hat aufgehört, in politischer Hinsicht Mensch zu sein, das heißt, ein Lebewesen, das mit Familie, Boden und Beruf verbunden ist. Er ist ,gemäß den einfachen und unbestreitbaren Prinzipien der Deklaration der Menschenrechte ein anonymer und austauschbarer Bürger geworden, dessen einziger Wert aus dem Wahlzettel erwächst, ebenso anonym und austauschbar [...]: Dort, wo der Geist ohne Wurzeln ist, wird er, wie wir wissen, schnell unfruchtbar." ${ }^{243}$

Noch einen Schritt weiter ging Rougemont. In seiner Politique de la Personne lehnte er den Gleichheitsgrundsatz ab, weil er in die Forderung nach „Egalisierung um jeden Preis" münde und somit geradewegs zu Unterdrückung und Tyrannei führe ${ }^{244}$. Mit der im Gleichheitspostulat begründeten Tendenz zur Nivellierung sah Rougemont vielmehr die Formen einer totalitären Diktatur angelegt. Der Liberalismus hatte sich demnach als der größte Feind des Freiheitsprinzips erwiesen. Er war in seinen Augen nicht nur der Ausgangspunkt, sondern die geistige Grundlage aller Diktaturen. Im Juni 1938 schrieb er: „Die vorrangige Aufgabe der Intellektuellen, die die totalitäre Bedrohung (von rechts und links) begriffen haben, ist nicht, irgendeinem, Antifaschismus' anzuhängen, sondern das Denken zu bekämpfen, aus dem Faschismus und Stalinismus zwangsläufig entstanden sind: das liberale Denken." 245

Die Betonung der ethnischen Bindung untermauerte somit diese Fundamentalkritik am Liberalismus, indem sie eine seiner Grundlagen in Frage stellte. Das Postulat der politischen Gleichberechtigung war demnach eine gefährliche Illusion, die zu Egoismus, Interessenpolitik und Machtmißbrauch verführte. Die im personalistischen Föderalismus angelegte Grundforderung, der Verschiedenheit der Menschen Rechnung zu tragen, richtete sich somit nachdrücklich gegen das liberale Repräsentativsystem, das nach Auffassung des Ordre Nouveau Mensch und Staat voneinander entfremdete und den gesellschaftlichen Konsens zerstörte (wirtschaftlich hingegen sah er mit der Planwirtschaft und der Garantie des Existenzminimums, wie oben erwähnt, gerade die Gleichberechti-

${ }^{242}$ In dieser Hinsicht hat Rougemont recht, wenn er die Distanz zu Barrès betont, vgl. Rougemont,

Vorwort zu Aron, Fragments, S. IV; vgl. zum Begriff der Freiheit Aron, Dictature, S. 14f., 207.

${ }^{243}$ Daniel-Rops, Ce qui meurt, S. 104.

${ }^{244}$ Rougemont, Politique de la personne, S. 176f., Zitat S. 176.

${ }^{245}$ Rougemont, Trop d'irresponsables s'engagent, in: ON, H. 42, 1938, S. 22. 
gung vor). Zugleich aber tendierte dieser Regionalismus dazu, den vom Ordre Nouveau so heftig bekämpften chauvinistischen Nationalismus lediglich in einer kleineren territorialen Größenordnung wieder einzuführen. In der Wendung gegen den Nationalstaat zeigte sich die Tendenz, der Region die politischen Funktionen, aber vor allem die affektiven Bindungen zuzuschreiben, die dem Staat abgesprochen wurden. Mit dem Betonen kultureller und ethnischer Kriterien versuchte der Ordre Nouveau das Bewußtsein der Gemeinschaft zu stärken, schärfte aber zugleich die Wahrnehmung der Differenzen zwischen den verschiedenen Volksgruppen. Dieser Gedanke der Verschiedenartigkeit förderte, auch wenn dies nicht beabsichtigt war, durch die Betonung der kulturellen Identität fast notwendigerweise auch Ressentiments und Vorstellungen der Über- bzw. Unterlegenheit. Auf diese Weise konnte der Regionalismus leicht das Gegenteil dessen bewirken, wozu er dienen sollte: statt zur Integration trug er dann zu Haß und Segregation bei; an die Stelle des Zusammenlebens verschiedener Volksgruppen trat deren Trennung. Tendenziell legitimierte diese Form des Regionalismus eine ethnopluralistische Ordnung.

In beiden Gruppierungen spielten antisemitische Ressentiments nur eine akzidentielle Rolle. Auch wenn sie wie bei der Jeune Droite seit 1936 eine deutlich aggressive Form annahmen, so hatten sie keinen Einfluß auf die Entwicklung der Ideologie. In diesem Punkt läßt sich die Jeune Droite deutlich von der gegenrevolutionären Rechten abgrenzen, die von der Idee einer jüdischen Verschwörung beherrscht war. Vielmehr erweist sich der Antisemitismus als eine Sonderform des Antiliberalismus ${ }^{246}$. Obwohl sich die positiven Entwürfe beider Gruppen stark unterscheiden, läßt sich doch in Neonationalismus und Föderalismus beziehungsweise Antizentralismus diese gemeinsame Wurzel ausmachen. Hier liegt der Schlüssel für die Verurteilung aller anderen Ideologien, die durch den Liberalismus "kontaminiert“ worden waren: des traditionellen Nationalismus ebenso wie des reformistischen Sozialismus. Der Marxismus schließlich war als Reaktion auf den Liberalismus nur ein abgeleitetes Phänomen ohne eigenen Ursprung. Vor allem aber handelte es sich um eine fremde Ideologie, die zum Teil dem germanischen, vor allem aber dem russischen Kulturkreis zugeordnet wurde.

In ihrem Bemühen um eine Erneuerung des politischen Denkens knüpften sowohl die Jeune Droite als auch der Ordre Nouveau an spezifisch nationale Traditionen an. Den unumstößlichen Bezugspunkt ihres politischen Koordinatensystems bildete die Französische Revolution: Sowohl im Positiven wie im Negativen bezeichneten die Ideen von 1789 den Ausgangspunkt ihres Denkens. Im Liberalismus bekämpften die Intellektuellen den inneren Feind, der für den Niedergang Frankreichs verantwortlich gemacht wurde. Nur eine neuerliche Revolution konnte das liberale System beseitigen. Die Haltung beider Gruppierungen war bestimmt von einer charakteristischen Ambiguität: Sie verurteilten die Folgen von 1789 und bejahten gleichzeitig das revolutionäre Prinzip als Voraussetzung politischen Wandels. Mit anderen Worten: Den dem Liberalismus zugeordneten Idealen der Freiheit und der Gleichheit setzten sie das revolutionäre Ideal der Brüderlichkeit entgegen. Diese doppelte Argumentation trennte sie eindeutig von der gegenrevolutionären Rechten (Action française und Umfeld), andererseits ermöglichte sie die Öffnung zur revolutionären Linken (Syndikalismus).

246 Vgl. Sternhell, Roots, S. 103-134. 


\section{Das Ende der Volksfront}

Mit dem Scheitern der Reformen und der Krise der Volksfront Ende 1937 mehrten sich die Überlegungen zu einer Wiederbelebung der Rassemblement-Idee von 1935, die mit dem erwarteten Ende der Volksfront neue Aussichten auf Erfolg zu haben schien. Mit der Distanzierung von der Volksfront entwickelte Bergerys Front Social ein eigenes Sammlungsprogramm, das sich sowohl an die Kreise der Sozialisten und der C.G.T. als auch an den PPF von Doriot richtete ${ }^{247}$. Ein erster Schritt zu diesem Unternehmen war die Zusammenarbeit mit dem Ordre Nouveau, die durch den Beitritt Arons konkrete Formen annahm. Zum Einstand erörterte Aron die Voraussetzungen für den nationalen Aufbruch: „Die französische Sammlungsbewegung wird das Werk derer sein, die außerhalb der politischen Organisationen von gestern (Ligen oder Parteien) stehen und überzeugt sind, daß Frankreich keinen Grund hat, sich mit vorschnellen oder aussichtslosen Lösungen abspeisen zu lassen, daß Frankreich zweifellos die einzige Hoffnung der Welt, der Menschheit ist.“248

In kurzer Zeit gewann Aron großen Einfluß auf die politischen Leitlinien des Front social. Neben den Artikeln Bergerys und Jean Mazes erschienen immer häufiger diejenigen Arons auf den ersten Seiten des Blattes. Die endgültige Niederlage der Regierung Blum im April 1938 gab ihm Gelegenheit zu einer vernichtenden Abrechnung mit der Sammlungspolitik der letzten zwei Jahre. Er beschuldigte Blum, mit seiner Reformpolitik grundsätzlich gescheitert zu sein. Schlimmer noch: die Volksfront war nach Ansicht Arons die eigentliche Wegbereiterin des Faschismus. Durch die Enttäuschung der Hoffnungen habe die Regierung Blum das Klima für einen faschistischen Umsturz bereitet ${ }^{249}$. Als wenig später Daladier sein Kabinett der "nationalen Konzentration" unter Ausschluß der Sozialisten bildete, blieb ihm daher nur übrig, diese Gefahr vorläufig als gebannt zu betrachten. Aron bekundete sein Desinteresse an der neuen Regierung und mahnte die Leser von La Flèche, das Ziel der Revolution nicht aus den Augen zu verlieren. "Wir scheren uns nicht darum, nicht aus Resignation oder Überdruß, sondern mit all unserer Wut und unserem Glauben an das Vaterland."250

Auch von seiten der Royalisten kamen deutliche Signale für eine Unterstützung der Sammlungsbestrebungen. Der Herzog von Guise - der Vater des Thronprätendenten hatte seine Bereitschaft bekundet, sich von der Bindung an die extreme Rechte zu lösen und alle nationalen Kräfte zu integrieren. Deutliches Zeichen für diese Neuorientierung war der Bruch des Hauses Orléans mit der Action française. Mit seinem im Courrier Royal veröffentlichten Manifest hatte der Herzog im November 1937 den Eklat provoziert, indem er Maurras vorwarf, durch seine polarisierende Polemik die Integrationsbemühungen der Monarchisten zum Scheitern gebracht zu haben: Mit seinen nationalistischen Parolen, so der Herzog, habe sich Maurras immer deutlicher einer Form des Cäsarismus angenähert, der von den Ideen seiner Hauptfeinde, der Jakobiner, inspiriert sei ${ }^{251}$.

\footnotetext{
247 Burrin, Dérive, S. 229.

${ }^{248}$ Aron, Conditions d'un rassemblement français, in: Flèche, H. 104, 1938, S. 1f., Zitat S. 2.

${ }^{249}$ Aron, L'abdication de Léon Blum, in: Flèche, H. 113, 1938, S. 1 f.

250 Aron, On s'en fout!, in: Flèche, H. 114, 1938, S. 1; vgl. Cointet, Marginaux, S. 262.

251 Duc de Guise, Manifeste aux français, in: Courrier Royal, H. 126, 1937, S. 1; ders., Mise au point, in: Courrier Royal, H. 127, 1937, S. 1; Weber, Action française, S. 403f.
} 
Die Initiative der Royalisten unterstützte Daniel-Rops in Temps présent. Auch er sah die Chance für eine Integration des gesamten Volkes durch die Versöhnung der republikanischen mit der monarchistischen Tradition Frankreichs. Nur eine nationale Revolution konnte seiner Ansicht nach die Spaltung überwinden. Allerdings galt die Sympathie Daniel-Rops' eher der tausendjährigen Monarchie als den hundertfünfzig Jahren revolutionärer Tradition. Von den politischen Errungenschaften der Revolution distanzierte er sich weitgehend und verurteilte insbesondere ihren radikalen Laizismus. Die Dynamik des Jakobinismus würdigte er insofern, als er darin ein Wiedererwachen des alten nationalen Bewußtseins der Jeanne d'Arc erblickte. Daniel-Rops rief Republikaner und Monarchisten dazu auf, mit dem Blick auf das gemeinsame Ziel die politischen Gräben zu überwinden. „Die nationale Ehre und Größe ist über dieses widerliche verbale Säbelrasseln erhaben." 252

Aron beobachtete in La Flèche die Initiative des Courrier Royal mit kritischer Sympathie. Er begrüßte den Bruch mit Maurras als Beginn einer Rückbesinnung auf die ursprünglich integrative Funktion der Monarchie. Die Stärkung des Föderalismus und die Garantie kommunaler Autonomie, die der Ordre Nouveau zu zentralen Forderungen erhoben hatte, glaubte Aron in einer Monarchie verwirklichen zu können, die gleichzeitig die politische Einheit und die lokale Selbstverwaltung garantierte. Deshalb meinte er, $\mathrm{daß}$ sie auch für den revolutionären Syndikalismus die geeignete Herrschaftsform sei ${ }^{253}$.

Auch der Courrier hatte bereits seine grundsätzliche Aufgeschlossenheit gegenüber dem Front social signalisiert, freilich unter der Voraussetzung, daß Bergery nicht nur mit der Volksfront, sondern grundsätzlich mit dem Parlamentarismus breche. Man glaubte sogar, aus den Reden Bergerys Ansätze zu einer Fundamentalkritik heraushören zu können. „Sicherlich hat sich Bergery nicht vollständig von den Gemeinplätzen dieser verbalen Dialektik distanziert, die gewissermaßen die illegitime Frucht der Demagogie der Radikalen und des marxistischen Dogmatismus sind. Er bedient sich noch immer nicht ohne Unbehagen - abgedroschener Klischees wie dem der ,zweihundert Familien“, er predigt die hohen Tugenden der Verstaatlichung, aber die Zwischentöne seiner Stimme und seiner Äußerungen verraten eine gewisse Unabhängigkeit, die ihn suspekt und unerwünscht erscheinen lassen. Es scheint, daß der Anführer des ,Frontisme ' im Grunde das Parlament verachtet. “254

Der Autor dieser Zeilen war niemand anderes als Xavier de Lignac, Anhänger des Ordre Nouveau, der unter dem Pseudonym Chauveau seit August 1936 regelmäßig für den Courrier Royal schrieb ${ }^{255}$. Lignac nutzte diese Gelegenheit, um die Ideen des personali-

${ }^{252}$ Daniel-Rops, Refaire la France, in: TP, H. 17, 1938, S. 1/5; Zitat S. 1.

${ }^{253}$ Aron, Crise du nationalisme, in: Flèche, H. 97, 1937, S. 3. Gerade auf die ursprünglich föderalistische Orientierung der Action française vor der Jahrhundertwende hat auch Alexandre Marc hingewiesen. Er betonte die völlige Übereinstimmung dieser Ideen mit denjenigen vom Ordre Nouveau, Marc, De Charles Maurras à Pellisson, in: ON, H. 40, 1937, S. 51-53; vgl. auch L. Ollivier, L'Idée de Décentralisation (1898), par Charles Maurras, in: ON, H. 24, 1935, S. 46-48.

${ }^{254}$ Chauveau [Lignac], La lente agonie du régime parlementaire, in: Courrier Royal, H. 99, 1937, S. 6.

${ }^{255}$ Unter demselben Pseudonym begann Lignac 1949 seine Karriere im gaullistischen Rassemblement du Peuple Français (R.P.F.), in dem er mehrere leitende Ämter innehatte, vgl. Loubet del Bayle, Non-conformistes, S. 420; Coston, Dictionnaire, Bd. 1, S. 246. Den Hinweis auf die Zusammenarbeit mit dem Courrier gab mir Alexandre Marc, Gespräch vom 4. 12. 1994. 
stischen Föderalismus zu verbreiten, und verdeutlichte auf diese Weise, wie weit sie sich mit denjenigen der Royalisten deckten. Seine Artikel waren von der kritischen Auseinandersetzung mit dem republikanischen Nationalismus geprägt, dessen voluntaristisches Prinzip er mit dem Hinweis auf die vielfältigen Bindungen an Geschichte, Landschaft und Herkunft relativierte ${ }^{256}$. Im Courrier bemühte sich Lignac insbesondere darum, die Gewerbetreibenden für die Monarchie zu gewinnen. Er rief dazu auf, die französische Handwerkstradition gegen den „zersetzenden“ Einfluß tayloristischer Produktionsweisen abzuschotten. Er betrachtete das Handwerk als Ausdruck einer nationalen Kultur, der kapitalistische und demokratisch-egalitäre Prinzipien fremd waren $^{257}$.

Ganz offensichtlich verfehlten diese Ideen nicht ihre Wirkung auf den Thronprätendenten, der daraufhin die Monarchie auf der Grundlage personalistischer Ideen restaurieren wollte. Zu diesem Zweck beauftragte er einen Vertrauten, einen Beraterkreis aus dem personalistischen Milieu zu bestellen. Dieser Vertraute war der Combat-Redakteur Jean Loisy, der im Namen des Grafen an Gabriel Marcel schrieb: „Er nähert sich einem Standpunkt, der ebenso weit vom demokratischen Individualismus wie von der totalitären Unterdrückung entfernt ist. Die personalistischen Theorien scheinen ihm der Wahrheit sehr nahe." 258

Im Unterschied zum Ordre Nouveau hütete sich die Jeune Droite, im Streit des Hauses Orléans mit den Monarchisten ausdrücklich Partei zu ergreifen. Das Manifest des Herzogs wurde mit keinem Wort im Combat erwähnt, jedoch deckte sich dessen Appell zur Öffnung der nationalen Bewegung weitgehend mit den Revisionsbestrebungen der Jeune Droite. Maurice Blanchot rief Kommunisten und konservative Nationalisten dazu auf, ihre Lager zu verlassen und sich gegenseitig im Kampf gegen das liberale Bürgertum zu unterstützen ${ }^{259}$. Auch die Kritik François Graviers am exklusiven Nationsbegriff der Rechten konnte als indirekte Zustimmung zum Bruch mit der Action française gelesen werden. „Was man 1937 im allgemeinen Nationalismus nennt, fügt sich sehr gut in die Definitionen marxistischer Begrifflichkeit: Es handelt sich um einen Kapitalismus mit boulangistischem Überbau. " 260

Mit einer dezidiert antikapitalistischen Programmatik versammelte der Combat seit März 1938 Sympathisanten einer antiliberalen Front. An der Umfrage zum Thema "Wie läßt sich der Staat von der Tyrannei des Geldes befreien?" beteiligten sich unter anderem Drieu la Rochelle, ein Führungsmitglied des royalistischen Unternehmerverbandes Métiers français, Le Cour-Grandmaison, aber auch Esprit-Chef Mounier, ein Vertreter des Front social, und Denis de Rougemont für den Ordre Nouveau. Mounier sah die Wurzel des Übels nicht in Demokratie und Liberalismus, sondern in einem „geistigen Imperia-

256 Vgl. Chauveau [Lignac], Avatars du nationalisme, in: Courrier Royal, H. 92, 1937, S. 3; ders., L'Esprit National?, in: Courrier Royal, H. 93, 1937, S. 3.

257 Chauveau [Lignac], Travail à la Yankee, in: Courrier Royal, H. 88, 1937, S. 3; ders., Travail à la Française, in: Courrier Royal, H. 90, 1937, S. 3.

258 BN Don 87.08, Brief Jean Loisys an Gabriel Marcel, Paris, 30.7. 1938; vgl. Volkoff, Marcel, S. 72-80.

259 Blanchot, On demande des dissidents, in: Combat, H. 20, 1937, S. 154f.

${ }^{260}$ Gravier, Deux démocraties: une seule révolution, in: Combat, H. 20, 1937, S. 152f., Zitat S. 152. 
lismus" als Resultat entfremdeter, "depersonalisierter" Gesellschaften ${ }^{261}$. Der anonym gebliebene Anhänger des Front social übte deutliche Kritik an einem Nationalismus, der es nötig habe, Chauvinismus und Fremdenhaß zu entfachen, schloß sich jedoch der Forderung des Combat nach einer nationalen Revolution an ${ }^{262}$. Rougemont präsentierte den Verfassungsentwurf vom Ordre Nouveau mit seiner zentral gelenkten Wirtschaft und einer weitgehend föderalistischen politischen Struktur als einzig wirksames Mittel zur Regeneration des Staates ${ }^{263}$. Auch die im Juni 1938 erschienene Neuauflage des Ordre Nonveau trat mit dem Anspruch auf, ein Forum für alle Bewegungen zu bilden, die sich für die revolutionäre Neuordnung Frankreichs einsetzten 264 . Sie vereinigte die Beiträge von Thierry Maulnier, Pierre Dominique von La République, Auguste Detœf von den Nouveaux Cabiers und Jean Maze, dem Chefredakteur von La Flèche.

\section{Zwischen Neopazifismus und Machtpolitik}

Mit dem Einmarsch deutscher Truppen in Österreich gerieten die Pläne einer nationalen Erneuerung verstärkt in den Sog der internationalen Entwicklung. Die aggressive Expansionspolitik Hitlers beherrschte nahezu vollständig die Debatten der letzten 18 Monate vor Kriegsausbruch. Der machtpolitische Konfrontationskurs des Dritten Reiches leitete eine Phase der Desillusionierung ein, die schließlich in die Revision des Neopazifismus und eine Rückkehr zur traditionellen Großmächtediplomatie mündete. Die Möglichkeiten zur Wahrung des Friedens wurden immer pessimistischer beurteilt, gleichzeitig trat der Gedanke der nationalen Verteidigung in den Vordergrund.

\section{Der ,Anschluß`Österreichs}

Mit wachsender Sorge betrachtete man im Combat-Kreis das machtpolitische Ausgreifen des Dritten Reiches und suchte nach Konzepten gegen eine deutsche Hegemonie. Noch kurz vor dem ,Anschluß` Österreichs waren die Überlegungen davon bestimmt, ein deutsch dominiertes Mitteleuropa zu verhindern. François Gravier sorgte sich noch im Februar 1938 vor allem um die Lage der kleinen Nachfolgestaaten des Habsburgerreichs im Südosten Europas. Er sah sie zunehmend in das Gravitationsfeld Deutschlands geraten. Durch die wachsende wirtschaftliche und diplomatische Verflechtung mit dem mächtigen Nachbarn, so fürchtete Gravier, würden sich die Machtverhältnisse zwangsläufig zugunsten des Dritten Reiches verschieben. Nur die Restauration der Donaumonarchie konnte seiner Ansicht nach ein ausreichendes Gegengewicht zum Dritten Reich bilden ${ }^{265}$.

${ }^{261}$ Mounier, Réponse, in: Combat, H. 25, 1938, S. 9f. In einer ausführlichen Besprechung von $A u$ delà $d u$ nationalisme solidarisierte sich Mounier mit dem neonationalistischen Thesen Maulniers, vgl. Mounier, Maulnier: Au-delà du nationalisme, in: Esprit, H. 69, 1938, S. 442-446.

${ }^{262}$ NN, Réponse de La Flèche, in: Combat, H. 26, 1938, S. 9.

${ }^{263}$ Rougemont, Réponse, in: Combat, H. 26, 1938, S. 8.

${ }^{264} \mathrm{NN}$, Les responsables, in: ON, H. 42, 1938, S. 1.

${ }^{265}$ Gravier, Nécessité de l'Autriche-Hongrie, in: Combat, H. 22, 1938, S. 10 f. 
Frankreich trug nach Ansicht Blanchots die Schuld für das Ausgreifen Deutschlands, da es sich der Restauration widersetze. Dies wiege besonders schwer, da Frankreich durch das selbstverschuldete Scheitern der Kleinen Entente die Verantwortung für die Machtverschiebungen in Mitteleuropa trage ${ }^{266}$. Erneut zielte die Kritik auf die Versailler Ordnung: erst sie habe das Machtvakuum entstehen lassen, das Deutschland für seine Expansion nutzen konnte.

Der Einmarsch Hitlers in Österreich am 12. März 1938 bestätigte die Befürchtungen des Combat, für den die offene Revisionspolitik Hitlers ein weiteres Mal die Schwäche der internationalen Diplomatie und das Versagen Frankreichs demonstrierte. Der Entrüstungssturm, den der ,Anschluß` im eigenen Land auslöste, wurde als Heuchelei abgetan: die Linke sei durch ihren Antifaschismus ideologisch verblendet, die traditionelle Rechte kaschiere ihre Minderwertigkeitskomplexe. Die unversöhnliche Haltung gegenüber Deutschland, wie sie in diesen beiden Lagern gefordert wurde, verurteilte Maulnier als Kriegshetze. Er mußte zwar zugeben, daß der ,Anschluß` auf gefährliche Weise das europäische Gleichgewicht und damit insbesondere die Interessen Frankreichs verletze. Doch gebe dies keinesfalls Anlaß, einen Konflikt mit dem Dritten Reich zu riskieren. "Aber wenn diese Wiedervereinigung der Deutschen aus Österreich mit Deutschland, unternommen von einem Österreicher - die Publikumspresse vergißt natürlich immer daran zu erinnern, daß Hitler Österreicher ist -, als barbarischer Angriff auf die internationale Moral, als neue Teilung Polens angeprangert wird, dann ist dies wirklich der Gipfel der Heuchelei in der Art und Weise von 1918.“267 Maulnier ergriff Partei für Deutschland und unterstützte dabei die nationalsozialistische Propaganda, die den ,Anschluß mit dem Hinweis auf das Nationalitätenprinzip legitimierte. Versagt hatte seiner Ansicht nach in erster Linie die europäische Sicherheitspolitik. Maulnier ging so weit, die traditionellen Nationalisten als Vaterlandsverräter zu bezeichnen, weil sie als Anhänger einer unnachgiebigen Haltung gegenüber Deutschland gemeinsame Sache mit den Linken machten und einen Krieg provozierten ${ }^{268}$.

Vincent beklagte das verzerrte Deutschlandbild in Frankreich: „Dieser Ausbruch unglaublichen und dummen Hasses, der die vergangenen Kriege charakterisierte, ist die verhängnisvolle Folge dés demokratischen Geistes, der uns lehrt, daß Krieg eine Unmöglichkeit ist, und der jeden Gegner zum Monster erklären muß, weil er eine ,unmögliche' Tat begeht." ${ }^{\text {"69 }}$ Diese Attacken auf Deutschland erinnerten ihn an die Propaganda während des Ersten Weltkriegs. Die französischen Demokraten müßten ihren Gegner zum Monster erklären, um die Aufrichtigkeit ihrer eigenen moralischen Intentionen zu demonstrieren.

Marc fürchtete, daß mit dem ,Anschluß` Österreichs die föderalistischen Pläne des Ordre Nouveau zum Scheitern verurteilt seien. Nun schien der Weg für ein von Deutschland beherrschtes Mitteleuropa geebnet. Die deutsche „imperialistische“ Konzeption von Europa drohe über die französische "universalistische“ Konzeption den Sieg davonzutragen. Doch die Schuldigen suchte auch Marc nicht jenseits des Rheins, sondern in der eigenen Regierung. In dieser Situation hielt er einen wirksamen Wider-

266 Blanchot, L'impasse, in: Insurgé, H. 6, 1937, S. 4.

${ }^{267}$ Maulnier, La mode est à l'Union sacrée, in: Combat, H. 24, 1938, S. $3 f$.

${ }^{268}$ Ebenda, S. 4.

269 Vincent, Perspectives, in: Combat, H. 24, 1938, S. 4 f. 
stand gegen Deutschland für zwecklos, betonte jedoch, daß sich Frankreich für zukünftige Schläge rüsten müsse: als nächstes Ziel der deutschen Expansion, darüber gab es in Frankreich kaum Zweifel, stand die verbündete Tschechoslowakei auf dem Plann ${ }^{270}$.

Auch Aron konstatierte in La Flèche die Unfähigkeit Frankreichs, Hitlers Expansionsdrang zu bremsen. Als Gegengewicht schlug er eine Föderation der Donaustaaten vor und griff damit ein Projekt auf, das Philippe Lamour und René Dupuis bereits 1931 als Antwort auf das Briand-Memorandum präsentiert hatten. Unter der Führung Ungarns sollten sich Jugoslawien, Rumänien und die Tschechoslowakei verbünden und sich zu einem supranationalen Bundesstaat zusammenschließen. Auf diese Weise glaubte Aron, Hitler von einem weiteren Ausgreifen nach Südosteuropa abhalten zu können ${ }^{271}$.

Rougemont versuchte in seiner Nachschrift zum Journal d'Allemagne, die er unter dem Eindruck von Hitlers Einmarsch in Österreich verfaßt hatte, die Ursachen für die Faszination des Nationalsozialismus zu ergründen. Der überwiegend freudige Empfang, den die österreichische Bevölkerung den deutschen Truppen bereitet hatte, bestärkte ihn in der Ansicht, daß das Dritte Reich nicht so sehr als Terrorregime, sondern als Erlösung empfunden wurde. Eine Erklärung für die Anziehungskraft des Dritten Reiches fand er in dem religiösen Stil der Herrschaft, für den die Menschen durch die fortschreitende Säkularisation anfällig geworden seien. Orientierungslosigkeit, innere Leere und die Suche nach einem Sinn trieben Rougemont zufolge die Menschen in die Arme des Diktators, der ihnen Erlösung und Heil versprach: Nicht die Person des Führers, auch nicht die Ideologie bestimme den Charakter des Regimes, sondern die Mechanismen von Entfremdung und freiwilliger Unterwerfung, wie sie für alle totalitären Systeme charakteristisch seien. Diese fatale Logik führte, wie Rougemont meinte, zwangsläufig in den Krieg, durch den ein totalitärer Staat dem Nachbarland seine eigenen Gesetze aufzwingen wollte. „Aus einem totalen Krieg, in den uns Deutschland hineinzieht, kann nichts anderes als ein totalitärer Staat entstehen. Daher geht es darum, diesen Krieg zu verhindern, stark genug zu sein, um ihn zu verhindern, und auf diese Weise das gegnerische Regime zu einer ,Selbstzerstörung seiner kriegerischen Energien' zu verurteilen. " 272 Rougement fürchtete, daß Frankreich in dem Versuch, den Nationalsozialismus mit seinen eigenen Mitteln zu bekämpfen, schließlich selbst im Falle eines Sieges der totalitären Herrschaft nicht entkommen könne. In der Hoffnung, daß sich die zerstörerischen Energien der Diktaturen schließlich gegen sich selbst richten würden, sah er die einzige Lösung in einem völligen Rückzug Frankreichs aus der Außenpolitik.

Sowohl die Jeune Droite als auch der Ordre Nouveau lehnten jegliche Sanktionen gegen Deutschland ab und blieben damit ihrer neopazifistischen Haltung treu, die sie spätestens seit der Ratifizierung der französisch-russischen Allianz im Februar 1936 eingenommen hatten. Aber die Begründung hatte sich gewandelt: Nicht mehr die Furcht vor dem Kommunismus hatte sie zu dieser Entscheidung bewogen, sondern die Furcht vor

270 Scrutator [Marc], Voir et juger, in: TP, H. 20, 1938, S. 2.

271 Aron, Après la pluie, le brouillard, in: Flèche, H. 112, 1938, S. If.

${ }^{272}$ Rougemont, Journal d'Allemagne, S. 67ff., Zitat S. 74. Diese Deutung des Nationalsozialismus als Ersatzreligion und die Parallelen zur Französischen Revolution hatte er während seines Frankfurter Lektorats entwickelt; vgl. ders., Jacobins en chemise brune, in: ON, H. 36, 1936, S. 1-6. 
einer Neuauflage der „Union sacrée“, die Léon Blum im Januar 1938 erstmals ins Spiel gebracht hatte und die Daladier mit dem Kabinett der „Nationalen Union“ als Antwort auf die außenpolitische Bedrohung verwirklichen wollte ${ }^{273}$. Ein solches Regierungsbündnis von den traditionellen Nationalisten bis hin zu den Kommunisten stieß auf entschiedene Ablehnung bei der Jeune Droite und beim Ordre Nouveau. Beide Gruppierungen waren überzeugt, daß mit der Bildung einer "Union sacrée“ der Krieg mit Deutschland unvermeidlich werden mußte. Beide lehnten diesen Krieg entschieden ab, weil er die innere Erneuerung Frankreichs blockiere. „Ob antifaschistisch oder nicht, der Krieg, die ,Union sacrée' wäre das Ende der sozialen Konflikte, sie wäre eine Bewährungsfrist für das soziale System, das unter dem Ansturm seiner revoltierenden Sklaven zusammenbricht, es herrschte Waffenruhe. “274 So unmißverständlich wie an dieser Stelle hatte Maulnier noch nie den Vorrang der inneren Neugestaltung Frankreichs vor der Machtpolitik formuliert.

Mit der gleichen Begründung warnte auch Rougemont vor einer Neuauflage der „Union sacrée“. Seiner Ansicht nach würden sich parlamentarische Rechte und Linke keineswegs gegenseitig ergänzen, sondern im Gegenteil jegliche Reform verhindern. Als Beleg für das Scheitern einer solchen Politik verwies er auf die Volksfront. Die Linke habe ihr soziales und wirtschaftliches Reformprogramm aufgegeben, während die Rechte die nationalen Interessen verraten habe. Rougemont zufolge drohte das Regierungsbündnis der "Union sacrée“ diese Blockade fortzusetzen und mit weiteren Zwangsmaßnahmen zu kompensieren. „Entweder wird das Chaos einziger Ausdruck unserer degenerierten Freiheiten, oder wir schaffen es, ein gemeinsames Ziel zu finden, jenseits unserer Auseinandersetzungen, ein gemeinsames geistiges Maß, nicht Aufrüstung, nicht nationale Verteidigung, sondern vor allem ein nationales Ideal.“275

\section{Das Münchener Abkommen}

Bereits unmittelbar nach dem ,Anschluß` Österreichs hatte die Jeune Droite deutlich gemacht, daß sie ebensowenig wie die übrige extreme Rechte bereit war, für die Tschechoslowakei einen Krieg zu riskieren ${ }^{276}$. Ein Engagement für den verbündeten Staat kam schon deshalb nicht in Frage, weil es sich um eine Demokratie handelte, die zudem durch einen Beistandspakt mit der Sowjetunion 1935 in den Kreisen der extremen Rechten als Einfallstor für den Kommunismus in Europa galt ${ }^{27}$.

Kaum zu verbergen war daher die Erleichterung, mit der Maulnier den Ausgang der Septemberkrise begrüßte. Maulnier rechtfertigte erneut Hitlers Vorgehen mit dem Hinweis auf das Nationalitätenprinzip: „Kein Gesetz kann drei Millionen Deutsche der

${ }^{273}$ Vgl. Micaud, French Right, S. $147 f$.

${ }^{274}$ Maulnier, La mode est à l'Union sacrée, in: Combat, H. 24, 1938, S. 4.

${ }^{275}$ Rougemont, Du danger de s'unir, in: NC, H. 23, 1938, S. 21f., Zitat S. 22. Genau derselben Ansicht war Marc, der den Artikel von Rougemont zustimmend zitierte, vgl. Scrutator [Marc], Voir et juger, in: TP, H. 25, 1938, S. 2.

${ }^{276}$ Maulnier, La mode est à l'Union sacrée, in: Combat, H.24, 1938, S. 3; Fabrègues, Bellicistes, ebenda, S. 6f.; vgl. Micaud, French Right, S. $149 f$.

277 Vgl. Maxence, Tous les partis sont coupables, in: Insurgé, H. 7, 1937, S. 1; vgl. die ähnliche Haltung der Action française, Hörling, Deutschlandbild, S. 88f. 
tschechischen Herrschaft unterstellen." ${ }^{278}$ Die Hinweise auf das Versagen der französischen Außenpolitik und die explosive internationale Situation boten einen willkommenen Vorwand, um die Sicherheitsgarantien für zweitrangig zu erklären. Er räumte zwar ein, daß die Schutzverpflichtung Frankreichs für die Tschechoslowakei noch bestehe, betonte jedoch, daß er nicht bereit sei, dafür einen Krieg mit Deutschland und folglich einen neuen Weltkrieg zu riskieren ${ }^{279}$.

Doch die Erleichterung über den gerade noch einmal bewahrten Frieden hielt nicht lange an. Der "Geist von München“, die Hoffnung, Hitler mit den Spielregeln der Diplomatie domestizieren zu können, wich bereits kurze Zeit später einer resignierten Sicht, in der die Zweifel an der Dauerhaftigkeit des Friedens überhandnahmen. Hitler war der eindeutige Gewinner dieses Kräftespiels. Der Blick auf die außenpolitische Situation erfüllte Maulnier mit äußerster Skepsis. Frankreich habe nun auch seinen letzten Verbündeten verloren, Deutschland hingegen habe sich den Weg für die Beherrschung des Ostens geöffnet: „Es gehört schon einiger Optimismus dazu, diese Ergebnisse als gleichwertig zu betrachten. “" ${ }^{280} \mathrm{Daß}$ die nationalsozialistische Außenpolitik auf einen Krieg im Osten zusteuerte, nahm die Jeune Droite bei ihrer Zustimmung zum Münchener Abkommen billigend in Kauf. Diese Haltung teilte die Jeune Droite außer mit dem Großteil der Rechten auch mit den Dissidenten der Linken, Bergery, Déat und Doriot, die einen Krieg gegen Deutschland ebenfalls um jeden Preis vermeiden wollten ${ }^{281}$.

Doch kurze Zeit später machte sich innerhalb der Jeune Droite ein wachsender Pessimismus breit. Mit der schwindenden Hoffnung auf eine friedliche Koexistenz mit dem Nachbarn Deutschland erwachte das Bewußtsein für die vitalen außenpolitischen Interessen Frankreichs. Zu Beginn des Jahres 1939 sprachen die Combat-Herausgeber von einem grundlegenden Wandel in der Einstellung zu den „faschistischen“ Regimen Italiens und Deutschlands, die nun erstmals mit demselben Maß gemessen wurden ${ }^{282}$ : „In den letzten Monaten haben beinahe alle feststellen können, daß die Zukunft der Regime, die den meisten Enthusiasmus und die meiste Hoffnung geweckt haben, möglicherweise genauso bedroht ist wie diejenige der dekadenten Regimes. In der Welt von 1938 gibt es keine Zivilisation, keine politische oder soziale Ideologie, die eine ewige Zukunft haben. Alles muß zerstört, gefestigt oder neu errichtet werden." 283 In aller Deutlichkeit sah Maulnier nun die tyrannischen Züge der beiden Diktaturen: Durch die Unterdrückung

${ }^{278}$ Maulnier, Il ne fallait pas cette guerre, in: Combat, H. 28, 1938, S. 3.

279 Ebenda, S. 3f.; vgl. die ähnlichen Überlegungen von Salleron, La France doit-elle se battre pour la Tchéchoslovaquie?, in: Combat, H.27, 1938, S. 8f.

280 Maulnier, Il ne fallait pas cette guerre, in: Combat, H. 28, 1938, S. 3.

281 Micaud, French Right, S. 163; Lacaze, Opinion publique, S. 311ff.; Weber, Action française, S. 426ff. Innerhalb des PPF stieß dieser neopazifistische Kurs Doriots auf Widerstand und führte zum Ausscheiden eines großen Teils der Führungsriege Ende Dezember 1938, darunter Paul Marion, Bertrand de Jouvenel, Yves Paringaux, Pierre Drieu la Rochelle, Pierre Pucheu, Victor Arrighi und Robert Loustau, APP Ba 1945, Berichte vom 3.1. 1939, 16. 2. 1939 sowie beiliegende Abschriften von Briefen Paul Marions an Doriot; vgl. Brunet, Doriot, S. 295.

${ }_{282}$ Bis dahin verwendete insbesondere Maulnier den Begriff des Faschismus in deutlicher Abgrenzung gegen den generalisierenden und polemischen Antifaschismus; vgl. Maulnier, Le fascisme et son avenir en France, in: Revue universelle 64/19, 1936, S. 13-26; ders., L'Etat des Forces en face de la Société Libérale, in: Combat, H.21, 1938, S. 4f.

${ }^{283}$ [Fabrègues/Maulnier] La quatrième année de Combat, in: Combat, H. 31, 1939, S. 3. 
der Meinungsfreiheit, den Antiintellektualismus, die Gewaltverherrlichung und den Militarismus drohe Italien und Deutschland der Rückfall in die Barbarei ${ }^{284}$.

Diese fundamentale Wandlung läßt sich nur teilweise mit Hitlers aggressiver Revisionspolitik erklären. Einen entscheidenden Beitrag leisteten auch die aggressiven Töne, die von der "lateinischen Schwester" seit Dezember 1938 zu vernehmen waren. Zwar hatte sich Mussolini in München erfolgreich als Vermittler zwischen den Westmächten und Hitler profiliert und wurde bei der nationalistischen Rechten als Retter des Friedens gefeiert. Doch als Anfang Dezember in der italienischen Kammer der Korporationen mit dem Herrschaftsanspruch über den "mare nostro" auch territoriale Forderungen gegenüber Frankreich laut wurden, regte sich das nationale Bewußtsein der Franzosen ${ }^{285}$.

Die Distanzierung von den vormals bewunderten Diktaturen läutete das Ende des Neopazifismus ein, der die Haltung der Jeune Droite seit dem Abessinienkrieg bestimmt hatte. Weitere Zugeständnisse an die Diktatoren durften nicht mehr gemacht werden, Frankreich mußte sich nach neuen Bündnispartnern umsehen. Allerdings vertrat Maulnier die Überzeugung, daß diese Orientierungslosigkeit Frankreichs ein Abbild seiner inneren Konflikte war: Solange sich Antifaschisten und Antikommunisten erbittert bekämpften, konnte sein Land keine glaubwürdige Außenpolitik machen. „Die einzige Möglichkeit Frankreichs, diesem Dilemma zu entkommen, ist eine innere Wandlung, die seine Institutionen und die Philosophie, auf der es basiert, an die Erfordernisse des nationalen Widerstands, des nationalen Lebenswillens und der nationalen Größe anpaßt." 286

Mit dem Hinweis auf die verschiedenen Nationalitäten, die nur durch einen ,jakobinischen Mythos der Einheit" zusammengehalten wurden, lehnten Aron, Dupuis, Rougemont und Marc ebenfalls jegliches Engagement für die Tschechoslowakei entschieden ab und unterstützten die neopazifistische Position gegenüber Deutschland ${ }^{287}$. Mit der Jeune Droite stimmte der Ordre Nouveau auch in der Ansicht überein, daß Frankreich die Hauptschuld an dem Hegemonialstreben Hitlers trage und somit das Münchener Abkommen ein notwendiger Tribut an das schlechte nationale Gewissen war.

Das Abkommen bildete ähnlich wie bei der Jeune Droite den Wendepunkt in der neopazifistischen Einstellung des Ordre Nouveau. Es bedurfte nicht erst der italienischen Territorialforderungen, um die Haltung gegenüber den Diktaturen in Frage zu stellen. Bereits während der Septemberkrise hatten die Mitarbeiter der Gruppierung nach Mitteln und Wegen gesucht, mit denen das Hegemonialstreben Deutschlands eingedämmt werden konnte. In La Flèche, den Nouveaux Cabiers und Temps présent setzte sich der Ordre Nouveau für den Entwurf eines europäischen Friedensprojektes ein, mit dem Frankreich die Handlungsinitiative zurückgewinnen sollte. Die Nouveaux Cabiers veröffentlichten in ihrer Oktoberausgabe eine Stellungnahme, die eine Liquidation der

\footnotetext{
${ }^{284}$ Maulnier, Notes sur le fascisme, in: Combat, H. 30, 1938, S. 4.

285 Vgl. Heimsoeth, Zusammenbruch, S. 69f.; Funke, Hitler, S. 365.

${ }^{286}$ Maulnier, Les nouvelles conditions imposées à l'action politique en France, in: Combat, H. 29, 1938, S. 3f., Zitat S. 4.

${ }^{287}$ Dupuis, Responsabilités du Quai d'Orsay, in: ON, H. 42, 1938, S. 15-18, Zitat S. 17; Rougemont, Journal d'une Epoque, S.347. Post-scriptum 1939. Diese Passage ist nachträglich dem Journal d'Allemagne hinzugefügt worden; Marc, Gagner la bataille de la paix, in: Grande Revue, Okt. 1938, S. 127-147, hier S. 140; Aron, Réponse à Léon la Honte, in: Flèche, H. 137, 1938, 1/4.
} 
Tschechoslowakei auf der Basis eines „europäischen Friedensstatuts, angemessen und akzeptabel für alle“, vorsah. Dieser Forderung schlossen sich nicht nur Jardin, Dupuis und Rougemont an, sondern auch zahlreiche Intellektuelle wie Alain (Emile Chartier), Jean Giono, Gabriel Marcel, Jacques Maritain, François Mauriac, Boris Souvarine, Simone Weil288. In einem eigens einberufenen Kongreß berieten die Sympathisanten der Nouveaux Cabiers über die wirtschaftlichen Grundlagen dieses Friedensplans. Auch der Front social, vertreten durch Aron und Bergery, beteiligte sich daran ${ }^{289}$.

Marc und Daniel-Rops riefen in Temps présent zur Unterstützung der Projekte der Nouveaux Cabiers und des Front social auf. Sie warnten die Franzosen davor, Hitler gewähren zu lassen und sich resigniert hinter die Maginot-Linie zurückzuziehen. Statt dessen sollte sich Frankreich um die Regelung des Friedens im Rahmen einer föderalistischen Neuordnung Europas bemühen. Die Reorganisation Mitteleuropas mußte Marc zufolge Teil eines umfassenden Plans sein, der auch die Wiederherstellung der Ordnung in Spanien, die Rückführung Danzigs an Deutschland, die Entwicklung eines europäischen Wirtschaftsplans und die Frage der Rüstungsbeschränkungen regelte ${ }^{290}$.

Das spektakulärste Projekt zur Sicherung des Friedens stammte von Aron und sah eine Wiederherstellung Großungarns vor. Es bildete einen wichtigen Bestandteil des Planes des Front social. Aron präzisierte seine bereits beim ,Anschluß' formulierten Überlegungen und schlug vor, die ungarischen Minderheiten in den Nachbarstaaten Jugoslawien, Tschechoslowakei, Rumänien und Österreich wieder dem Kernland anzugliedern. An Stelle des ehemaligen Habsburgerreichs sollte das solchermaßen gestärkte Ungarn den Kern einer neuen Donauföderation bilden, die dem Hegemonialstreben Hitlers in Mitteleuropa Einhalt gebieten sollte. Ungarn eignete sich, wie Aron unterstrich, deshalb besonders als Führungsmacht, weil es ein ethnisch relativ homogener Staat war, der über eine starke herrschende Klasse verfügte. Zudem konnte es auf eine jahrhundertealte Geschichte zurückblicken, die ihm aus Arons Sicht die notwendige nationale Legitimation verlieh. Indem Frankreich diesen Konsolidierungsprozeß unterstützte, konnte es seine guten Beziehungen zu Ungarn noch verbessern und damit einen dauerhaften und starken Verbündeten in Südosteuropa gewinnen ${ }^{291}$.

Damit waren die Föderalismuspläne des Ordre Nouveau wieder bei dem Problem angelangt, das zu Beginn des Jahrzehnts den Ausgangspunkt der Überlegungen gebildet hatte: Eine föderalistische Organisation sollte als Gegenkonzept zu den Mitteleuropaplänen das deutschen Expansionsstreben eindämmen. Deutlicher als zu Beginn der dreiBiger Jahre trat der Ruf nach einem starken Staat in den Vordergrund.

Unter dem Druck der äußeren Bedrohung näherten sich die Standpunkte beider Gruppierungen deutlich an. Die Abkehr von der neopazifistischen Haltung gab den Forderungen nach der inneren Einheit und Stärke Frankreichs neue Impulse. Die Sammlungsbestrebungen konzentrierten sich auf das Thema der nationalen Verteidigung. Maulniers Plan einer „nationalen und konstruktiven Revolution“ sah eine autoritäre Stärkung der Staatsgewalt, Aufrüstung und die Förderung der wirtschaftlichen Pro-

${ }^{288}$ In: NC, H. 32, 1938, S. 16; vgl. Sirinelli, Intellectuels et passions françaises, S. $117 \mathrm{f}$.

${ }^{289}$ Les conditions économiques de la paix, in: NC, H. 40, 1939, S. 1.

${ }^{290}$ Scrutator [Marc], Voir et juger, in: TP, H. 44, 1938, S. 2; ders., Voir et juger, in: TP, H. 45, 1938,

S. 2; Daniel-Rops, Equilibre européen ou Fédéralisme, in: TP, H. 67, 1939, S. 2.

${ }^{291}$ Aron, La Hongrie et ses Alsace-Lorraine, in: Flèche, H. 140, 1938, S. 2. 
duktion vor ${ }^{292}$. Als Reaktion auf die italienischen Territorialforderungen setzte er sich zudem für eine Intensivierung der Kolonialpolitik ein. Maulnier hielt daran fest, daß sich Frankreich in diesen äußeren Aspekten der Herrschaft an der Effizienz der Diktaturen orientieren müsse. Doch er betonte, daß dies alles zur Verteidigung einer Kultur geschehe, die durch den Faschismus bedroht werde. Die nationale Revolution sollte die humanistischen Werte bewahren, "die auf dem französischen Boden entstanden sind, sich dort entwickelt haben und die er verkörpert “" ${ }^{293}$.

Für Salleron bildete diese Rückbesinnung auf den Humanismus den gemeinsamen Ansatzpunkt der Jeune Droite und der Personalisten. Beide bekämpften mit der Betonung der menschlichen Würde und der Unantastbarkeit der Person die Ideen von 1789 und die Demokratie. Allerdings kritisierte er die Zurückhaltung der Personalisten in Fragen der Macht. „Wir brauchen die Macht, um unsere hohen Ziele zu erreichen.“294 Doch auch der Ordre Nouveau sah die Notwendigkeit der nationalen Verteidigung. Die Gruppierung hatte sich bereits seit 1935 mit militärischen Reformplänen auseinandergesetzt ${ }^{295}$. Als Leiter der Collection Présences bemühte sich Daniel-Rops Anfang 1938 erneut, den Plänen de Gaulles Gehör zu verschaffen ${ }^{296}$. Er unterstrich, daß ein starkes Frankreich die Voraussetzung für einen dauerhaften Frieden in Europa war. Nur ein militärisch wie geistig gerüstetes Land konnte als ernstzunehmender Verhandlungspartner von Deutschland akzeptiert werden ${ }^{297}$.

Angesichts der italienischen Mittelmeerpläne war auch das Thema der Kolonialpolitik nicht mehr tabu. Hatte sich der Ordre Nouveau bis dahin entschieden gegen den Kolonialismus gewandt, so revidierte zumindest Aron seine Ansicht. Nach wie vor distanzierte er sich ausdrücklich vom Imperialismus Mussolinis und hob als Besonderheit der französischen Kolonialpolitik hervor, daß sie von einer "menschlichen Mission“ inspiriert sei ${ }^{298}$. Aus dieser zivilisatorischen Aufgabe erwuchs seiner Ansicht nach geradezu die Verpflichtung, den Einfluß Frankreichs auszudehnen. Der geistige Einfluß und die territoriale Ausdehnung seines Landes mußten Aron zufolge zwar nicht deckungsgleich sein, aber sie waren auch keineswegs voneinander zu trennen.

\section{Der Einmarsch in Prag}

Der Einmarsch deutscher Truppen in Prag und die Errichtung des „Reichsprotektorats Böhmen und Mähren“ im März 1939 machten die Aussichten auf eine friedliche Koexistenz mit Deutschland vollends zunichte. Das Vorgehen Hitlers zerstörte auch die letzten Hoffnungen darauf, daß sich das Nachbarland auf eine Politik der Revision beschränken werde. Sowohl die Jeune Droite als auch der Ordre Nouveau konstatierten

\footnotetext{
${ }^{292}$ Maulnier, Pour une politique de la France, in: Combat, H. 31, 1939, S. 5f., Zitat S. 5.

${ }^{293}$ Ebenda, S. 6; vgl. zur Kolonialpolitik Bertin [Maulnier], Notes Politiques, in: Combat, H. 31, 1939, S. 12.

${ }^{294}$ Salleron, Réflexions sur le régime à naître, in: Combat, H. 31, 1939, S. 7-9; Zitat S. 9; ders., Réflexions sur le régime à naître, in: Combat, H. 30, 1938, S. 10-12.

$295 \mathrm{Vgl}$. oben Kapitel 4.

${ }^{296}$ De Gaulle, La France et son armée; vgl. Lacouture, de Gaulle, Bd. 1, S. $273 \mathrm{ff}$.

297 Daniel-Rops, Equilibre européen ou Fédéralisme, in: TP, H. 67, 1939, S. 2.

${ }^{298}$ Aron, N'imitons pas le Fascisme, in: Flèche, H. 155, 1939, S. 2.
} 
einen grundlegenden Wandel in Hitlers Strategie. Hatten sie nach dem Münchener Abkommen noch geglaubt, Hitlers Expansionsdrang werde sich auf die deutschsprachigen Gebiete beschränken, so mußten sie nun einsehen, daß sie sich über dessen Ziele getäuscht hatten. Nach der Zerschlagung der Tschechoslowakei konnte kein Zweifel mehr darüber bestehen, daß der Versuch der vertraglichen Einbindung Hitlers durch das Münchener Abkommen gescheitert war und Hitler zielstrebig den Krieg vorbereitete ${ }^{299}$.

Für die Jeune Droite war damit die Grenze der Zugeständnisse erreicht. Das politische Klima hatte sich mittlerweile in Frankreich deutlich gewandelt, ein großer Teil der Rechten kam zu der Einsicht, man könne Hitler nicht weiter gewähren lassen, auch nicht im Osten. Im Einklang mit dieser Haltung befürwortete François Gravier internationale Garantien für Polen ${ }^{300}$.

Doch die aktive Rolle Frankreichs in der internationalen Politik hatte die innere Umgestaltung zur Voraussetzung. Mit dem Schlagwort des „Minimalfaschismus“ konkretisierte Maulnier sein Programm einer nationalen Revolution, das er bereits Anfang 1939 skizziert hatte. Maulnier forderte einen autoritären Staat, der durch eine forcierte Kriegswirtschaft, massive Aufrüstung, Ausbau der Kolonialherrschaft und eine starke Exekutive in Konkurrenz zu den faschistischen Staaten treten konnte: „In dem Maß, wie der Faschismus unseren Nachbarn eine außerordentliche Schlagkraft, Effizienz und Schnelligkeit im diplomatischen und militärischen Handeln gegeben hat, wie sie die Demokratie nicht kennt, brauchen wir ebenfalls ein Mindestmaß an Faschismus, um ihnen zu widerstehen. Es geht hier nicht um ideologische Vorlieben. Es geht um die Macht. " 301 Maulnier glaubte, daß Frankreich durch diese Form der Annäherung an den Gegner die notwendige Überlegenheit erlangen könne. Die extreme Stärkung der staatlichen Autorität sah er dabei als eine Art Notstandsprogramm an. Sie sollte nur so lange Bestand haben, bis die Gefahr durch die beiden Nachbarländer gebannt war, mit anderen Worten: bis Frankreich wieder seine unumstrittene Hegemonialstellung auf dem Kontinent erobert hatte ${ }^{302}$.

Zudem besann sich die Jeune Droite auf den Wert der klassischen Großmächtediplomatie zurück. Als einzig verläßlichen Verbündeten Frankreichs entdeckte sie nun England wieder, von dem sie sich 1935 zugunsten Italiens abgewandt hatte ${ }^{303}$. War die Option für England bestimmt von rein machtstrategischem Kalkül, so suchte die Jeune Droite nach einem adäquaten Ersatz für die verlorene "lateinische Schwester" und richtete dabei ihr Augenmerk auf die Diktaturen der iberischen Halbinsel. Über den katholischen Korporatismus glaubte Gravier Anknüpfungspunkte mit dem Spanien Francos und dem Portugal Salazars zu finden, aus denen sich ein tragfähiges Fundament für ein neues Europa entwickeln konnte. Auf diese Weise sollte eine neue Kulturgemeinschaft als Bollwerk sowohl gegen die östliche Barbarei der faschistischen und

${ }^{299}$ Maulnier, La guerre, peut-être. Encore il faut savoir pourquoi, in: Combat, H. 34, 1939, S. 3;

Rougemont, Hitler hors la loi, in: NC, H. 42, 1939, S. 9f.; Aron, Demain la guerre?, in: Flèche, H. 166, 1939, S. 1f.; vgl. Wendt, Großdeutschland, S. 160 f.

300 Gravier, Deux impasses: Dantzig [sic] et Tien-Tsin, in: Combat, H. 37, 1939, S.6; vgl. Micaud,

French Right, S. 211.

301 Maulnier, Un fascisme minimum?, in: Combat, H. 35, 1939, S. 5.

302 Vgl. ebenda, S. 3.

${ }^{303}$ Maulnier, La guerre, peut-être. Encore il faut savoir pourquoi, in: Combat, H. 34, 1939, S. 3. 
totalitären Diktaturen als auch gegen die westliche Dekadenz der Vereinigten Staaten entstehen ${ }^{304}$.

Die Anhänger des Ordre Nouveau konnten keine Einigung darüber erzielen, auf welche Art der totalitären Bedrohung am besten Widerstand geleistet werden konnte. Alexandre Marc teilte die Ansicht der Jeune Droite, daß Frankreich geistig, politisch, wirtschaftlich und militärisch reorganisiert werden müsse, um Hitler Widerstand leisten zu können. Das einzige Mittel gegen die totalitäre Dynamik des Nationalsozialismus war nach Marcs Dafürhalten eine „überlegene Dynamik“, die in eine konstruktive Europapolitik Frankreichs münden sollte ${ }^{305}$. Rougemont hingegen äußerte sich skeptisch über den Nutzen eines nationalen Verteidigungsprogramms. Er warnte die Franzosen davor, die Gefahr nur in der äußeren Bedrohung zu sehen. Frankreich drohe als Mutterland des liberalen Systems vielmehr eine ähnliche Entwicklung zur totalitären Herrschaft wie Deutschland. Er rief dazu auf, die Auswüchse der Ideen von 1789 im eigenen Land zu bekämpfen: „den antisozialen Individualismus, den anonymen Kapitalismus, den staatlichen Zentralismus, die Zollbarrieren, die Aufrüstung " ${ }^{306}$.

Im Unterschied zur Jeune Droite lehnte der Ordre Nouveau jegliche Garantien für Polen und Danzig entschieden ab. Wiederholt bekundete Marc in Temps présent, daß Frankreich um keinen Preis einen Krieg mit Deutschland riskieren dürfe ${ }^{307}$. In ähnlicher Weise wandte sich Aron in La Flèche gegen Sicherheitsgarantien für Danzig und Polen. Er empfand es als Heuchelei, wenn Frankreich und England ihre Garantien erneuerten, gleichzeitig aber Hitler in Prag gewähren ließen. Zunächst mußten Böhmen und Mähren befreit werden, erst dann waren seiner Ansicht nach weitere Schutzverpflichtungen glaubwürdig. Aron machte jedoch keinen Hehl daraus, daß er keineswegs bereit war, sich für den Staat Beneš' einzusetzen ${ }^{308}$. Auch Rougemont forderte in den Nouveaux Cabiers zwar die internationale Ächtung Hitlers, jedoch ohne damit weiterreichende Verpflichtungen zu verbinden ${ }^{309}$. Damit gehörte der Ordre Nouveau zum Kreis der Befürworter einer isolationistischen Haltung Frankreichs. Im Mai 1939 hatte Marcel Déat mit seiner Parole „Sterben für Danzig?“" dieser Haltung erstmals öffentlich Ausdruck gegeben ${ }^{310}$. Marc übte zwar Kritik an dem Artikel Déats, doch verurteilte er nicht seine Begründung, sondern vielmehr das öffentliche Eingeständnis dieser Haltung, mit dem er Hitler gewissermaßen einen Freibrief für die Annexion gab ${ }^{311}$.

Auch ein Teil der extremen Rechten teilte diese isolationistische Haltung, doch waren deren Motive ganz andere als diejenigen Déats und des Ordre Nouveau. Aus der Sicht der Action française und Je suis partout, die von der Furcht vor einer jüdisch-bolschewistischen Verschwörung beherrscht waren, bildete das Dritte Reich nach wie vor das

\footnotetext{
${ }^{304}$ Gravier, Hypothèse panibérique, in: Combat, H. 34, 1939, S.11. Vgl. auch die Sympathien Maulniers für Salazar: Salazar, in: Revue Universelle 68 (1937), H. 21, S. 430-434; ders., Les paroles de Salazar, in: Revue Universelle 69 (1937), H. 4, S. 496-500.

${ }^{305}$ Scrutator [Marc], Voir et juger, in: TP, H. 71, 1939, S. 2.

306 Rougemont, Hitler hors la loi, in: NC, H. 42, 1939, S. 10.

${ }^{307}$ Scrutator [Marc], Voir et juger, in: TP, H. 71, 1939, S. 2; ders., Voir et juger, in: TP, H. 73, 1939, S. 2.

308 Aron, La Bohême-Moravie nouvelle Alsace-Lorraine, in: Flèche, H. 175, 1939, S. 1.

${ }^{309}$ Rougemont, Hitler hors la loi, in: NC, H. 42, 1939, S. 10.

310 Vgl. Micaud, French Right, S. 211.

311 Scrutator (Marc), Voir et juger, in: TP, H. 78, 1939, S. 2.
} 
wirksamste Bollwerk gegen die Sowjetunion ${ }^{312}$. Hinter dem Kurs Déats stand dagegen, wie Reinhold Brender überzeugend darlegt, der in den dreißiger Jahren entwickelte Gedanke einer radikalen Revision des Sozialismus, mit dem er der inneren Umgestaltung Frankreichs den absoluten Vorrang vor dem außenpolitischen Engagement einräumte. Diese Haltung Déats war keineswegs von defätistischen Motiven geprägt. Er hatte sich bereits mit der Frage der Landesverteidigung auseinandergesetzt, als die meisten Politiker sich noch hinter der Maginot-Linie sicher wähnten. Ebenso wie der Ordre Nouveau hatte der Neosozialist Mitte der dreißiger Jahre de Gaulles Projekt der Berufsarmee unterstützt ${ }^{313}$. Auch wenn sich die Ideen des Ordre Nouveau nicht mit denjenigen Déats deckten, so räumten beide der inneren Umgestaltung Vorrang vor einer aktiven Außenpolitik ein.

\section{Zusammenfassung}

Seit Ende 1935 geriet die innenpolitische Entwicklung Frankreichs in den Sog der Außenpolitik. Stärker denn je war der Standort von einem Koordinatensystem bestimmt, das durch die ideologischen Fronten zwischen Nationalsozialismus und Faschismus auf der einen und dem Bolschewismus auf der anderen Seite polarisiert wurde. Diese Situation charakterisierte die französischen Debatten bis zum Kriegsausbruch. Der Erfolg des Volksfront-Bündnisses steigerte die Furcht vor den Kommunisten in bislang unbekannter Weise. Die französischen Kommunisten wurden aus dieser Sicht zu bloßen Vollstreckern feindlicher Direktiven. Sie waren nichts anderes als Marionetten, die, von Moskauer Hand geführt, Einfluß auf die französische Politik nahmen. Nicht mehr Deutschland, sondern Rußland erschien nun als die größte Bedrohung aus dem Osten. In den Augen der Neopazifisten bedeutete dies, daß Frankreich zum Handlanger des internationalen Kommunismus und damit erstes Angriffsziel des nationalsozialistischen Deutschland werden würde.

Der Äthiopienkrieg, die Ratifizierung des französisch-russischen Beistandspaktes und die Remilitarisierung des Rheinlands brachten beide Gruppierungen in das Lager der Neopazifisten. Für die Jeune Droite war diese Option gewissermaßen eine zwangsläufige Konsequenz der bisherigen Position. Sie kam daher wenig überraschend. Erstaunlicher ist dieser Wandel beim Ordre Nouveau, der keine vergleichbaren Affinitäten zur nationalistischen Rechten hatte. Doch ist diese Entwicklung symptomatisch für eine ganze Reihe linker Dissidenten, die in Opposition zum Kommunismus standen. Eine vergleichbare Haltung läßt sich bei Déat, Doriot und zum Teil auch bei Bergery beobachten. Das Zusammengehen der bürgerlichen Parteien mit den Kommunisten hatte sie in das Lager der Gegner getrieben.

Hitler als selbsternannter Retter vor dem Bolschewismus erschien einigen Anhängern der extremen Rechten als machtvoller Verbündeter, einem Großteil der Neopazifisten aber zumindest als das geringere Übel. Im Unterschied zur traditionellen nationalisti-

312 Vgl. Weber, Action française, S. 430; Dioudonnat, Je suis partout, S. 283ff.; Wirsching, Kollaborationsideologie, S. 55f.

313 Neben Paul Reynaud war er der einzige Parlamentarier, der die Notwendigkeit dieser Reform erkannt hatte; vgl. Brender, Kollaboration, S. $51 \mathrm{ff}$. 
schen Rechten war das Hauptmotiv für den Neopazifismus bei den Nonkonformisten weniger in der außenpolitischen Konstellation zu suchen als vielmehr in der Einsicht in die Notwendigkeit einer inneren Umgestaltung. Die Bereitschaft zu Zugeständnissen an den Nachbarn östlich des Rheins darf daher nicht als Defätismus verstanden werden. Vielmehr gründete sie auf dem Vorrang der nationalen Erneuerung vor dem außenpolitischen Engagement. Bereits frühzeitig hatte der Ordre Nouveau die Schwächen des Verteidigungssystems erkannt und versucht, die Reform der Armee voranzutreiben.

Die Zuspitzung der außenpolitischen Situation nach dem ,Anschluß Österreichs brachte die Gruppierungen wieder näher zusammen. Nach dem Ende der Volksfront lebte die Strategie eines übergreifenden Bündnisses der antirepublikanischen Kräfte wieder auf: In Bergerys Frontisme, in Déats Tribune de France, in der Doriot-Bewegungund im Courrier Royal zogen die nonkonformistischen Intellektuellen die Fäden einer neuen Sammlungspolitik. Je bedrohlicher die Lage wurde, desto mehr wuchs die Furcht vor einer weiteren Blockade der inneren Umgestaltung durch das Wiedererstehen der „Union sacrée“. Angesichts der äußeren Bedrohung rückten die Gruppierungen wieder enger zusammen und fanden im Thema der nationalen Erneuerung einen gemeinsamen Ausgangspunkt.

Die Feindschaft zum Kommunismus bestimmte auch die innenpolitische Strategie der beiden Gruppierungen. Beide konzentrierten sich in der Phase der Volksfront auf eine antikommunistische Gewerkschaftspolitik. Der Erfolg der Streikwelle unmittelbar nach dem Wahlsieg der Volksfront hatte sie in der Überzeugung bestärkt, daß ein großes Potential der Arbeiterbewegung existierte, das gegen die Regierung mobilisiert werden konnte. Darüber hinaus machten die Erfolge der verstärkt unter kommunistischem Einfluß stehenden C.G.T. eine aktive Gewerkschaftspolitik erforderlich.

Beide Gruppierungen versuchten mit unterschiedlichen Strategien, die Arbeiterschaft für ihre revolutionären Zielsetzungen einzuspannen. Ein Teil der Jeune Droite schuf unter Berufung auf Sorel ein Klima von Haß und Gewalt und versuchte, die Gewerkschaftskreise mit nationalistischen Ideen zu infiltrieren. Sein Ziel war es, die Arbeiterbewegung dem Einfluß der Kommunisten zu entziehen und sie zum Umsturz der Regierung aufzustacheln. Die Thematik des Klassenkampfes wurde instrumentalisiert und umgestaltet zum Kampf der Arbeiter und Mittelschichten gegen das liberale System. Parallel zum ideologischen Kampf gegen den Kommunismus baute die Jeune Droite die Verbindungen zu militanten Randgruppen der extremen Rechten aus und verbündete sich mit dem kommunistischen Renegaten Doriot.

Der Ordre Nouveau bemühte sich ebenfalls, mit einer aktiven Gewerkschaftspolitik Einfluß auf die Arbeiterbewegungen zu gewinnen. Die Sympathien für Sorel und den Anarchismus teilte die Gruppierung mit der Jeune Droite. Jedoch hatte sie ein anderes Verständnis von Gewalt: Nicht der Umsturz mit allen Mitteln, sondern die allmähliche Zersetzung der Gesellschaft war das Ziel. Zu diesem Zweck intensivierte der Ordre Nouveau die Kontakte zu Gewerkschaftskreisen und die eigene Propagandatätigkeit. Mit großem Aufwand versuchte er, neue Sympathisanten in und außerhalb von Paris zu finden und ein Netzwerk von „revolutionären Zellen“ für den Umsturz aufzubauen.

Der Radikalisierung der beiden Gruppierungen war eine Grenze gesetzt. In der Untersuchung des Antisemitismus wird deutlich, daß diese Ressentiments aus dem Antiliberalismus abgeleitet waren: Der Typus des Juden stand stellvertretend für den bürgerlichen Intellektuellen und für den ausbeuterischen Kapitalisten. Revolutionäres Potential 
wurde den Juden nicht zugebilligt. Zwar wurden antisemitische Vorurteile insbesondere innerhalb der Jeune Droite mit beachtlicher Vehemenz vertreten, doch erreichten sie zu keinem Zeitpunkt den Rang einer eigenständigen Verschwörungstheorie. Das Ausmaß des Antisemitismus unterscheidet die beiden Gruppierungen von dem radikalisierten Flügel der extremen Rechten, bei dem militanter Antikommunismus und militanter Antisemitismus miteinander verschmolzen.

Dies ist für die Beurteilung des Standorts der beiden Gruppierungen innerhalb des politischen Spektrums von großer Bedeutung. Denn trotz aller antikommunistischen Attacken blieb der Liberalismus der Hauptfeind. Nur vorübergehend überwog die antikommunistische Agitation den Kampf gegen das liberale System und den Kapitalismus. Wirklich bedrohlich waren nur die liberalen Ideen, da diese der ureigenen französischen Tradition entstammten, während das kommunistische Gedankengut keinen Rückhalt in der französischen und europäischen Kultur hatte. Allenfalls unterstellte man dem Liberalismus, daß er den Nährboden für den Kommunismus geschaffen habe.

Den Liberalismus galt es zu bekämpfen. Und da die Qualität des Gegners auch die Wahl der Mittel bestimmte, bedeutete dies, daß dem Vernichtungswillen Grenzen gesetzt waren. Handelte es sich doch beim Liberalismus um ein dekadentes System, das aus der Sicht der Nonkonformisten sich selbst überlebt hatte. Ihm einen Gnadenstoß zu versetzen, erforderte weniger schlagkräftige Maßnahmen als der Kampf gegen eine straff organisierte Bewegung, die auf der Straße jederzeit ihre Truppen mobilisieren konnte. 